\title{
Compostos químicos isolados de extratos e óleos essenciais do gênero Zanthoxylum Linnaeus (Rutaceae) e seu potencial antimicrobiano
}

\author{
Daniel Eugenio Saraiva Filho ${ }^{1,5}$, (1) Josenir Barreto de Sousa ${ }^{2}$, (1) Hélcio Silva dos Santos ${ }^{3}$ \\ e (1) Raquel Oliveira dos Santos Fontenelle ${ }^{4}$
}

Recebido 27.09.2019; aceito 11.12.2019

Como citar: Saraiva Filho, D.E., Sousa, J.B., Santos, H.S. \& Fontenelle, R.O.S. 2020. Compostos químicos isolados de extratos e óleos essenciais do gênero Zanthoxylum Linnaeus (Rutaceae) e seu potencial antimicrobiano. Hoehnea 47: e882019. http://dx.doi.org/10.1590/2236-8906-88/2019

\begin{abstract}
Chemical compounds isolated from extracts and essential oils of the genus Zanthoxylum Linnaeus (Rutaceae) and its antimicrobial potential). This review covers the documentation of the isolated and biologically active chemical constituents of 20 species of the genus Zanthoxylum Linnaeus distributed all over the world. The species extracts and oils chemical constituents were isolated and characterized by different analytical methods. This review was carried out through the survey of the Master's Dissertations, Doctoral Theses and mainly published scientific articles about the biological activity and phytochemical characterization of Zanthoxylum species, available at in the CAPES, PubMed, ScienceDirect, Scopus, Scielo and Google Scholar databases from 1985 to 2019. The species presented a diverse chemical composition in which alkaloids, terpenes and coumarins predominate. In addition, those chemical compounds perform different types of biological activity for the plant, such as larvicidal, anti-inflammatory, analgesic, antinociceptive, antioxidant, antibiotic, hepatoprotective, antiplasmodial, cytotoxic, antiproliferative, anthelmintic, antiviral and antifungal.

Keywords: analytical methods, biological activity, chemical constituents, essential oil, Zanthoxylum
\end{abstract}

RESUMO - (Compostos Químicos Isolados de Extratos e óleos essenciais do Gênero Zanthoxylum Linnaeus (Rutaceae) e seu Potencial Antimicrobiano). Este artigo de revisão reporta ao estudo químico e farmacológico de metabolitos secundários isolados de 20 espécies do gênero Zanthoxylum Linnaeus. Os constituintes químicos voláteis e fixos das espécies desse gênero foram isolados e caracterizados por métodos analíticos. Esta revisão foi realizada através da busca organizada de Dissertações de Mestrado, Teses de Doutorado e principalmente artigos científicos publicados sobre estudos fotoquímicos e atividades antimicrobianas das espécies do gênero Zanthoxylum disponíveis nos Periódicos CAPES, PubMed, ScienceDirect, Scopus, Scielo e Google Acadêmico entre 1985 e 2019. As espécies apresentaram composição química diversificada onde predominam alcaloides, terpenos e cumarinas com diferentes tipos de atividades antimicrobianas, tais como: antifúngica, antibiótica, antiprotozoário e antiviral.

Palavras-chave: atividade antimicrobiana, constituintes químicos, métodos analíticos, óleo essencial, Zanthoxylum

\section{Introdução}

O Brasil apresenta grande parcela de sua população como consumidor de plantas com fins fitoterápicos, e esse consumo sofre variação dependendo da região. Estas plantas têm origem no cultivo caseiro ou são encontradas diretamente na flora silvestre, onde neste último caso são frequentemente comercializadas nas feiras livres (Reis et al. 2003). No

1. Universidade Estadual do Ceará, Mestrado em Recursos Naturais, Avenida Dr. Silas Munguba, 1700, Itaperi, 60714-903 Fortaleza, CE, Brasil

2. Instituto Federal de Ciências e Tecnologia do Ceará, Avenida Santos Dumont, S/N, Júlia Santiago, 62940-000 Morada Nova, CE, Brasil

3. Universidade Estadual Vale do Acaraú, Curso de Química, Laboratório de Química de Produtos Naturais, Síntese e Biocatálise de Compostos Orgânicos, Campus da Betânia, Avenida da Universidade, 850, 62.040-370 Sobral, CE, Brasil

4. Universidade Estadual Vale do Acaraú, Departamento de Ciências Biológicas, Laboratório de Microbiologia, Avenida da Universidade, 850, Campus da Betânia, 62.040-370 Sobral, CE, Brasil

5. Autor para correspondência: danieleugenio@ifce.edu.br 
entanto, é necessário estabelecer se o uso tradicional de plantas para o tratamento de doenças infecciosas é apoiado por ação farmacológica ou meramente baseado no folclore (Pessini et al. 2003).

Nesse sentido, os estudos fitoquímicos visam esclarecer sobre os efeitos farmacológicos, caracterizar o seu uso in natura ou em diferentes formas farmacêuticas, e obter substâncias ativas para uso na população (Carvalho \& Conceição 2015). Nos últimos anos os antimicrobianos de origem vegetal têm despertado o interesse da classe científica em consequência de suas atividades sobre grandes diversidades de micro-organismos além de serem usados como alternativas aos antibióticos tradicionais (Deus 2011). Compostos químicos com atividade biológica isolados de plantas e utilizados pela população por meio de extratos são fontes promissoras para a prospecção de novos antimicrobianos. Essas substâncias também podem atuar sinergicamente com outras drogas, melhorando potencialmente a ação antibiótica (Al-Fatimiet et al. 2007).

Diante da importância terapêutica e científica do gênero Zanthoxylum, esta revisão teve como objetivo fazer um levantamento bibliográfico sobre a composição química dos extratos e do óleo essencial de espécies desse gênero, bem como a atividade antimicrobiana dos metabólitos secundários já descritos e isolados.

\section{Material e métodos}

Este trabalho trata de uma revisão bibliográfica acerca do estudo fitoquímico dos extratos e óleo essencial de espécies do gênero Zanthoxylum Linnaeus (Rutaceae) bem como o potencial antimicrobiano dos principais metabólitos secundários já isolados e comprovados em testes in vitro. Para o levantamento bibliográfico foi realizada uma pesquisa usando vários bancos de dados, incluindo Periódicos Capes, PubMed, Science Direct, Scielo e Google Acadêmico.

Os critérios de inclusão foram Dissertações de Mestrado, Teses de Doutorado e principalmente artigos científicos publicados em inglês, espanhol e português que analisassem o estudo fitoquímico dos extratos e óleos essenciais das espécies do gênero Zanthoxylum e sua atividade antimicrobiana. Este levantamento foi realizado no período de junho de 2017 a abril de 2018, com publicações no período de 1960 a 2019 , e que incluíssem os seguintes termos de pesquisa de palavrachave: atividade antimicrobiana, prospecção fitoquímica, atividade antibacteriana e antifúngica de Zanthoxylum.

\section{Família Rutaceae}

Com ampla distribuição nas regiões tropicais e temperadas do mundo, a família Rutaceae é constituída por mais de 1.600 espécies distribuídas em cerca de 150 gêneros. Na região neotropical, ocorrem aproximadamente de 52 gêneros dos quais 33 gêneros estão presentes no Brasil, onde a Floresta Atlântica e a Amazônia representam os centros de maior diversidade (Pirani 1999).
É uma família reconhecida pela produção de grande quantidade de metabólitos secundários, tais como: cumarinas (Fernandes 2016), alcaloides (Zhang et al. 2017), triterpenos (Lima et al. 2007) e limonoides (Terezan et al. 2010), bem como pelas propriedades antimicrobianas já conhecidas, como antifúngica (Gong et al. 2009), antibacteriana (Zhang et al. 2017), antiprotozoário (Cebrián-Torrejón et al. 2011, Lima et al. 2015b) e antiviral (Nguyen et al. 2002, Cheng et al. 2008,).

Nesse sentido essa família é exemplo do potencial vegetal no Brasil, apresentando muitos representantes nativos, como as espécies do gênero Pilocarpus, onde a espécie Pilocarpus microphyllus, conhecidas popularmente como jaborandi, é uma fonte natural da pilocarpina, utilizada na formulação de colírios para tratamento do glaucoma (Tsai et al. 2003, Nordstrom et al. 2005, Lima et al. 2015a). Destaca-se também o gênero Ruta onde a espécie Ruta graveolens, conhecida popularmente como arruda, é usada na medicina por seu efeito como antihelmíntica, febrífuga e emenagoga (Silva 2018) e Zanthoxylum com várias espécies utilizadas na medicina popular e grande diversidade de metabólitos secundários (Villalba et al. 2007).

Em função da multifuncionalidade de usos e aplicação das espécies deste gênero, há uma crescente necessidade de mais estudos fitoquímicos das espécies de Rutaceae.

\section{Gênero Zanthoxylum Linnaeus (Rutaceae)}

O gênero Zanthoxylum apresenta mais de 200 espécies distribuídas por zonas tropicais e temperadas do mundo. É um dos gêneros mais conhecidos da família Rutaceae, com ocorrência em praticamente todo o Brasil, onde 25 espécies estão presentes (Pirani 1999). As árvores desse gênero variam de 6 a 18 metros de altura, frequentemente apresentam espinhos e algumas espécies possuem tronco ereto, com volume de madeira apreciável para uso em serraria (Loureiro, et al. 1981, Lorenzi 1992).

Apresenta relevante importância etnobotânica especialmente na América do Sul, África e Ásia. Há relatos do uso do chá das folhas e raízes do Zanthoxylum ekmanii na região Norte do Brasil, no tratamento da malária (Facundo et al. 2005); Z. monophyllum usado na Venezuela no tratamento de corrimento nasal, icterícia, oftalmia e como analgésico (Gómez et al. 2007); Z. chalybeum usado na Uganda no tratamento da tuberculose (Tabuti 2011) e Z. liebmannianum usado no México para o tratamento de dores estomacais, amebíase, parasitas intestinais e como agente anestésico local (Ross et al. 2004).

Nesse gênero são conhecidas espécies com composição química bastante diversificada e grande potencial farmacológico, destacando-se os alcaloides, como a classe de compostos mais frequente e relevante neste gênero, assim como as lignanas, cumarinas, amidas, flavonoides e terpenos que são extraídos na forma de óleo e extratos de diferentes partes da planta como as raízes, caule, ramos, e folhas ( Zanon 2010, Ladino et al. 2012).

De acordo com o levantamento bibliográfico realizado nesta pesquisa, estão relacionadas na tabela 1 as principais 
Tabela 1. Principais metabólitos e atividades biológicas de diferentes extratos e óleos essenciais de espécies do gênero Zanthoxylum Linnaeus (Rutaceae)

\begin{tabular}{|c|c|c|c|c|c|}
\hline $\begin{array}{l}\text { Espécies de } \\
\text { Zanthoxylum }\end{array}$ & $\begin{array}{l}\text { Parte } \\
\text { Vegetal }\end{array}$ & Extrato/Óleo & Classes & Atividades Biológicas & Referências \\
\hline Z. alatum & Folha & $\begin{array}{l}\text { Aquoso, } \\
\text { Metanólico }\end{array}$ & Terpenos & $\begin{array}{c}\text { Atividade Antifúngica } \\
\text { (Colletotrichum) e antibacteriana } \\
\text { (Corynebacterium diptheriae) }\end{array}$ & $\begin{array}{l}\text { (Wazir et al. 2014, } \\
\text { Stappen et al. 2018) }\end{array}$ \\
\hline Z. budrunga & $\begin{array}{l}\text { Folha, } \\
\text { raiz }\end{array}$ & $\begin{array}{l}\text { Éter de } \\
\text { petróleo, } \\
\text { Hexânico, } \\
\text { Etanólico }\end{array}$ & $\begin{array}{l}\text { Alcaloides, } \\
\text { terpenos, } \\
\text { esteroides, } \\
\text { flavonoides }\end{array}$ & $\begin{array}{c}\text { Atividade antibacteriana } \\
\text { (Bacillus cereus, B. subtilis, } \\
\text { Shigella dysenteriae, Escherichia } \\
\text { coli e Streptococcus aureus) e } \\
\text { antifúngico Aspergillus fumigatus } \\
\text { e Hensinela californica }\end{array}$ & $\begin{array}{l}\text { (Ahsan et al. 2014, } \\
\text { Islam et al. 2001, } \\
\text { Islam et al. 2014, } \\
\text { Rahman et al. 2005) }\end{array}$ \\
\hline Z. bungeanum & $\begin{array}{l}\text { Folha, } \\
\text { fruto }\end{array}$ & $\begin{array}{l}\text { Etanólico, } \\
\text { Metanólico }\end{array}$ & $\begin{array}{l}\text { Alcaloides, } \\
\text { terpenoides, } \\
\text { flavonoides }\end{array}$ & $\begin{array}{l}\text { Atividade antibacteriana } \\
\text { (S. aureus e E. coli) e antifúngica } \\
\text { (Leptosphaeria maculans, } \\
\text { Bipolaris maydi) }\end{array}$ & $\begin{array}{l}\text { (Gong et al. 2009, } \\
\text { Zhang et al. 2017) }\end{array}$ \\
\hline Z. chalybeum & Raiz & Metanólico & $\begin{array}{l}\text { Alcaloides, } \\
\text { flavonoides } \\
\text { terpenos, } \\
\text { taninos }\end{array}$ & $\begin{array}{c}\text { Atividade antibacteriana } \\
\text { (B. subtilis, M. luteus e } S . \text { aureus) }\end{array}$ & $\begin{array}{l}\text { (Anza et al. } 2014 \text {, } \\
\text { Matu \& Van Staden } \\
\text { 2003, Nantongo et al. } \\
\text { 2018) }\end{array}$ \\
\hline Z. caribaeum & Folha & Etanólico & Terpenos & $\begin{array}{l}\text { Atividade antibacteriana } \\
\quad(\text { S. enterica })\end{array}$ & $\begin{array}{c}\text { (Nogueira et al. } \\
\text { 2014a, Souza et al. } \\
\text { 2017) }\end{array}$ \\
\hline \multirow[t]{2}{*}{ Z. chiloperone } & $\begin{array}{l}\text { Caule, } \\
\text { folha }\end{array}$ & Hexânico, & Alcaloides & $\begin{array}{l}\text { Atividade antiplasmodial } \\
\text { (P. faciparum), tripanocida } \\
\text { (Trypanossoma cruzi) }\end{array}$ & $\begin{array}{l}\text { (Cebrián-Torrejón et } \\
\text { al. 2011, Ferreira et } \\
\text { al. 2007, Ferreira et } \\
\text { al. 2011, }\end{array}$ \\
\hline & & Etanólico & & & Hamuy et al. 2013) \\
\hline Z. djalma-batistae & Galhos & Hexânico & Terpenos & $\begin{array}{l}\text { Atividade antileishmanial } \\
\quad(\text { L. donovani })\end{array}$ & (Lima et al. 2015b) \\
\hline Z. ekmanii & $\begin{array}{c}\text { Folha e } \\
\text { raiz }\end{array}$ & Etanólico & $\begin{array}{l}\text { Alcaloides, } \\
\text { terpenos }\end{array}$ & Atividade antimalárica & $\begin{array}{l}\text { (Facundo et al. 2003, } \\
\text { Facundo et al. 2005) }\end{array}$ \\
\hline Z. fagara & $\begin{array}{l}\text { Fruto e } \\
\text { caule }\end{array}$ & $\begin{array}{l}\text { Etanólico, } \\
\text { Aquoso }\end{array}$ & $\begin{array}{l}\text { Terpenos, } \\
\text { alcalóides, } \\
\text { cumarinas, } \\
\text { flavonoides, } \\
\text { lignanas }\end{array}$ & $\begin{array}{c}\text { Atividade antifúngica } \\
\text { (C. acutatum, S. cerevisiae } \\
\text { e Microsporum canis), } \\
\text { antibacteriana (B. subtilis e } \\
\text { Vibrio cholerae) }\end{array}$ & $\begin{array}{l}\text { (Amaro-Luis et } \\
\text { al. 1988, Diéguez- } \\
\text { Hurtado et al. 2003, } \\
\text { Prieto et al. 2011, } \\
\text { Macías et al. 2010) }\end{array}$ \\
\hline Z. hyemale & $\begin{array}{l}\text { Caule, } \\
\text { folha }\end{array}$ & $\begin{array}{l}\text { Metanólico, } \\
\text { Aquoso }\end{array}$ & Alcaloide & $\begin{array}{l}\text { Atividade bacteriostática } \\
\quad \text { (S. epidermidis })\end{array}$ & $\begin{array}{l}\text { (Simionatto 2004, } \\
\quad \text { Zanon 2010) }\end{array}$ \\
\hline Z. monophyllum & $\begin{array}{l}\text { Fruto, } \\
\text { caule }\end{array}$ & $\begin{array}{l}\text { Etanólico, } \\
\text { Aquoso }\end{array}$ & $\begin{array}{l}\text { Terpenos, } \\
\text { alcaloides }\end{array}$ & $\begin{array}{c}\text { Atividade antifúngica (Fusarium } \\
\text { oxysporum e } \text { A. fumigados), } \\
\text { antibacteriana (S. aureus) e } \\
\text { antiplasmodial (Plasmodium } \\
\text { falciparum) }\end{array}$ & $\begin{array}{l}\text { (Ladino et al. 2011, } \\
\text { Prieto et al. 2011, } \\
\text { Rodríguez-Guzmán } \\
\quad \text { et al. 2011) }\end{array}$ \\
\hline
\end{tabular}


Tabela 1 (continuação)

\begin{tabular}{|c|c|c|c|c|c|}
\hline $\begin{array}{l}\text { Espécies de } \\
\text { Zanthoxylum }\end{array}$ & $\begin{array}{l}\text { Parte } \\
\text { Vegetal }\end{array}$ & Extrato/Óleo & Classes & Atividades Biológicas & Referências \\
\hline Z. naranjillo & Folha & Hexânico & Lignanas & $\begin{array}{l}\text { Atividade antiplasmodial } \\
\text { (P. falciparum) e tripanocida } \\
\text { (T. cruzi) }\end{array}$ & $\begin{array}{l}\text { (Bastos et al. 1999, } \\
\text { Braguine et al. 2009, } \\
\text { Saraiva et al. 2007, } \\
\text { Gansane } \text { et al. 2010) }\end{array}$ \\
\hline Z. petiolare & Folha & Óleo essencial & Terpenos & $\begin{array}{l}\text { Atividade antifúngica } \\
\text { Trichophyton rubrum) }\end{array}$ & $\begin{array}{l}\text { (Arruda et al. 1994, } \\
\text { Arruda et al. 1992, } \\
\text { Mesquita, 2018) }\end{array}$ \\
\hline Z. quinduense & Caule & Etanólico & Alcaloides & $\begin{array}{l}\text { Atividade antibacteriana } \\
\text { (S. aureus, E. faecalis, } \\
\text { S. typhimurium) }\end{array}$ & (Ladino et al. 2011) \\
\hline Z. riedeliano & Folha & Metanólico & $\begin{array}{l}\text { Lignanas, } \\
\text { terpenos }\end{array}$ & $\begin{array}{l}\text { Atividade antibacteriana } \\
\text { (Streptococcus agalactiae e } \\
\text { Flavobacterium columnare) }\end{array}$ & (Castro et al. 2008) \\
\hline Z. rhoifolium & $\begin{array}{l}\text { Folha, } \\
\text { caule }\end{array}$ & Etanólico & $\begin{array}{l}\text { Alcaloides, } \\
\text { taninos, } \\
\text { flavonoides }\end{array}$ & $\begin{array}{l}\text { Atividade antibacteriana ( } E \text {. } \\
\text { coli e Staphylococcus aureus) e } \\
\text { antifúngica (Candida albicans) }\end{array}$ & $\begin{array}{l}\text { (Costa et al. 2010, } \\
\text { Gonzaga et al. 2003, } \\
\text { Tavares et al. 2014, } \\
\text { Zanon 2010, Melo } \\
\text { Neto et al. 2016) }\end{array}$ \\
\hline Z. syncarpum & Folha & Etanólico & $\begin{array}{l}\text { Taninos, } \\
\text { flavonoide, } \\
\text { esteroides, } \\
\text { alcaloides }\end{array}$ & $\begin{array}{c}\text { Atividade leishmanicida } \\
\text { (Leishmania infantum chagasi) e } \\
\text { antiplasmodial (P. falciparum) }\end{array}$ & $\begin{array}{l}\text { (Ross et al. 2004, } \\
\text { Silva et al. 2014) }\end{array}$ \\
\hline Z. stelligerum & Raiz & Metanólico & $\begin{array}{l}\text { Alcaloide, } \\
\text { cumarinas, } \\
\text { esteroides }\end{array}$ & $\begin{array}{c}\text { Atividade antibacteriana }(S . \\
\text { aureus e } M . \text { luteus }) \text { e antifúngica } \\
\text { (Candida sp.) }\end{array}$ & $\begin{array}{l}\text { (Silva et al. 2009, } \\
\text { Hohlemwerger et al. } \\
\text { 2012) }\end{array}$ \\
\hline Z. scandens & Caule & Metanólico & Alcaloides & Atividade antiviral & $\begin{array}{l}\text { (Cheng et al. 2008, } \\
\text { Nguyen et al. 2002) }\end{array}$ \\
\hline Z. schinifolium & $\begin{array}{l}\text { Fruto. } \\
\text { folha }\end{array}$ & $\begin{array}{l}\text { Metanólico, } \\
\text { Aquoso }\end{array}$ & Terpenos & $\begin{array}{c}\text { Atividade antibacteriana } \\
\text { (S. epidermidis e M. tuberculosis) } \\
\text { e antiviral }\end{array}$ & $\begin{array}{l}\text { (Diao et al. 2013, } \\
\text { Kim et al. 2018, } \\
\text { Choi, 2016, Hu et al. } \\
\text { 2016) }\end{array}$ \\
\hline Z. tingoassuiba & $\begin{array}{l}\text { Folha, } \\
\text { raiz }\end{array}$ & $\begin{array}{l}\text { Hexânico, } \\
\text { diclorometano, } \\
\text { Aquoso }\end{array}$ & $\begin{array}{l}\text { Alcaloides, } \\
\text { lignanas, } \\
\text { terpenos }\end{array}$ & $\begin{array}{c}\text { Atividade antibacteriana } \\
\text { (S. aureus e M. luteus), } \\
\text { antifúngica (T. mentagrophytes } \\
\text { e M. gypseum) e antiprotozoário } \\
\text { (T. cruzi e L. amazonenses) }\end{array}$ & $\begin{array}{c}\text { (Costa et al. 2017b, } \\
\text { Detoni et al. 2009, } \\
\text { Hohlemwerger et } \\
\text { al. 2012,Costa et al. } \\
\text { 2018) }\end{array}$ \\
\hline Z. usambarense & $\begin{array}{l}\text { Raiz, } \\
\text { caule }\end{array}$ & Metanólico & Alcaloides & $\begin{array}{l}\text { Atividade antibacteriana } \\
\text { (B. subtilis, } \text { M. luteus } \mathrm{e} \\
\text { S. aureus), antiplasmodial } \\
\quad \text { (P. falciparum) }\end{array}$ & $\begin{array}{l}\text { (He et al. 2002, } \\
\text { Kirira et al. 2006, } \\
\text { Matu \& Van Staden } \\
\text { 2003, Were } \text { et al. } \\
\text { 2010) }\end{array}$ \\
\hline
\end{tabular}


atividades antimicrobianas de 20 espécies do gênero Zanthoxylum, indicando ainda a parte da planta usada e o composto bioativo presente.

\section{Zanthoxylum petiolare A.St.-Hil. \&Tul}

Popularmente conhecida como limãozinho, laranjinha ou pau-barrão, Z. petiolare se apresenta como árvores ou arbustos que podem atingir um porte de até 14 metros de altura, com ocorrência em quase todas as regiões do Brasil, exceto a região Norte do país (Melo \& Zickel 2004).

Quanto aos ensaios antifúngicos do óleo essencial extraído das folhas de Z. petiolare, frente a cepas de Candida spp. e T. rubrum pelo método de microdiluição em caldo, ocorreu sensibilização apenas de T. rubrum com 0,156 e $0,312 \mathrm{mg} / \mathrm{ml}$ para CIM e CFM como os menores valores observados, respectivamente (Mesquita 2018).

Os estudos químicos de estratos e óleo essencial isolados de Z. petiolare levou ao isolamento e identificação de dimetilalilpiperitol (1), 3-oxo-skimmiarepin (2), (E,E)-N-(2-methylpropyl)-2,4 tetradecadienamide (3), lupeol (4), sitosterol (5), (+) - sesamina (6), (+) - piperitol (7), piperitol-3,3-dimethylallyl ether (8), (E,E,Z)-N-(2-methylpropyl)-2,4 tetradecadienamide (9), lionirosinol-3- $\alpha-O-\beta$-glucopiranosídeo (10), cis3-Hexen-1-ol (11), D-limoneno (12), linalool (13), espatulenol (14), Viridiflorol (15), cariofileno (16), 6-Methyl-5-heptene-2-one (17), cis-Citral (18), geranial (19), $\beta$-cubebeno (20), $\delta$-elemeno (21), $\alpha$-muurolol (22), $\alpha$-cadinol (23), $\alpha$-copaeno (24), $\beta$-bourboneno (25), nerol (26), acetato de geranil (27), geraniol (28), 2-undecanol (29), epóxido de humuleno II (30) (figura 1) (Arruda, et al. 1992, Arruda et al. 1994, Mesquita 2018).

\section{Zanthoxylum syncarpum Tull.}

Conhecido popularmente como limãozinho, $Z$. syncarpum Tul. é uma árvore perene que ocorre na América do Norte e do Sul, com ampla distribuição na região Nordeste do Brasil, especialmente nos Estados do Ceará, Rio Grande do Norte, Paraíba e Pernambuco (Ross et al. 2004, Vieira et al. 2009).

Os ensaios antiprotozoário realizados por Ross et. al. (2004) a partir dos metabólitos syncarpamide e decarine isolados do extrato metanólico extraído do caule de $Z$. syncarpum apresentaram atividade frente clones de $P$. falcipaum $\mathrm{D}_{6} \mathrm{e} \mathrm{W}_{2}$ com $\mathrm{IC}_{50} 2,04$ e $1,44 \mu \mathrm{M}$ contra clones de $P$. falciparum D6 e 3,06 e $0,88 \mu \mathrm{M}$ contra clones de $P$. falciparum W2, respectivamente. Estudos reportam também a boa atividade leishmanicida a partir de extratos etanólico das folhas de $Z$. syncarpum, frente a $L$. infantum chagasi, com $\mathrm{CE}_{50}=16,03 \mu \mathrm{g} / \mathrm{mL}$ semelhante à droga padrão pentamidina $\left(\mathrm{CE}_{50}=23,71 \mu \mathrm{g} / \mathrm{mL}\right.$ ) (Silva et al. 2014).
Quanto aos aspectos químicos dos extratos das folhas e galhos de Z. syncarpum destaca-se a presença de (Z)3-hexenol (11), limoneno (12), linalool (13), espatulenol (14), viridiflorol (15), cariofileno (16), $\alpha$-cadinol (23), E-2hexen-1-ol (31), $n$-hexanol (32), $\alpha$-tujeno (33), sabineno (34), $\alpha$-pineno (35), $\beta$-mirceno (36), trans- $\beta$-ocimeno (37), $\alpha$-felandreno (38), p-cimeno (39), $\beta$-felandreno (40), criptona (41), $\beta$-elemeno (42), $\alpha$-copaeno (43), $\beta$-bourboneno (44), $\alpha$-duprezianeno e $\beta$-duprezianeno (45), $\alpha$-cis-bergamoteno (46), $\alpha$-trans-bergamoteno (47), $E$ - $\beta$-farneseno (48), E-nerolidol (49), $\alpha$-curcumeno (50), $\beta$-curcumeno (51), $\beta$-bisabolol (52) germacreno - D (53), epi-cubebol (54), cubebol (55), biciclogermacreno (56), $\delta$-cadineno (57), 1-epicubenol (58), cubenol (59), hidrato de cis-sesquisabineno (60) e óxido de globulol (61) (figura 1) (Facundo et al. 1999, Vieira et al. 2009, Silva et al. 2014).

\section{Zanthoxylum rhoifolium Lam}

Nativa da América do Sul (Brasil, Uruguai, Paraguai e Argentina), Z. rhoifolium (syn. Fagara rhoifolium) é conhecido popularmente como: mamica de cadela, mamica de porca, tembetari, juvevê e espinho de vintém (Lorenzi 1992). Seu uso tem sido relatado na medicina tradicional para o tratamento de diversos problemas de saúde (Freitas et al. 2011), como infecções por malária (Jullian et al. 2006), processos inflamatórios e microbianos (Gonzaga et al. 2003, Silva et al. 2006, Silva et al. 2007b).

Com relação à atividade antimicrobiana de $Z$. rhoifolium a literatura traz que o extrato metanólico das cascas dessa espécie apresentou atividade contra várias cepas de bactérias (B. subtilis, S. aureus, Enterococcus spp, E. coli, Salmonella typhimurium) e fungos (C. tropicalis, C. parapslosis, $C$. albicans, Morganella morganii), exibindo assim um amplo espectro de atividade, variando de 12,5 a $100 \mathrm{mg} / \mathrm{mL}$ pelo o método de bioautografia e de 125 a $500 \mathrm{mg} / \mathrm{mL}$ no bioensaio por microdiluição (Tavares et al. 2014).

Melo Neto et al. (2016) avaliaram a atividade antileishmanial do extrato etanólico e sua fração n-hexana extraído da casca do caule de Z. rhoifolium contra infecção de macrófagos murinos por formas promastigotas de $L$. amazonensis, revelando efeito inibitório na infecção de macrófagos com $\mathrm{IC}_{50} 88.58,16.41$ e $9.57 \mu \mathrm{g} / \mathrm{mL}$ para o extrato metanólico e $\mathrm{IC}_{50} 19.24,13.66,7.96 \mu \mathrm{g} / \mathrm{mL}$ para fração hexânica nos tratamentos de 24, 48 e 72 horas, respectivamente.

Óleos essenciais obtidos a partir das folhas, flores e frutos revelaram a presença de limoneno (12), espatulenol (14), $\beta$-cariofileno (16), $\delta$-elemeno (21), sabineno (34), $\beta$-mirceno (36), $\beta$-felandreno (40), $\beta$-elemeno (42), E- $\beta$-farneseno (48), germacreno - $\mathrm{D}(53)$, biciclogermacreno (56), 1-epi-cubenol (58), 2-undecanona(62), Z-E-farnesol (63), Z,Z-farnesol (64), E-cariofileno (65), germacreno - A (66), valenceno 
(67), calacoreno (68), $\alpha$-eudesmol (69), germacrono (70), menth-2-em-1-ol (71), $\gamma$-curcumeno (72), Z- $\alpha$-bisabolene (73), $\alpha$-bisabolol (74), epi- $\alpha$-bisabolol (75), 2-hexil-Zcinamaldeído (76), ciclohexeno (77), $\beta$-bisabolene(78), (-) $\alpha$-terpineol (79), isoledene (80), $\alpha$-gurjunene (81), $\beta$-patchouleno (82), $\beta$-cedreno (83), cedrol (84), bulnesol (85), $\alpha$-gleenol (86), $\alpha$-acorenol (87), $\beta$-acorenol (88), $\beta$-acoradienol (89), álcool patchouli (90) e 8-cedren-13-ol (91) (figura 1) (Gonzaga et al. 2003, Prieto et al. 2011, Costa et al. 2017a).

\section{Zanthoxylum budrunga (Roxb) D.C}

Conhecida popularmente como bazna, ou bazinali (Ahsan et al. 2014), Z. budrunga (Roxb) D.C. (Syn. Zanthoxylum rhetsa, Fam. Rutaceae) é uma árvore caducifólia de tamanho médio nativa de áreas subtropicais de todo o mundo e amplamente distribuídas em Bangladesh, Índia, Sri Lanka, Mianmar, China, Tailândia, Malásia, Indonésia, Filipinas e Papua Nova Guiné (Islam et al. 2014).

$\mathrm{Na}$ medicina tradicional, o fruto e a casca do caule desta planta são usados como carminativos, antieméticos, no tratamento de reumatismo (Islam, et al. 2018), cólera, disenteria, asma, infecções, doenças cardíacas, bronquite e hemorroidas (Kirtikar \& Basu 1993). O óleo essencial extraído das folhas é usado no tratamento de cólera e extrato da casca é considerado benéfico no tratamento de vômitos, tosse, disenteria e dor de cabeça (Islam et al. 2014b)

A atividade antimicrobiana do extrato clorofórmico de folhas e cascas de $Z$. budrunga, realizada por difusão em disco, mostrou um amplo espectro de comportamento antibacteriano contra B. cereus, B. subtilis, S. dysenteriae, S. boydii, E. coli e S. aureus, com variação de inibição entre 9 $\mathrm{mm}$ e $20 \mathrm{~mm}$ para as referidas espécies enquanto a atividade antifúngica foi contra Rhizupuz orizae, Schizosporum sp. A. fumigatus e H. californica com variação de inibição $8 \mathrm{e}$ $14 \mathrm{~mm}$ para as referidas espécies (Islam et al. 2001).

Pesquisa realizada por Rahman et al. 2002 relata ainda atividade antinociceptiva e antidiarreica a partir do extrato metanólico da casca do caule de $Z$. budrunga em experimentos com ratos. Estes achados corroboram os resultados dos testes de contorção induzida em camundongos que apresentaram 65,28 e 74,30\% de inibição da contorção nas doses de 250 e $500 \mathrm{mg} / \mathrm{kg}$, respectivamente (Islam et al. 2014a).

Estudos fitoquímicos das folhas, sementes, frutos e cascas desta espécie revelaram a presença de lupeol (4), (-) sesamina (6), N-metilflindersina (92), zantobobeanina (93), $\gamma$-fagarine (94), esquimianina (95), canthin-6-ona (96), dictamine (97), rutecarpina (98), $(+)$ - evodiamina (99), (-) - syringaresinol (100), diidrocelerythrine (101), N-norchelerythrine (102), lunacridina (103), pseudofrinina (104), quelerybulgarine (105), episimulanoquinolina (106) e rhetsidimerine (107) (figura 1) (Banerjee et al. 1989, Joshi et al. 1991, Ahmad et al. 2003, Rahman et al. 2005, Ahsan et al. 2014).

\section{Zanthoxylum ekmanii (Urb.) Alain}

A espécie Z. ekmanii é uma árvore com cerca de 7 a 13 metros de altura, conhecida popularmente no Brasil como mamica de porca, possuindo acúleos na base do tronco, com ampla distribuição na Bolívia, Brasil, Costa Rica, Cuba, Equador, Guiana Francesa, México, Panamá e Peru. Pesquisas etnobotânica relatam os efeitos de Z. ekmanii na medicina tradicional, como o uso do chá das folhas e raízes no tratamento da malária, em lavagens vaginais e para aliviar dor de dente pela população da região do baixo Madeira, Porto Velho - Rondônia (Facundo et al. 2005).

A análise do óleo essencial obtido a partir das folhas de Z. ekmanii revelou a presença de espatulenol (14), $\beta$-cariofileno (16), $\beta$-cubebeno (20), sabineno (34), $\alpha$-pineno(35), $\beta$-mirceno (36), E- $\beta$-ocimeno (37), p-cimeno (39), $\beta$-felandreno (40), $\beta$-elemeno (42), $\alpha$-copaeno (43), $\beta$-bourboneno (44), germacreno - D (53), $\alpha$-terpineol (79), $\alpha$-cubebeno (108), 1-octen-3-ol (109), 3-octanol (110), $\beta$-pineno (111), $\delta$-3-careno (112), aromadendreno (113), aloaromadendreno (114), $\alpha$-terpineno (115), terpinolene (116), $\delta$-elemeno (117), $\gamma$-terpineno (118), $\alpha$-humuleno (119), $\gamma$-muroleno (120), $\beta$-selineno (121), $\alpha$-calacoreno (122), $\alpha$-cadineno (123), Z- $\beta$-ocimeno (124), cânfora (125), borneol (126), acetato de bornil (127), óxido de epi-ligulil (128), óxido de cariofileno (129) e curzerenone (130) (figura 1) (Facundo et al. 2003, Facundo \& Silveira 2005).

\section{Zanthoxylum djalma-batistae (Albuq.) P.G. Waterman}

A espécie Zanthoxylum djalma-batistae (Albuq.) (Syn. Fagara djalma-batistae Albuq., Fam. Rutaceae) é popularmente conhecida como tamanqueira, sendo conhecida exclusivamente da parte oriental do Amazonas, região de Manaus (Pirani, 2005).

Para os ensaios antiplasmodial, Lima et al. 2015b reportam que a infusão foliar e o extrato clorofórmico dos ramos de $Z$. djalma-batistae e exibiram atividade moderada contra $P$. falciparum com valores de $\mathrm{IC}_{50}=15,6 \pm 2,9 \mathrm{e}$ $17,4 \pm 1,3 \mu \mathrm{g} / \mathrm{mL}$, respectivamente com citotoxicidade significativa $\mathrm{IC}_{50}=24,7 \mu \mathrm{g} / \mathrm{mL}$.

Estudos químicos feitos a partir do extrato metanólico dos galhos de Z. djalma-batistae forneceram a mistura dos triterpenos lupeol (4) e epilupeol (131) (figura 1) (Carvalho, 2009).

\section{Zanthoxylum chalybeum (Engl.)}

Conhecida popularmente na Etiópia como $G a$ 'da, Zanthoxylum chalybeum é uma árvore caducifólia que cresce em altitudes médias de até 1500 metros acima do nível do mar em florestas secas, e mata nativa no sul e no sudoeste da Etiópia (Anza et al. 2014). É usada na medicinal popular no tratamento da tuberculose e doenças associadas (Lamorde et al. 2010), malária (Tabuti 2011), doenças bucais/dentárias (Ocheng et al. 2016), sendo a casca das raízes ou caule a fonte mais importante para o uso medicinal (Engeu et al. 2008). 
Em relação à atividade antibacteriana verificou-se que o extrato metanólico e hexânico da casca da raiz de $Z$. chalybeum apresentou atividade contra B. subtilis e $S$. aureus com maior valor de zona de inibição de $0.53 \pm 0.07$ e $1.00 \pm$ $0.14 \mathrm{mg} / \mathrm{ml}^{-1}$, respectivamente (Matu \& Van Staden 2003). Nesse sentido foi constatado que o suco da polpa fresca de Z. chalybeum exibiu boa atividade contra o Lactobacillus acidophillus, produzindo 63,52 e $45 \%$ de zonas de inibição com as forças não diluídas de 50 e $25 \%$, respectivamente e com CIM $=1 \mathrm{mg} / \mathrm{mL}$ (Ocheng et al. 2014).

Quanto à atividade antiplasmodial, Gessler et al. (1994) reportaram que o extrato aquoso da casca da raiz de $Z$. chalybeum apresentou boa atividade antimalárica com $\mathrm{IC}_{50}=1,2 \mu \mathrm{g} / \mathrm{mL}$ contra $P$. falciparum in vitro, ficando entre as quatro categorias de plantas com maior atividade nesta pesquisa. Resultados semelhantes foram constatados ao verificarem que o extrato aquoso das folhas de $Z$. chalybeum apresentou atividade supressiva de $81,45 \%$ sobre camundongos contaminados com $P$. berghei (Kiraithe et al. 2016).

Análises fitoquímicas das cascas do tronco de $Z$. chalybeum revelaram a presença de benzofenantridina (132), magnoflorina (133), xanthoplanine (134), reticulina (135), edulitina (136), Des-N-methyl-thalifoline (137), queleritrine (138), magnocurarina (139), nitidina (140), berberina (141), (-) xilopinidina (142), $\alpha$-allocryprotopine (143), flindersine (144), buegenina (145), 8-O-demethylchelerythrine (146), 9,10-didemethylchelerythrine (147), 6-hydroxy10-methylsanguinarine (148), 2-dimethoxy-3hydroxybeugenine (149), (-) isotembetina (150), 10-hydroxy-2,3,9,12-tetramethoxy-jatrorrhizine (151) e (+) - N-metilplatidamina (152) (figura 1) (Kato et al. 1996, Tian et al. 2017).

\section{Zanthoxylum tingoassuiba A. St. Hil.}

A espécie Zanthoxylum tingoassuiba A. St. Hil. (Rutaceae), têm como sinonímias botânicas Zanthoxylum articulatum Engl., Xanthoxylum tingoassuiba e ou Fagara tingoassuiba Hoene (Pirani 1999). É uma espécie endêmica do Brasil sendo popularmente conhecida como casca preciosa, tinguaciba-da-restinga, tinguaciba, limãobravo, laranjeira-do-mato, mamica-de-porca, limãozinho e guando-do-mato (Pavarini 2000). Encontra-se distribuída nos Estados da Bahia, Pernambuco, Maranhão, Amazonas, Minas Gerais, Rio de Janeiro, Goiás e São Paulo (Silva et al. 2008). Atualmente esta espécie encontra-se extinta em vários destes Estados (Pirani, 1999).

A casca do seu caule é utilizada na medicina tradicional, na forma de chás, como antimicrobiano (Detoni et al. 2009), relaxante muscular (Silva et al. 2008), antiparasitario, antinflamatório (Costa et al. 2017b) analgésico, sudorífero e diurético (Pavarini 2000).

A avaliação da atividade antimicrobiana do óleo essencial de Z. tingoassuiba pelo método de difusão em disco, mostrou atividade contra bactérias gram-positivas S. aureus,
Micrococcus luteus, E. coli, Pseudomonas aeruginosa, S. cholerea-suis e fungos dermatófitos Trichophytom mentagrophytes e A.niger em discos de papel de filtro com $6 \mathrm{~mm}$ de diâmetro impregnados com 5 ou $10 \mu \mathrm{L}$ do óleo essencial (Detoni et al. 2009).

Resultados semelhantes foram constatados por Costa et al. (2017b) em pesquisa realizada com a cepa padrão do $S$. aureus ATCC 25923 (American Type Culture Collection), e com cepas multirresistentes de $S$. aureus isoladas de amostras clínicas, confirmaram a ação moderada do extrato metanólico da raiz de $Z$. tingoassuiba contra todas as linhagens testadas com valor da CIM entre 120 e $480 \mu \mathrm{g} / \mathrm{ml}$.

Quanto à atividade antiprotozoário, Costa et al. (2018) isolaram o furofurano tipo lignina syringaresinol das raízes de Z. tingoassuiba e confirmaram sua atividade antiparasitária com valores de $\mathrm{IC}_{50}=11,98$ e 7,55 $\mu \mathrm{M}$ contra $L$. amazonensis e $T$. cruzi, respectivamente.

A investigação fitoquímica de folhas, frutos, raízes e caule desta espécie resultou no isolamento e identificação de lupeol (4), $\beta$-sitosterol (5), sesamina (6), espatulenol (14), $\alpha$-bisabolol (74), diidrocelerythrine (101), norchelerythrine (102), benzofenantridina (132), queleritrine (138), arnotianamida (153), acetato de citronelilo (154), xantoxina (155), isopimpinelina (156), imperatorina (157), xantotoxina (158) O-prenilumbeliferona (159), N - metilantranilato (160), estigmasterol (161), 7-geraniloxicumarina (162), 7-preniloxicumarina (163), e N-metilcanadina (164) (figura 1) (Silva et al. 2008, Hohlemwerger et al. 2012, Costa et al. 2017b).

\section{Zanthoxylum stelligerum (Turcz)}

Variando de 3 a 6 metros de altura, Z. stelligerum (Turcz) é uma árvore ou arbusto conhecida popularmente como laranjinha brava, umbuzeiro-brabo, limãozinho e jurubeba-de-chapada (Melo \& Zickel 2004). É uma espécie distribuída no norte de Minas Gerais e Nordeste do Brasil, nos Estados da Bahia, Ceará, Piauí e Pernambuco, ocorrendo preferencialmente em áreas de caatinga, cerrado, carrasco e capoeira (Pirani 1999).

Ensaios antimicrobianos realizados por difusão em disco a partir do extrato metanólico da raiz de Z. stelligerum, demonstram atividade antibacteriana frente a $S$. aureus e $M$. luteus com inibição de 14 e 19 mm, respectivamente, bem como atividade antifúngica frente às leveduras do gênero Candida, com os melhores resultados frente a C. albicans $\mathrm{e}$ C. tropicalis com inibição de 13 e $16 \mathrm{~mm}$, respectivamente (Silva et al. 2009).

Estudos fitoquímicos das raízes revelaram a presença de substâncias como lupeol (4), $\beta$ sitosterol (5), sesamina (6), esquimianina (95), diidrocelerythrine (101), benzofenantridina (132), arnotianamida (153), imperatorina (157), estigmasterol (161), robustina (165), dictinamina (166), angolina (167), canadina (168), hidroprotoberberina (169) e hesperidina (170) (figura 1) (Silva, et al. 2002, Oliveira et al. 2002, Hohlemwerger et al. 2012). 


\section{Zanthoxylum monophyllum St. Hill}

A espécie Zanthoxylum monophyllum é uma árvore ou arbusto que cresce de 4 a 12 metros de altura em países das Américas em elevações de 200-1000 metros (Quesada \& Fernández 2005). Na Colômbia é conhecido com o nome comum de tachuelo ou palorubio, sendo usado na medicina popular para o tratamento de infecções de olhos (Díaz \& Ortega 2006). No Brasil é popularmente conhecida como laranjeira-do-mato, tinguaciba-da-restinga, tinguaciba, limo-bravo ou limoeiro, ocorrendo nos Estados de Alagoas, Espírito Santo (Melo \& Zickel 2004).

$\mathrm{O}$ extrato cru obtido do macerado Z. monophyllum se mostrou bioativo contra A. terreus, A. flavus, P. digitatum, P. funiculosum, P. citrinum, Paecilomyces e C. albicans com diâmetro do ralo de inibição entre 20 e $40 \mathrm{~mm}$ enquanto a subfração $\mathrm{MeOH} / \mathrm{EtOAc}$ obtida do extrato metanólico apresentou CIM $>512,>512, \geq 128 \mathrm{e} \geq 32$ contra A. flavus, P. funiculosum, P. digitatum e C. albicans, respectivamente (Gómez et al. 2007).

Nesse sentido, bioensaios antimicrobianos de novos metabólitos secundários isolados do extrato de folhas e cascas de Z. monophyllum apresentaram forte atividade contra $S$. aureus com valores de $\mathrm{IC}_{50}$ variando de 1,0 a 8,0 $\mu \mathrm{M}$ (ciprofloxacina $\mathrm{IC}_{50}=0,3 \mu \mathrm{M}$ ), A. fumigatus com $\mathrm{IC}_{50}$ apresentando valores entre 0,90 e 1,6 $\mu \mathrm{M}$ (anfotericina B $\mathrm{CI}_{50}=0,75 \mu \mathrm{M}$ ) e clones de P. falciparum (D6 e W2) com um $\mathrm{IC}_{50}$ de 7,5 e $6,4 \mu \mathrm{M}$, respectivamente (cloroquina $\mathrm{IC}_{50}=$ $0,05 \mu \mathrm{M}$ ) (Rodríguez-Guzmánet al. 2011).

Estudos fitoquímicos de $Z$. monophyllum revelaram a presença de $\alpha$-cadinol (23), $\alpha$-tujeno (33), sabineno (34), $\alpha$-pineno (35), E- $\beta$-ocimeno (37), $\alpha$-felandreno (38), $\alpha$-copaeno (43), germacreno - D (53), biciclogermacreno (56), $\delta$-cadineno (57), E-cariofileno (65), $\alpha$-terpineol (79), $\alpha$-cubebeno (108), $\alpha$-terpineno (115), $\gamma$-terpineno (118), $\alpha$-cariofileno (119), Z- $\beta$-ocimeno (124), berberina (141), $\beta$-myrceno (171), 1,8 cineol (172), trans-4-tujanol (173), cis-4-tujan (174), $\alpha$-terpinoleno (175), 2-ciclohexeno-1-ol (176), terpinene-4-ol (177), dihydroneoisocarveol (178), elemol (179), germacreno - B (180), acetato de hidrato de sabineno (181), germacreno-D-4-ol (182), tau-muurolol (183), torreiol (184), $\beta$-eudesmol (185), talifolina (186), jatrorrizina (187) e E.E-farnesol (188) (figura 1) (Prieto et al. 2011, Rodríguez-Guzmánet al. 2011, Cuca et al. 1998, Pavela \& Govindarajan 2016).

\section{Zanthoxylum fagara (L.) Sarg.}

Com cerca de 6 metros de altura, Zanthoxylum fagara é uma árvore ou arvoreta amplamente distribuído nas Américas, onde é conhecida como limãozinho (PE), mamicade-porca (São Paulo), coentrão (PB), mapurito (Venezuela), colima (Texas), limoncillo (Cuba), xic-ché (Yucatan), unade-gato (Colômbia), espino-rubial (Porto Rico) (Melo \& Zickel 2004). Na medicina popular existem relatos do uso de infusões feitas a partir da casca de seu caule como um sedativo (Fernandes 2016).
$\mathrm{O}$ extrato etanólico das folhas frescas de Z. fagara apresentou atividade antifúngica contra $S$. cerevisiae, $M$. canis e T. mentagrophytes com $500 \mu \mathrm{g}$ disco tão eficaz como a nistatina $8 \mu \mathrm{g}$ disco, com valores de zona de inibição 15 , 12 e $11 \mathrm{~mm}$, respectivamente. Este mesmo estudo relatou ainda que não houve nenhuma atividade contra $S$. aureus ATCC-25923, E. coli ATCC-25922, K. pneumoniae ATCC29665 e P. aeruginosa ATCC-27853) (Diéguez-Hurtado et al. 2003).

Outros estudos evidenciaram atividade antibacteriana do extrato etanólico das cascas de Z. Fagara frente às bactérias B. subtilis, V. cholerea El Tor, V. cholerea caso clínico e $S$. epidermidis com zona de inibição de 17, 11, 10 e 9 mm, respectivamente (Macías et al. 2010).

Estudos fitoquímicos desta espécie revelaram a presença de lupeol (4), $\beta$-sitosterol (5), cis-3-hexenol (11), esquimianina (95), diidrocelerythrine (101), meridinol (189), escopoletina (190), sinefrina (191), citronelol (192), citronelal (193), zanthoxilina (194), nornitidina (195), tembamida (196), O-metilbalsamida (197), alatamida (198), O-metiltembamida (199), metil-lupeol (200) e tripterigiol (201) (figura 1) (Macías et al. 2010, Villamizar et al. 2011, Fernandes 2016).

\section{Zanthoxylum usambarense (Engl.)}

Altamente ramificada, Zanthoxylum usambarense (Engl.) é uma árvore com cerca de 2 a 15 metros de altura encontrada em florestas intertropicais da África e norte do Quênia, onde é conhecida popularmente pela tribo Kikuyu como mugucua. Cresce abundantemente em áreas de altitude, especialmente em florestas ao redor de Nairobi, Masai Mara, Samburu e Sudoeste do Monte Quênia (Nanyingi et al. 2008).

No Quênia esta planta tem sido usada na medicina tradicional por muitas comunidades no tratamento de malária, infecções do trato respiratório superior, tosse, reumatismo, cárie dentária e gengivas doloridas (Nanyingi et al. 2008, Nguta et al. 2010). Estudos relatam ainda a ação antibacteriana, antifúngico, inseticida, antinflamatório (He et al. 2002, Matu \& Van Staden 2003) e antimalárico (Nguta et al. 2010, Were et al. 2010).

Os ensaios antimicrobianos realizados com os extratos hexânico, metanólico e aquoso da raiz e casca de $Z$. usambarense reportam a alta atividade antibacteriana frente as cepas de $B$. subtilis e $S$. aureus com zonas de inibição entre 0,40 a 0,58 e 0,30 a $1,09 \mathrm{mg} / \mathrm{ml}^{-1}$, respectivamente (Matu \& Van Staden 2003). Para a atividade antifúngica observou-se que o fracionamento do extrato diclorometano das raízes e da casca de $Z$. usambarense levou ao isolamento do metabólito canthin-6-one que apresentou atividade frente a cepas de Coriolus versicolor, Coniophora puteana, $P$. islandicum, Chaetomium globosum, Aureobasidium pullulans, Trichoderma viride, Cladosporium resinae, $A$. favus e A. niger com CIM entre 25 e $100 \mu \mathrm{M}$ (He et al. 2002).

Quanto à atividade antimalárica Were et al. (2010) reportam a ação antiplasmodial do extrato aquoso, 
clorofórmico, etílico e metanólico obtido da casca fresca dos ramos de $Z$. usambarense, avaliada in vitro frente a $P$. knowlesi, e como atividade profiláticas e curativas em camundongos frente a $P$. berghei, apresentando $\mathrm{IC}_{50}$ entre 3,14 e $75 \mu \mathrm{g} / \mathrm{ml}$, até $69 \%$ de aumento da cobertura de parasitas e sobrevida de $80 \%$ de camundongos tratados.

A investigação fitoquímica das raízes e caule de $Z$. usambarense espécie resultou no isolamento das seguintes substâncias: sesamina (6), piperitol-3,3 dimetilaliléter (8), canthin-6-ona (96), $(+)$ magnoflorina (133), queleritrine (138), nitidina (140), $(+)$ - N-methylplatydesmine (152), cis-N-metilcanadina $(164),(+)$ tembetarina $(202),(-)$ edulinina (203), (-) oblongine (204), usambarine (205), O-metilcedrelopsin (206), oxiqueleritrina (207) e norqueleritrina (208) (figura 1) (Kato et al. 1996, He et al. 2002).

\section{Zanthoxylum caribaeum Lam.}

Encontrada principalmente em regiões tropicais e subtropicais, com ocorrência em todos os Estados brasileiros, Zanthoxylum caribaeum Lam. é uma árvore ou arbusto com 5 a 9 metros de altura, conhecida no Nordeste por espinhode-barrão (PE), espinho cheiroso (BA), espinheiro-preto (CE) (Melo \& Zickel 2004).

Para os ensaios antibacterianos alguns autores reportam a atividade do óleo essencial e extrato das folhas de $Z$. caribaeum frente a $S$. enterica, onde 5 sorotipos apresentaram CIM e CBM variando de 7000 a $437 \mu \mathrm{g} / \mathrm{mL}^{-1}$ para o óleo essencial enquanto os extratos metanólico, etanólico e acetona apresentaram as melhores atividades frente a 11 sorotipos de $S$. enterica com CIM e CBM variando de 200 a $25 \mathrm{mg} / \mathrm{mL}^{-1}$ (Souza et al. 2017). Estudos com extrato aquosos, hexânico e acetona obtida da casca do caule de Z . caribaeum apresentaram atividade frente a $S$. aureus com CIM entre 0,78 e $1,56 \mu \mathrm{g} / \mathrm{mL}$ e E. coli com CIM entre 25 e $>100 \mu \mathrm{g} / \mathrm{mL}$ (Pichardo et al. 2014).

Quanto à atividade antifúngica Cornejo-Garrido et al. (2015) avaliaram o extrato de acetona obtido da casca de $Z$. caribaeum frente a fungos dermatófitos (Epidermophyton floccosum, M. canis, T. mentagrophytes, T. rubrum e $T$. tonsurans) onde o tratamentos efetivos com $2,5 \mathrm{mg} / \mathrm{kg}$ de extrato de Z. caribaeum foi comparável com $1 \mathrm{mg} / \mathrm{kg}$ de clotrimazol em camundongos, com porcentagem de inibição de crescimento a $50 \mu \mathrm{g} \mathrm{ml}$ de $56,7 \%, 26,7 \%, 40,0 \%, 20,0 \%$ e $90 \%$ respectivamente.

A análise do óleo essencial obtido a partir das folhas de $Z$. caribaeum forneceu os seguintes componentes: D-limoneno (12), linalool (13), espatulenol (14), $\beta$-cariofileno (16), $\alpha$-muurolol (22), $\alpha$-cadinol (23), copaeno (24), $\beta$-Bourboneno (25), $n$-hexanol (32), $\alpha$-tujeno (33), sabineno (34), $\alpha$-pineno (35), $\beta$-mirceno (36), $\beta$-E-ocimeno (37), $\alpha$-felandreno (38), $\beta$-elemeno (42), germacreno - D (53), cubebol (55), 1-epicubenol (58), cubenol (59), $\alpha$-terpineol (79), $\beta$-pineno (111), $\alpha$-terpineno (115), terpinolene (116), $\delta$-elemeno
(117), $\gamma$-terpineno (118), $\alpha$-humuleno (119), $\beta$-selineno (121), $\beta$-Z-ocimeno (124), 1,8 cineol (172), terpinene-4-ol (177), elemol (179), germacreno - B (180), citronelol (192), citronelal (193), canfeno (209), $\alpha$-carene (210), O - cimeno (211), sylvestrene (212), p-trans-menth-2-en-ol (213), trans-carveol (214), B-ciclocitral (215), $\alpha$-cubeneno (216), cis-muruola-3,5-dieno (217), di-epi-aristolochene (218), G-muurolene (219), muurola-4,5-tran-dieno (220), selineno7-epi- $\alpha$ (221), zonarene (222), germacra-4(15),5,10(14)trien-1- $\alpha$-ol (223), eremofilene (224), $\alpha$-guaiene (225), G-gurjunene (226), isoduceno (227), viridifloreno (228), ledol (229), myltayl-4(12)-ene (230), premnaspirodiene (231), hexanal (232), hexenol (233) e $\alpha$-panasinsene (234) (figura 1) (Nogueira et al. 2014b, Souza et al. 2017, Feder et al. 2019).

\section{Zanthoxylum quinduense Tul.}

Zanthohylum quinduense Tul. [syn Fagara quinduense (Tul.)] é uma árvore que cresce na América do Sul e é encontrada principalmente na Colômbia, Venezuela, Equador e Peru (Facility 2018).

Quanto a atividade antibacteriana foi avaliadoa ação de substâncias isoladas do extrato etanólico das cascas e madeira de Z. quinduense, frente a $S$. aureus ATCC 6538, E. faecalis ATCC 29212, E. coli ATCC 25922, S. typhimurium ATCC 14028s e MS7953 e S. typhimurium ATCC 14028s, revelando que a queleritrine foi o composto mais ativo, com valores de halos de inibição entre 8,5 e 10,3 mm para as cepas testadas, com atividade de inibição comparável à dos 3 antibióticos utilizados como controles, com halos de inibição entre 6,0 e $14 \mathrm{~mm}$. Outras substâncias ativas isoladas apresentaram valores de halos de inibição iguais ou superiores a $3 \mathrm{~mm}$ (Ladino et al. 2011).

Foi avaliado também a atividade antifúngica por meio de bioautografia direta em um bioensaio por TLC do extrato etanólico, frações e compostos puros extraídos da madeira de $Z$. quinduense frente a $F$. oxysporum $\mathrm{f}$. sp. lycopersici, onde apenas evofilina $C$ e norqueleritrina foram as únicas substâncias que apresentam atividade antifúngica na concentração de $25 \mu \mathrm{g}$ (Ladino \& Suárez, 2010).

A análise fitoquímica obtida a partir do extrato etanólico das cascas e madeira de $Z$. quinduense apresentou os seguintes metabólitos secundários: lupeol (4), $\beta$-sitosterol (5), queleritrine (138), berberina (141), (-) - isotembetina (150), estigmasterol (161), nornitidina (195), norqueleritrina (208), 6-acetona-dihidrocelerythrine (235), decarine (236), 6-carboximetil-dihydrochelerythrine (237), (-) - 6-acetonildihidroqueleritrina (238), decarina (239), p-hidroxibenzaldeído (240), ácido vanílico (241), evofilina-C (242), siringarossinol (243), campesterol (244), N-metiltetra-hidrocolumbamina (245), N-metiltetrahidralmatina (246), (R) - (-) - xilopinidina (247) e queleritrina (248) (figura 1) ( Ladino \& Suárez 2004, 2007, 2010, Ladino et al. 2011). 


\section{Zanthoxylum chiloperone Mart.}

Encontrada no Sudeste e Sul do Brasil e na América do Sul, Zanthoxylum chiloperone Mart. é uma árvore dioica com 15 metros de comprimento, sendo conhecida popularmente por tembetaryhu e mamicão (Silva \& Soares 2003, Tabanez et al. 2005).

Tribos indígenas do Paraguai usam a espécie como antimalárico, enemagogo, antirreumático, antimicrobiano e para dor de cabeça (Ferreira et al. 2007, Guy et al. 2001a). É usado ainda na medicina tradicional para tratar infecções fúngicas e protozoárias na região central da América do Sul (Cebrián-Torrejónet et al. 2011).

Os ensaios antifúngicos dos metabólitos canthin-6-one e 5-metoxicantina-6-ona fracionados do extrato alcalóide e das cascas do caule de $Z$. chiloperone exibiu um amplo espectro de atividades contra $A$. fumigatus, A. niger, A. terreus, C. albicans, C. tropicalis, C. glabrata, C. neoformans, Geotrichum candidum, S. cerevisiae, Trichosporon beigelii, T. cutaneum $\mathrm{e} T$. cutaneum mentagrophytes var. interdigitale com valores da CIM entre 5,3 e $46 \mu \mathrm{mol} / \mathrm{L}$ para canthin6-one enquanto a 5-metoxicantina-6-ona foi ativa contra apenas T. mentagrophytes var. interdigitale com um valor da CIM de 12,3 $\mu \mathrm{mol} / \mathrm{L}$ (Thouvenel et al. 2003).

Quanto à atividade antiprotozoário Ferreira et al. (2007) reportam a ação tripanocida do extrato bruto e do alcaloide canthin-6-ona isolado das cascas do caule e das folhas de $Z$. chiloperone frente a camundongos infectados aguda ou cronicamente com T. cruzi, levando a altos níveis de depuração parasitológica atestado pelo controle da parasitemia e uma diminuição do título de anticorpos pela análise ELISA bem como uma taxa de sobrevivência de $100 \%$ para os camundongos tratados por via oral com canthin-6-ona.

Estes resultados corroboram os testes realizados por Hamuy et al. (2013) na avaliação da sensibilidade in vitro do extrato das folhas de $Z$. chiloperone frente a formas epimastigotas de dez linhagens de $T$. cruzi, testadas em três concentrações diferentes 500, 700 e $900 \mu \mathrm{g} / \mathrm{mL}$, com variações nas porcentagens de lise entre as linhagens com as duas primeiras concentrações, entre $2,1 \%$ - 100\%, e lise total em todas as cepas na concentração de $900 \mu \mathrm{g} / \mathrm{mL}$.

Além disso a avaliação antimicrobiana do extrato alcoólico obtido da casca do caule de Z $Z$. chiloperone, revelou ação antiplasmodial de três compostos isolados: trans-avicenol, metoxicantina-6-ona e cantina-6-ona que apresetaram $\mathrm{IC}_{50}$ frente a cepas de $P$. falciparum resistentes e sensíveis à cloroquina/mefloquina variando de 0,5 a 2,7; 2,0 a 5,3 e 5,1 a $10,4 \mu \mathrm{g} / \mathrm{mL}$, respectivamente (CebriánTorrejón et al. 2011).

A análise do óleo essencial obtido a partir das partes aéreas de $Z$. chiloperone revelou a presença de limoneno (12), linalool (13), espatulenol (14), $\beta$-cariofileno (16), $\alpha$-tujeno (33), sabineno (34), $\alpha$-pineno (35), $\alpha$-felandreno (38), p-cimeno (39), $\beta$-felandreno(40), $\beta$-elemeno (42), $\alpha$-copaeno (43), $\delta$-cadineno (57), $\alpha$-terpineol (79), canthin-6- ona (96), $\alpha$-cubebeno (108), $\beta$-pineno (111), aromadendreno (113), $\delta$-elemeno (117), $\alpha$-humuleno (119), óxido de cariofileno (129), $\beta$-myrceno (171), terpinen-4-ol (177), $p$-cymen-8-ol (249), cis-nerolidol (250), 5-metoxicantina6-ona (251) e trans-avicenol (252) (figura 1) (Guy et al. 2001a, Ferreira et al. 2011, Cebrián-Torrejón et al. 2016).

\section{Zanthoxylum scandens Blume}

A trepadeira lenhosa Zanthoxylum scandens Blume (Z. cuspidatum Champ. Ex Benth.) é distribuída na Índia, China, Ryukyus, Sumatra, Java e Bornéu, crescendo em baixas altitudes em todo o território de Taiwan. Extratos da raiz, caule e folhas dessa planta têm sido usados como remédio popular para tratar dor abdominal, dor de dente, reumatismo e lesão traumática (Chang \& Hartley 1993).

Os ensaios antivirais dos metabólitos secundários decarina, $\gamma$-fagarina e $(+)$ - platidesmina obtidos do fracionamento do extrato metanólico das cascas do caule de $Z$. scandens apresentaram ação anti-HIV com $\mathrm{IC}_{50}$ variando de 0,1 a $1,34 \mu \mathrm{g} / \mathrm{mL}$, sendo considerada como uma das espécies mais ativas quanto à atividade anti-HIV in vitro com um índice terapêutico $>200$ (Cheng et al. 2008).

Estudo químico realizado com $Z$. scandens demonstrou a presença de lupeol (4), $\beta$-sitosterol (5), $(+)$ - sesamina (6), $\gamma$-fagarina (94), esquimianina (95), nitidina (140), arnotianamida (153), estigmasterol (161), hesperidina (170), oxiqueleritrina (207), norqueleritrina (208), decarina (239), ácido vanílico (241), oxinitidina (253), ditamnina (254), haplopina (255), platidesmine (256), vanilina (257), vanilato de metila (258), tetracosiloferulado (259) e hexacosanoato de 2- (4'-hidroxifenil) etilo (260) (figura 1) (Nguyen et al. 2002, Cheng et al. 2008).

\section{Zanthoxylum hyemale A.St.-Hill}

Bastante comum no Paraguai, Argentina e sul do Brasil, Zanthoxylum hyemale A. St. Hil. é conhecida vulgarmente como mamica-de-cadela, coentrilho, temberatu ou culantrilo (Cruz 1985, Lorenzi 1992).

Na medicina popular esta planta é utilizada como agente antiespasmódico, adstringente, agente tônico (Moura et al. 2002), analgésico, sudorífero, emético (Guy et al. 2001b), antimicrobiano, antiparasitário, anticancerígeno e antinflamatório (Chan et al. 2016).

Ensaios antimicrobianos realizados com óleos essenciais extraídos por hidrodestilação de diferentes partes da planta $Z$. hyemale apresentaram atividade contra bactérias Grampositivas: S. aureus (ATCC 6538p), S. epidermidis (ATCC 12228), B. subitilis (ATCC 6633); e Gram-negativas: $K$. pneumoniae (ATCC 10031), E. coli (ATCC 11103), P. aeruginosa (ATCC 27873), S. setubal (ATCC 19196), com o melhor valor da CIM de $0,67 \mathrm{mg} / \mathrm{mL}$ para o óleo essencial de flores contra K. pneumoniae. Este mesmo estudo relatou ainda atividade antifúngica contra $C$. albicans (ATCC 10231) e $S$. cerevisiae (ATCC 2601) com melhor valor da CIM de $2,5 \mathrm{mg} / \mathrm{mL}$ contra $S$. cerevisiae (Simionatto et al. 2005). 
A análise do óleo essencial revelou a presença de limoneno (12), $\beta$-cariofileno (16), $\alpha$-pineno (35), $\beta$-mirceno (36), $\beta$-elemeno (42), germacreno - D (53), biciclogermacreno (56), $\delta$-cadineno (57), germacreno-A (66), menth-2-en-1-ol (71), epi- $\alpha$-bisabolol (75), $\beta$-bisabolene (78), $\alpha$-terpineol (79), $\beta$-pineno (111), $\delta$-elemeno (117), $\alpha$-humuleno (119), óxido de cariofileno (129), elemol (179), germacreno - B (180), tembamida (196), O-metilbalsamida (197), $\alpha$-muroleno (261), epi- $\alpha$-muurolol (262), epi- $\alpha$-cadinol (263), cadinol (264), $\beta$-calacoralene (265), transnerolidol (266), $\alpha$-fenchene (267), R-geilbalansine (268), hiemaline (269), trans- $\beta$-terpineol (270), neo-isopulegol (271), carvacrolethylether (272), 3-decanone (273), 2 -undecanone (274), $\alpha$-acoradiene (275), $\delta$-himachalene (276), álcool cariofileno (277), hiemalol (278) e cadineno (279) (figura 1) (Moura et al. 2002, 2006, Simionatto et al. 2005, Chan et al. 2016).

\section{Zanthoxylum schinifolium Sieb. et Zucc}

Nativo da China, Japão e Coréia, Z. schinifolium é uma arbusto aromático com folhas caducifólias, que cresce a $5-7 \mathrm{~m}$ (Paik et al. 2005). Seu fruto é amplamente utilizado como um condimento e tempero na Coréia e outros países do Leste Asiático, o óleo extraído das sementes ainda é usado nestes países na medicina tradicional para dor epigástrica, atividade anticancerígena, anti-inflamatória (Seo et al. 2012), antidiabetes (Fang et al. 2010) e para revigorar a circulação do sangue e como analgésico (Cui et al. 2009, Min et al. 2011).

A avaliação antibacteriana do óleo essencial extraído do fruto maduro de $Z$. schinifolium presentou atividade frente a S. epidermidis com CIM e CBM de 2,5 e 5,0 mg/ $\mathrm{mL}$, respectivamente (Diao et al. 2013). Estudos reportam também a ação antibacteriana do extrato etanólico das folhas de Z. schinifolium frente a cepas de E. coli, S. aureus e Helicobacter pylori, com maior atividade contra H. pylori, com zona de inibição $>10 \mathrm{~mm}$ em ensaios de disco (Choi et al. 2012).

Pesquisas realizadas com o metabólito colina isolado do extrato metanólico das folhas de $Z$. schinifolium revelaram atividade antitubercular contra cepas de M. tuberculosis sensíveis e resistentes a drogas com $\mathrm{CIM}_{50}$ de 3,13-6,25 $\mu \mathrm{g} / \mathrm{ml}$ em caldo de cultura e CIM $_{50}$ de 6,25 - 12,50 $\mu \mathrm{g} / \mathrm{ml}$ dentro das células Raw264.7 e A549. A colinina não apresentou citotoxicidade contra pneumócitos pulmonares humanos até uma concentração de $100 \mu \mathrm{g} / \mathrm{ml}$ (índice de seletividade > 16 - 32) (Kim et al. 2018).

Hu et al. (2016) avaliaram a citotoxicidade e ação antiviral do sesquiterpeno identificado como schinifolenol isolado a partir do extrato etanólico de rizomas de Z. schinifolium em células iSLK.219 humanas infectadas pelo vírus do herpes associado ao sarcoma de Kaposi (KSHV), indicando potente índice de seletividade e uma hipotoxicidade segura com $\mathrm{EC}_{50}=1,99$ e $501,3 \mu \mathrm{M}$, respectivamente. Estes resultados corroboram as pesquisas realizadas por Choi et al. (2016) que avaliaram a citotoxicidade e atividade antiviral de extratos das folhas de Z. schinifolium em células HeLa infectadas com picornavírus HRV2 e HRV3, que se mostrou ativo contra HRV2 com IC $\mathrm{IC}_{50}=47,05 \mathrm{~m} \mu / \mathrm{mL}$ e índice terapêutico 4 com leve toxicidade $\mathrm{IC}_{50}=202,30 \mathrm{~m} \mu / \mathrm{mL}$.

A análise do óleo essencial obtido a partir do fruto maduro de Z. schinifolium revelou a presença de limoneno (12), linalool (13), espatulenol (14), $\beta$-cariofileno (16), nerol (26), acetato de geranil (27), geraniol (28), $\alpha$-tujeno (33), sabineno (34), $\alpha$-pineno (35), $\beta$-mirceno (36), $\alpha$-felandreno (38), p-cimeno (39), $\beta$-felandreno (40), germacreno - D (53), biciclogermacreno (56), $\alpha$-terpineol (79), $\beta$-pineno (111), $\alpha$-terpineno (115), $\gamma$-terpineno (118), $\alpha$-humuleno (119), Z- $\beta$-ocimeno (124), acetato de citronelilo (154), 1,8-cineol (172), terpinoleno (175), terpinene-4-ol (177), citronelal (193), trans-carveol (214), trans-nerolidol (266), $\gamma$-cadineno (279), acetato de linalilo (280), hexadecano (281), 3-metilpentadecano (282), pinocarvone (283), myrtenal (284), hotrienol (285), cis-p-2-menten-1-ol (286), $\alpha$-terpinil acetato (287), carvone (288), éster metílico do ácido benzenoacético (289), 2,4-dimetilacetofenona (290), acetato de 2-feniletilo (291), isopulegol (292), 3-metil-6(1-metiletil) -2-ciclo-hexeno-1-ol (293), schinifolenol (294), 6-metilheptanal (295), acetato de nerilo (296), nonanol (298), isodecanal (299), óxido trans-linalol (300), óxido de cislinalol (301), $\beta$-tujeno (302), hidrato de cis-sabineno (303), hidrato de trans-sabineno (304), 6-metil-1-heptanol (305), e 1,4-dimetilpirazole (306) (figura 1) (Paik et al. 2005, Diao et al. 2013, Li et al. 2014, Hu et al. 2016, Kim etal. 2018).

\section{Zanthoxylum alatum Hemsl.}

A espécie Z. alatum (syn. Z. armatum $\mathrm{DC}, Z$. planispinum Sieb.) é um arbusto verde com inflorescências axilares com até $6 \mathrm{~m}$ de altura, nativo do continente asiático, onde cresce em diferentes habitats, sendo conhecido no Nepal por Timur, Timpur, Prumo e Tebu (Phuyal et al. 2019). É amplamente cultivado em vários países da América do Sul onde é usado como planta ornamental e medicinal, representando uma importante fonte de produção de metabólitos secundários (Jain et al. 2001).

Vários estudos etnobotânicos documentaram os diferentes usos etnomedicinais dos extratos e infusões obtidos das cascas, sementes e frutos de Z. alatum no tratamento de diferentes tipos de doenças. Na Índia, onde é conhecido por mukthrubi, é utilizado na preparação de medicamentos indígenas contra várias doenças como asma, bronquite, indigestão, veias varicosas, diarreia, reumatismo, dispepsia e cólera (Singh et al. 2015, Nooreen et al. 2017). No Nepal é usado contra dor de dente, diabetes, problemas estomacais (Balami, 2006), intoxicação alimentar (Malla et al. 2014) e tuberculose (Subedi 2017).

Os ensaios antibacterianos realizados a partir do óleo essencial extraído das folhas de $Z$. alatum frente a bactérias Gram positivas e Gram negativas M. leutus, $(E$. coli, S. aureus, Pasteurella multocida, P. aeruginosa, $B$. subtilis e $S$. viridines) mostrou potencial antibacteriano 
contra todas as cepas, com efeito máximo contra M. leutus $(23,33 \pm 0,58)$ seguido por $S$. viridans $(17,67 \pm 0,58 \mathrm{~mm})$ e B. subtilis $(15,83 \pm 0,41 \mathrm{~mm})$ na concentração de $125 \mu \mathrm{g} /$ ml. Foi calculado ainda a CIM para as amostras de teste neste ensaio, revelando valores muito baixos variando entre 0,65 e $1,25 \mu \mathrm{g} / \mathrm{ml}$. Este mesmo estudo avaliou ainda a atividade antifúngica do óleo essencial frente a $T$. longifusis, C. albicans, F. solani, M. canis, A. flavus e C. glabrata, com melhor efeito de inibição de crescimento micelar contra $C$. albicans $(66,67 \pm 0,57)$, seguido por A. flavus $(55,33 \pm 0,57)$ e $F$. solani $(46,33 \pm 0,33)$ na concentração de $125 \mu \mathrm{g} / \mathrm{ml}$ (Barkatullah et al. 2013).

Estudo semelhante foi realizado a partir do extrato metanólico obtido de plantas secas de Z. alatum por microdiluição em caldo contra cepas de bactérias Gram positivas (Corynebacterium diptheriae, C. hofmanii, $C$. xerosis, S. saprophyticus, S. fecalis e S. pyogenes ) e Gram negativas (Klebsiella pneumoniae, Serratia marcesens, Acinetobacter baumanii, V. cholerae e Aeromonas hydrophila) revelando uma zona de inibição no intervalo de $15 \pm 0$ a $20 \pm 0 \mathrm{~mm}$ frente a bactérias Gram negativas e $15 \pm$ 2 para $29 \pm 0 \mathrm{~mm}$ para Gram positivas (Wazir et al. 2014)

Pesquisas sobre a toxicidade do óleo essencial de $Z$. alatum contra larvas de um dia de idade de Aedes aegypti, mostraram $100 \%$ de mortalidade nas doses de $125,62,5$ e 31,25 ppm, sendo considerado como inseticida natural potente. Nesse mesmo estudo foi analisada a atividade antifúngica do óleo essencial contra espécies de fungos do gênero Colletotrichum, revelando atividade antifúngica moderada com Inibição Média do Crescimento fúngico entre $3.0 \pm 0.71$ e $4.0 \pm 0.71$ (Stappen et al. 2018).

A análise do óleo essencial revelou a presença de (Z)-3hexenol (11), limoneno (12), linalool (13), E- $\beta$-cariofileno (16), acetato de geranil (27), 2-undecanol (29), epóxido de humuleno II (30), hexanol (32), $\alpha$-tujeno (33), sabineno (34), $\alpha$-pineno (35), mirceno (36), (E)- $\beta$-ocimeno (37), $\alpha$-felandreno (38), p-cimeno (39), criptona (41), $\beta$-bourboneno (44), (E)nerolidol (49), germacreno - D (53), biciclogermacreno (56), $\delta$-cadineno (57), 2-undecanona (62), $\alpha$-terpineol (79), $\beta$-pineno (111), $\alpha$-terpineno (115), terpinolene (116), $\gamma$-terpineno (118), $\alpha$-humuleno (119), cânfora (125), óxido de cariofileno (129), 1,8-cineol (172), terpinen-4-ol (177), citronelal (193), canfeno (209), $\gamma$-cadineno (279), acetato de linalilo (280), acetato de $\alpha$-terpinil (287), nonanol (298), hidrato de cis-sabineno (303), hidrato trans-sabineno (304), (E)-2-hexenal (307), 2-nonanone (308), 4,8-dimetil-1,3,7nonatrieno (309), p-mentha-1,3,8-trieno (310), cis-p-ment2-en-1-ol (311), trans-p-ment-2-en-1-ol (312), $\delta$-terpineol (313), trans-piperitol (314), piperitona (315), 2-decanona (316), pinocamfeol (317), acetato de cis-crisantenilo (318), 2-metilbutanoato de cis-3-hexenilo (319), 2-dodecanona (320), (E,E)- $\alpha$-farneseno (321), 2-tridecanona (322), e $\alpha$-muurol (323) (figura 1) (Jain et al. 2001, Phuyal et al. 2018, Stappen et al. 2018).
Zanthoxylum bungeanum Maxim.

Amplamente distribuída nos países asiáticos, incluindo China, Japão, Índia, Coréia entre outros, Z. bungeanum, é um pequeno arbusto com aproximadamente 3 a 7 metros de altura (Zhang et al. 2017). Na China seus frutos, conhecidos como "Honghuajiao" são usados como condimento na culinária local e na medicina tradicional apresenta aplicações para o tratamento de dor abdominal, dor de dente, dispepsia, vômito, diarreia, ascaridíase e eczema (Yu et al. 2009, Xiang et al. 2016).

Para os ensaios antifúngicos, alguns autores reportaram a atividade inibitória do óleo essencial extraído dos frutos secos de $Z$. bungeanum frente a cepas parasitas de plantas incluindo L. maculans, B. maydis, Rhizoctonia cerealis e Magnaporthe grisea, com os valores mais baixos do $\mathrm{IC}_{50}$ equivalentes a $0,13,0,24,0,27$ e $0,28 \mathrm{mg} / \mathrm{mL}$, respectivamente. É relatado ainda neste ensaio que esse óleo essencial inibiu fortemente o crescimento micelial de $R$. solani $\mathrm{e} R$. cerealis com valores de $\mathrm{IC}_{50}$ de 0,95 e 1,22 $\mathrm{mg} / \mathrm{mL}$, respectivamente (Gong et al. 2009). Em estudos semelhantes foram constatados a atividade inibitória do óleo essencial extraído das sementes de $Z$. bungeanum frente a F. sulphureum com inibição do desenvolvimento micelar, para o óleo e $\alpha$-pineno $(19,59 \%)$ seu principal constituinte de $6,25 \%$ e $12,50 \%$, respectivamente (Xing-Dong \&HuaLi, 2014).

Estudos reportam também a atividade antibacteriana do óleo essencial dos frutos de $Z$. bungeanum frente a cinco espécies de bactérias comuns de origem alimentar - $S$. aureus, B. subtilis, B. cereus, B. laterosporus laubach e E. coli, com CIM de $5,0,1,25,2,5,1,25$ e $2,5 \mathrm{mg} / \mathrm{mL}$, e CBM de $20,2,5,10,5,0$ e $5,0 \mathrm{mg} / \mathrm{mL}$, respectivamente (Zhu et al. 2011). Esses achados corroboram os resultados apresentados por Tu et al. (2018) na avaliação da atividade antibacteriana por difusão em ágar do óleo essencial de Z. bungeanum frente a cepas de bactérias Gram-positivas (B. subtilis e $S$. aureus) e Gram-negativas (E. coli e $S$. typhimurium) de origem alimentar com CIM de 4,1 e 4,2 $\mathrm{mg} / \mathrm{mL}$, respectivamente.

A análise do óleo essencial obtido a partir dos frutos de Z. bungeanum revelaram a presença de limoneno (12), linalool (13), espatulenol (14), $\beta$-cariofileno (16), $\beta$-cubebeno (20), $\alpha$-cadinol (23), acetato de geranila (27), sabineno (34), $\alpha$-pineno (35), $\alpha$-felandreno (38), p-cimeno (39), $\beta$-elemeno (42), (E)-nerolidol (49), $\delta$-cadineno (57), $\beta$-pineno (111), terpinolene (116), $\gamma$-terpineno (118), $\alpha$-humuleno (119), (Z) -3,7-Dimetil-1,3,6-octatrieno (124), cânfora (125), 1,8 cineol (172), 4-carvomentenol (177), $\alpha$-carene (210), $\alpha$-muroleno (261), $\gamma$-cadineno (279), acetato de linalilo (280), acetato de terpinila (287), D-carvone (288), feniletil acetato (291), acetato de nerilo (296), farneseno (321), geranillinalol (324), eudesmol (325), $\beta$-cadineno (326), cumarina (327), $\beta$-terpilenol (328), (R)-4-terpineol (329), $\alpha$-terpilenol (330), p-isopropilbenzaldeído (331), trans- 
p-mentha-2,8-dienol (332), (Z)-carveol (333), cariofilina (334) e oxiranometanol (335) (figura 1) (Zhu et al. 2011, Xing-Dong \& Hua-Li 2014, Lan et al. 2016, Liu et al. 2017, Jie et al. 2019).

\section{Zanthoxylum naranjillo Griseb.}

Conhecida por popularmente por juva, naranjillo, tembetari, e espinho, Z. naranjillo Griseb. (Fagara naranjillo Engler) é uma árvore com até 15 metros pertencente à família Rutaceae e que crescem na América do Sul tropical (Paraguai, Norte da Argentina, Sul do Brasil e Uruguai) (Guy et al. 2001b). No Brasil essa planta é usada na medicina popular contra doenças associadas a processos inflamatórios, o chá de suas folhas é usado no Paraguai como analgésico e também como emético, sudorífico e para favorecer a salivação (Guy et al. 2001b).

Em relação à atividade antiprotozoário ensaios in vitro realizados com sete lignanas isoladas do extrato hexânico das folhas de $Z$. naranjillo em sangue de ratos albinos contaminados com duas cepas de T. cruzi, indicaram melhor atividade tripanocida do composto metilpluviatolido que se mostrou efetivo frente as cepas Bolívia e $\mathrm{Y}$ com valores de $88 \pm 1.00$ e $99 \pm 0.58$ na concentração de $25 \mu \mathrm{g} / \mathrm{mL}$, respectivamente (Bastos et al. 1999). Esses resultados não corroboram as pesquisas de Costa et al 2007 que avaliaram a ação tripanocida da partição diclorometano do extrato diclorometano extraídos das folhas de Z. noranjillo de onde foi obtido o composto metilpluviatolido como uma das amostras com menor atividade entre as amostras testadas $\left(\mathrm{IC}_{50}=11,0 \mu \mathrm{g} / \mathrm{mL}\right)$, quando comparado ao extrato bruto etanólico que apresentou o melhor resultado $\left(\mathrm{IC}_{50}=1,03 \mu \mathrm{g} / \mathrm{mL}\right)$ frente a cepa Y.

A análise do óleo essencial obtido a partir das folhas de Z. noranjillo, revelaram a presença de $(+)$ - sesamina (6), (+)-piperitol (7), limoneno (12), linalool (13), espatulenol (14), $\beta$-cariofileno (16), $\delta$-elemeno (21), $\alpha$-copaene (24), $\alpha$-tujeno (33), sabineno (34), $\alpha$-pineno (35), $\beta$-mirceno (36), $\alpha$-felandreno (38), p-cimeno (39), $\beta$-felandreno (40), ß-elemeno (42), germacreno - D (53), biciclogermacreno (56), $\delta$-cadineno (57), $\alpha$-cubebeno (108), $\beta$-pineno (111), aromadendreno (113), aloaromadendreno (114), $\alpha$-humuleno (119), Z-ß-ocimeno (124), óxido de cariofileno (129), terpinen-4-ol (177), cis-nerolidol (250), B-gurjunene (336), metilpluviatolido (337), (-) cubebina (338) e (-) cariofilina (339) (figura 1) (Bastos et al. 1999, Guy et al. 2001b).

\section{Zanthoxylum riedelianum Engl.}

Árvore proeminente da flora brasileira, Zanthoxylum riedelianum Engl. (Rutaceae) é comumente encontrada no Estado de Goiás, podendo atingir de 8 a18 metros de altura com diâmetro que pode chegar a $50 \mathrm{~cm}$ (Costa et al. 2017a, Guy et al. 2001a). É conhecida popularmente no Brasil como mamica-de-porca devido à forma particular de seus espinhos (Beirigo et al. 2016). Na medicina popular a decocção de sua casca é usada contra diferentes tipos de inflamações, analgésico, reumatismo e manchas na pele (Lima et al. 2007).

Os ensaios antibacterianos realizados por difusão em ágar do extrato metanólico das folhas de $Z$. riedelianum frente três cepas de bactérias patogênicas de peixes apresentou zona de inibição apenas para $S$. agalactiae e $F$. columnare nos valores de 7 e $11,5 \mathrm{~mm}$ respectivamente, enquanto a CIM foi de $1500 \mu \mathrm{g} / \mathrm{mL}^{-1}$ apenas para F. columnare (Castro et al. 2008).

A análise do óleo essencial obtido a partir dos frutos e estudos fotoquímicos dos extratos da cascado caule e folhas de $Z$. riedelianum exibiram a presença de lupeol (4), sesamina (6), limoneno (12), espatulenol (14), $\beta$-cariofileno (16), $\beta$-cubebeno (20), $\delta$-elemeno (21), $\alpha$-copaene (24), $\alpha$-tujeno (33), sabineno (34), $\alpha$-pineno (35), $\beta$-mirceno (36), $\beta$ - ocimeno (37), $\alpha$-felandreno (38), $\beta$ - elemeno (42), germacreno - D (53), biciclogermacreno (56), $\delta$-cadineno (57), germacreno - A (66), $\alpha$-cubebeno (108), $\beta$-pineno (111), aromadendreno (113), $\alpha$-terpinolene (116), $\gamma$-muroleno (120), germacreno - B (180), metilpluviatolido (337), cariofilina (339), $\beta$-linalol (340), $\gamma$-elemeno (341), 6-acetonildiidroavicina (342), dimetilmatiresinol (343), hinocinina (344), 6-acetonil- $N$-metil-diidrodecarina (345), 6-acetonildiidroqueleritrina (346) e piperito- $4^{\prime}-O-\gamma, \gamma-$ dimethylallyl ether (347) (figura 1) (Lima et al. 2007, Fernandes et al. 2009, Costa et al. 2017a, Pereira et al. 2018).

\section{Considerações finais}

O gênero Zanthoxylum possui um registro de espécies com grande potencial antimicrobiano e farmacológico, com amplo uso na medicinal tradicional em várias regiões do mundo, com destaque para os extratos com propriedades antibacterianas, antifúngicas, leishmanicida e larvicidas contra muitos micro-organismos testados, entre eles $S$. aureus, $P$. aeruginosa, C. albicans e $L$. infantum chagasi. Das espécies pesquisadas foram identificados 347 compostos químicos dentre os quais destacamos os alcaloides, fenóis, amidas, cumarinas, flavonoides, terpenoides, esteroides e taninos. A ação biológica já comprovada de muitos desses metabólitos, justifica a importância das pesquisas feitas com as espécies desse gênero na busca de novos compostos de uso medicinal e agroquímico. 
Figura 1. Representação estrutural de metabólitos secundários isolados do gênero Zanthoxylum Linnaeus (Rutaceae)

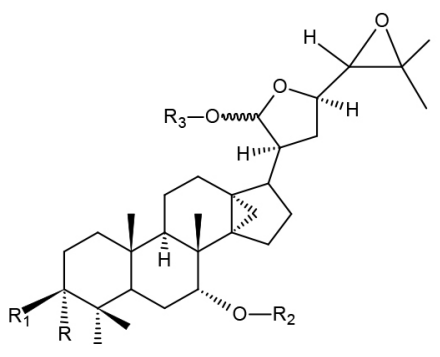

1. $\mathrm{R}=\mathrm{R}_{1}=\mathrm{O} ; \mathrm{R}_{2}=\mathrm{R}_{3}=\mathrm{H}$

2. $\mathrm{R}=\mathrm{OCOCH}_{2} \mathrm{CH}\left(\mathrm{CH}_{3}\right)_{2} ; \mathrm{R}_{1}=\mathrm{R}_{2}=\mathrm{R}_{3}=\mathrm{COCH}_{3}$

3. $\mathrm{R}=\mathrm{R}_{1}=\mathrm{O} ; \mathrm{R}_{2}=\mathrm{R}_{3}=\mathrm{COCH}_{3}$

4. $\mathrm{R}=\mathrm{R}_{1}=\mathrm{O} ; \mathrm{R}_{2}=\mathrm{COCH}_{3} ; \mathrm{R}_{3}=\mathrm{H}$<smiles>C=C(C)C(O)CC</smiles>

5. $\mathrm{R}_{1}=\mathrm{R}_{2}=\mathrm{CH}_{3}$

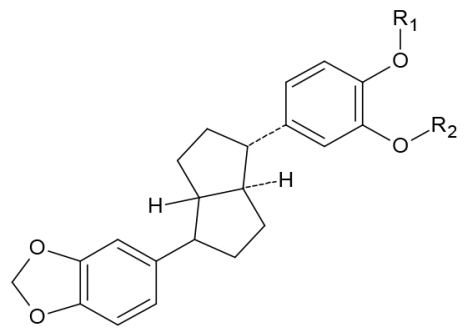

6. $\mathrm{R}_{1}=\mathrm{R}_{2}=-\mathrm{OCH}_{2} \mathrm{O}-$

7. $\mathrm{R}_{1}=\mathrm{H} ; \mathrm{R}_{2}=\mathrm{CH}_{3}$

7a. $\mathrm{R}_{1}=\mathrm{CH}_{3} ; \mathrm{R}_{2}=\mathrm{H}$<smiles>CCC=C(C)C</smiles>

8. $\mathrm{R}_{1}=\mathrm{R}_{2}=\mathrm{CH}_{3}$

9. $\mathrm{CH}_{3}\left(\mathrm{CH}_{2}\right)_{4} \mathrm{CH}=\mathrm{CHCH}_{2} \mathrm{CH}_{2}(\mathrm{CH}=\mathrm{CH})_{2} \mathrm{CONHCH}_{2} \mathrm{CHCH}_{3}$<smiles>COc1cc([C@H]2c3ccccc3C[C@H](COC(=O)CN)[C@H]2CO)cc(OC)c1O</smiles>

10.

11.

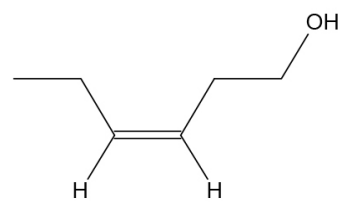<smiles>[R]C1C([R])C([R])C([R])C([R])C1[R]</smiles>

12. $\mathrm{R}_{1}=\mathrm{CH}_{3} \mathrm{CHCH}_{3} ; \mathrm{R}_{2}=\mathrm{R}_{3}=\mathrm{R}_{5}=\mathrm{R}_{6}=\mathrm{H}, \mathrm{H} ; \mathrm{R}_{4}=\mathrm{CH}_{3}$<smiles>C=CC(C)(O)CCC=C(C)C</smiles>

13.

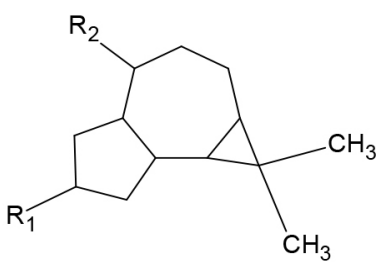

14. $\mathrm{R}_{1}=\mathrm{OH}, \mathrm{CH}_{3} ; \mathrm{R}_{2}=\mathrm{CH}_{2}$

15. $\mathrm{R}_{1}=\mathrm{CH}_{3}(\mathrm{R}) ; \mathrm{R}_{2}=\mathrm{CH}_{3}, \mathrm{OH}$

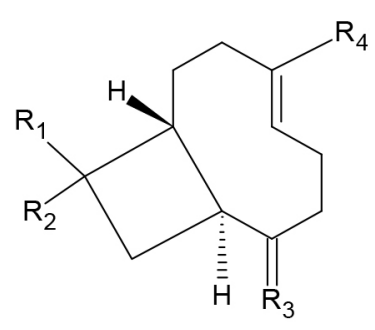

16. $\mathrm{R}_{1}=\mathrm{R}_{2}=\mathrm{R}_{4}=\mathrm{CH}_{3} ; \mathrm{R}_{3}=\mathrm{CH}_{2}$<smiles>[R]/C(C)=C\CCC(C)=O</smiles>

17. $\mathrm{R}_{1}=\mathrm{CH}_{3}$<smiles>[R]C(=O)/C([R])=C/CC=C([R3])C</smiles>

18. $\mathrm{R}_{1}=\mathrm{H}(\mathrm{Z}) ; \mathrm{R}_{2}=\mathrm{R}_{3}=\mathrm{CH}_{3}$

19. $\mathrm{R}_{1}=\mathrm{H}(\mathrm{E}) ; \mathrm{R}_{2}=\mathrm{R}_{3}=\mathrm{CH}_{3}$ 
Figura 1 (continuação)

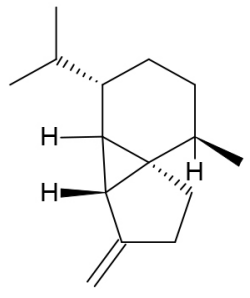

20.<smiles>C=C[C@]1(C)CCC(C(C)C)CC1C(C)C</smiles>

21.<smiles>[R]C1C([R])C([R])C2([R])C([R])C([R])C([R])C([R])C2([R])C1[R]</smiles>

22. $\mathrm{R}_{1}=\mathrm{R}_{4}=\mathrm{R}_{6}=\mathrm{R}_{1}=\mathrm{R}_{4}=\mathrm{H}, \mathrm{H} ; \mathrm{R}_{2}=\mathrm{CH}\left(\mathrm{CH}_{3}\right)_{2}(\mathrm{R}) ; \mathrm{R}_{3}=\mathrm{R}_{2}=\mathrm{H}$; $\mathrm{R}_{5}=\mathrm{CH}_{3} ; \mathrm{R}_{3}=\mathrm{OH}, \mathrm{CH}_{3}$

23. $\mathrm{R}_{1}=\mathrm{R}_{4}=\mathrm{R}_{6}=\mathrm{R}_{1}=\mathrm{R}_{4}=\mathrm{H}, \mathrm{H} ; \mathrm{R}_{2}=\mathrm{CH}\left(\mathrm{CH}_{3}\right)_{2}(\mathrm{~S}) ; \mathrm{R}_{3}=\mathrm{R}_{2}=\mathrm{H}$; $\mathrm{R}_{5}=\mathrm{CH}_{3} ; \mathrm{R}_{3}=\mathrm{OH}, \mathrm{CH}_{3}$

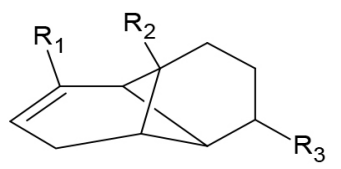

24. $\mathrm{R}_{1}=\mathrm{R}_{2}=\mathrm{CH}_{3} ; \mathrm{R}_{3}=\mathrm{CH}\left(\mathrm{CH}_{3}\right)_{2}$

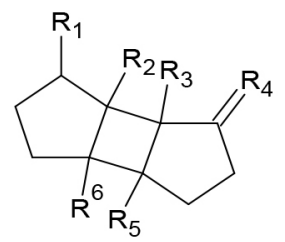

25. $\mathrm{R}_{1}=\mathrm{CH}\left(\mathrm{CH}_{3}\right)_{2} ; \mathrm{R}_{2}=\mathrm{R}_{3}=\mathrm{R}_{5}=\mathrm{R}_{6}=\mathrm{CH}_{3} ; \mathrm{R}_{4}=\mathrm{CH}_{2}$<smiles>[R1]CC=C([R2])CCC=C([R3])C</smiles>

26. $\mathrm{R}_{1}=\mathrm{OH} ; \mathrm{R}_{2}=\mathrm{R}_{3}=\mathrm{CH}_{3}$<smiles>[R3]C(C)=CCC/C([R])=C\COC([R1])C</smiles>

27. $\mathrm{R}_{1}=\mathrm{O} ; \mathrm{R}_{2}=\mathrm{R}_{3}=\mathrm{CH}_{3}$<smiles>[R1]/C(=C/CC)CC/C=C(\[R2])C</smiles>

28. $\mathrm{R}_{1}=\mathrm{R}_{2}=\mathrm{CH}_{3}$<smiles>[R]C([R2])CCCCCCCCC</smiles>

29. $\mathrm{R}_{1}=\mathrm{OH} ; \mathrm{R}_{2}=\mathrm{CH}_{3}$<smiles>[R2]/C1=C/CC2CC2([R7])/C=C\C([R3])([R3])CC1</smiles>

30. $\mathrm{R}_{1}=\mathrm{R}_{2}=\mathrm{R}_{3}=\mathrm{R}_{4}=\mathrm{CH}_{3}$

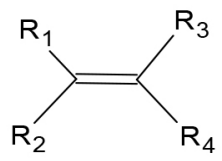

31. $\mathrm{R}_{1}=\mathrm{C}_{2} \mathrm{H}_{5} ; \mathrm{R}_{2}=\mathrm{R}_{4}=\mathrm{H} ; \mathrm{R}_{3}=\mathrm{C}_{2} \mathrm{H}_{5}-\mathrm{OH}$<smiles>CCCCCCO</smiles>

32.<smiles>[R4]C1C[C@@]2([R3])C[C@]2([R2])C1[R]</smiles>

33. $\mathrm{R}_{1}=\mathrm{CH}_{3} ; \mathrm{R}_{2}=\mathrm{R}_{4}=\mathrm{H} ; \mathrm{R}_{3}=\mathrm{CH}_{3} \mathrm{CHCH}_{3}$ 34. $\mathrm{R}_{1}=\mathrm{CH}_{2} ; \mathrm{R}_{2}=\mathrm{R}_{4}=\mathrm{H} ; \mathrm{R}_{3}=\mathrm{CH}_{3} \mathrm{CHCH}_{3}$

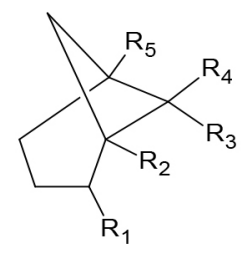

35. $\mathrm{R}_{1}=\mathrm{R}_{3}=\mathrm{R}_{4}=\mathrm{CH}_{3} ; \mathrm{R}_{2}=\mathrm{H}$ 
Figura 1 (continuação)<smiles>[R]C=CC([R])C([R])([R])C=[R]</smiles>

36. $\mathrm{R}_{1}=\mathrm{R}_{2}=\mathrm{CH}_{3} ; \mathrm{R}_{3}=\mathrm{H}, \mathrm{H} ; \mathrm{R}_{4}=\mathrm{R}_{5}=\mathrm{CH}_{2} ; \mathrm{R}_{6}=\mathrm{H}$ 37. $\mathrm{R}_{1}=\mathrm{R}_{2}=\mathrm{CH}_{3} ; \mathrm{R}_{3}=\mathrm{H} ; \mathrm{R}_{4}=\mathrm{CH}_{3} ; \mathrm{R}_{5}=\mathrm{CH}_{2} ; \mathrm{R}_{6}=\mathrm{H}$<smiles>[R3]C1C([R3])C([R3])C([R])C([R])C1[R]</smiles>

38. $\mathrm{R}_{1}=\mathrm{CH}_{3} \mathrm{CHCH}_{3} ; \mathrm{R}_{2}=\mathrm{R}_{5}=\mathrm{R}_{6}=\mathrm{H} ; \mathrm{R}_{3}=\mathrm{H}, \mathrm{H} ; \mathrm{R}_{4}=\mathrm{CH}_{3}$ 39. $\mathrm{R}_{1}=\mathrm{CH}_{3} \mathrm{CHCH}_{3} ; \mathrm{R}_{2}=\mathrm{R}_{3}=\mathrm{R}_{5}=\mathrm{R}_{6}=\mathrm{H} ; \mathrm{R}_{4}=\mathrm{CH}_{3}$ 40. $\mathrm{R}_{1}=\mathrm{CH}_{3} \mathrm{CHCH}_{3} ; \mathrm{R}_{2}=\mathrm{R}_{3}=\mathrm{H} ; \mathrm{R}_{5}=\mathrm{R}_{6}=\mathrm{H}, \mathrm{H} ; \mathrm{R}_{4}=\mathrm{CH}_{2}$ 41. $\mathrm{R}_{1}=\mathrm{CH}_{3} \mathrm{CHCH}_{3} ; \mathrm{R}_{2}=\mathrm{R}_{3}=\mathrm{H} ; \mathrm{R}_{5}=\mathrm{R}_{6}=\mathrm{H}, \mathrm{H} ; \mathrm{R}_{4}=\mathrm{O}$

42. $\mathrm{R}_{1}=\mathrm{CH} 3, \mathrm{CHCH}_{2} ; \mathrm{R}_{2}=\mathrm{R}_{3}=\mathrm{R}_{5}=\mathrm{H}, \mathrm{H} ; \mathrm{R}_{4}=\mathrm{CH}_{2} \mathrm{CCH}_{3} ; \mathrm{R}_{6}=$ $\mathrm{CH}_{3} \mathrm{CHCH}$

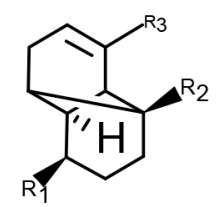

43. $\mathrm{R}_{1}=\mathrm{CH}_{3} \mathrm{CHCH}_{3} ; \mathrm{R}_{2}=\mathrm{R}_{3}=\mathrm{CH}_{3}$

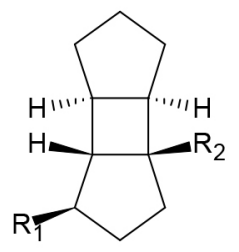

44. $\mathrm{R}_{1}=\mathrm{R}_{2}=\mathrm{CH}_{3}$

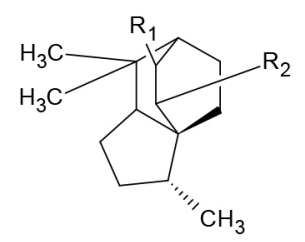

45. $\mathrm{R}_{1}=\mathrm{CH}_{3} ; \mathrm{R}_{2}=\mathrm{H}$<smiles>[2H]C1(CCC=C(C)C)C2CC=C(C)C1C2</smiles>

46. $\mathrm{R}_{1}=\mathrm{CH}_{3}$

47. $\mathrm{R}_{1}=\mathrm{CH}_{3}(\mathrm{~S})$<smiles>[R]C([R9])CC/C(C)=C(/[B])CCC([R9])C([2H])[2H]</smiles>

48. $\mathrm{R}=\mathrm{R}_{1}=\mathrm{R}_{5}=\mathrm{CH}_{3} ; \mathrm{R}_{2}=\mathrm{R}_{1}=\mathrm{CH}_{2} ; \mathrm{R}_{3}=\mathrm{R}_{4}=\mathrm{H}$

49. $\mathrm{R}=\mathrm{R}_{1}=\mathrm{R}_{2}=\mathrm{H} ; \mathrm{R}_{3}=\mathrm{R}_{1}=\mathrm{CH}_{3} ; \mathrm{R}_{4}=\mathrm{OH}, \mathrm{CH}_{3} ; \mathrm{R}_{5}=\mathrm{CH}_{2}$<smiles>[R7]C1CCC([R2])(C([R3])CCC=C(C)C)CC1</smiles>

50. $\mathrm{R}_{1}=\mathrm{R}_{3}=\mathrm{CH}_{3} ; \mathrm{R}_{2}=\mathrm{H}$

51. $\mathrm{R}_{1}=\mathrm{CH}_{3} ; \mathrm{R}_{2}=\mathrm{H} ; \mathrm{R}_{3}=\mathrm{CH}_{3}(\mathrm{R})$

52. $\mathrm{R}_{1}=\mathrm{CH}_{3} ; \mathrm{R}_{2}=\mathrm{OH} ; \mathrm{R}_{3}=\mathrm{H}$<smiles></smiles>

53. $\mathrm{R}_{1}=\mathrm{CH}_{3} ; \mathrm{R}_{2}=\mathrm{CH}_{3} \mathrm{CHCH}_{3} ; \mathrm{R}_{3}=\mathrm{CH}_{2}$<smiles></smiles>

54. $\mathrm{R}_{1}=\mathrm{CH}_{3}(\mathrm{R}) ; \mathrm{R}_{2}=\mathrm{CH}_{3} \mathrm{CHCH}_{3} ; \mathrm{R}_{3}=\mathrm{H}$ 55. $\mathrm{R}_{1}=\mathrm{CH}_{3}(\mathrm{~S}) ; \mathrm{R}_{2}=\mathrm{CH}_{3} \mathrm{CHCH}_{3} ; \mathrm{R}_{3}=\mathrm{H}$

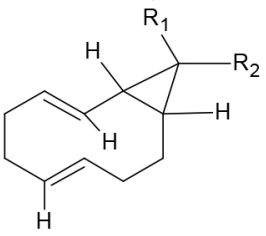

56. $\mathrm{R}_{1}=\mathrm{R}_{2}=\mathrm{CH}_{3}$

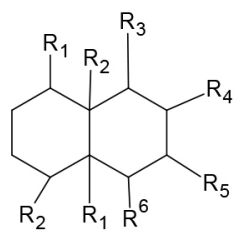

57. $\mathrm{R}_{1}=\mathrm{R}_{5}=\mathrm{CH}_{3} ; \mathrm{R}_{3}=\mathrm{H}, \mathrm{H} ; \mathrm{R}_{6}=\mathrm{R}_{1}=\mathrm{H} ; \mathrm{R}_{2}=\mathrm{CH}_{3} \mathrm{CHCH}_{3}$

58. $\mathrm{R}_{1}=\mathrm{CH}_{3} \mathrm{CHCH}_{3} ; \mathrm{R}_{2}=\mathrm{R}_{3}=\mathrm{H} ; \mathrm{R}_{4}=\mathrm{R}_{2}=\mathrm{CH}_{3} ; \mathrm{R}_{5}=\mathrm{R}_{6}=\mathrm{H}, \mathrm{H}$; $\mathrm{R}_{1}=\mathrm{OH}$

59. $\mathrm{R}_{1}=\mathrm{CH}_{3} \mathrm{CHCH}_{3}(\mathrm{R}) ; \mathrm{R}_{2}=\mathrm{R}_{3}=\mathrm{H} ; \mathrm{R}_{4}=\mathrm{R}_{2}=\mathrm{CH}_{3} ; \mathrm{R}_{5}=\mathrm{R}_{6}=\mathrm{H}, \mathrm{H}$; $\mathrm{R}_{1}=\mathrm{OH}$ 
Figura 1 (continuação)

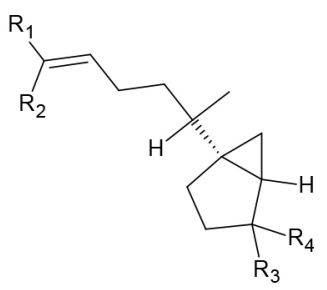

60. $\mathrm{R}_{1}=\mathrm{R}_{2}=\mathrm{R}_{3}=\mathrm{CH}_{3} ; \mathrm{R}_{4}=\mathrm{OH}$<smiles>[R8]C1CCC2C(CC([R8])C2(C)C)C1C</smiles>

61. $\mathrm{R}_{1}=\mathrm{CH}_{3} ; \mathrm{R}_{2}=\mathrm{CH}_{3}, \mathrm{OH}$<smiles>[R]C([2H])C([R3])C([R9])CCC([2H])CC([R])C([R])C</smiles>

62. $\mathrm{R}_{1}=\mathrm{O} ; \mathrm{R}_{2}=\mathrm{R}_{3}=\mathrm{R}_{4}=\mathrm{R}_{5}=\mathrm{H}, \mathrm{H} ; \mathrm{R}_{6}=\mathrm{H}, \mathrm{H} ; \mathrm{R}=\mathrm{CH} 3$

63. $\mathrm{R}_{1}=\mathrm{CH}_{3} ; \mathrm{R}_{2}=\mathrm{R}_{6}=\mathrm{H}(\mathrm{E}), \mathrm{R}_{3}=\mathrm{R}_{5}=\mathrm{CH}_{3} ; \mathrm{R}_{4}=\mathrm{H}, \mathrm{H} ; \mathrm{R}=\mathrm{OH}$

64. $\mathrm{R}_{1}=\mathrm{CH}_{3} ; \mathrm{R}_{2}=\mathrm{R}_{6}=\mathrm{H}(\mathrm{Z}), \mathrm{R}_{3}=\mathrm{R}_{5}=\mathrm{CH}_{3} ; \mathrm{R}_{4}=\mathrm{H}, \mathrm{H} ; \mathrm{R}=\mathrm{OH}$<smiles>[R]C1CC([R6])(C)C1CCC(Br)=CCC</smiles>

65. $\mathrm{R}_{1}=\mathrm{R}_{2}=\mathrm{R}_{3}=\mathrm{CH}_{3} ; \mathrm{R}_{4}=\mathrm{CH}_{2}$

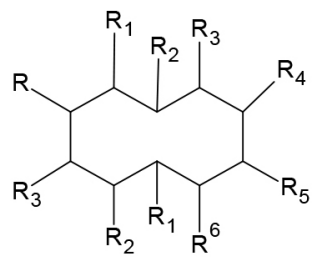

66. $\mathrm{R}=\mathrm{H}, \mathrm{H} ; \mathrm{R}_{1}=\mathrm{H} ; \mathrm{R}_{2}=\mathrm{CH}_{3} ; \mathrm{R}_{3}=\mathrm{R}_{4}=\mathrm{R}_{3}=\mathrm{R}_{6}=\mathrm{H}, \mathrm{H} ; \mathrm{R}_{5}=$ $\mathrm{CH}_{3} \mathrm{CCH}_{2} ; \mathrm{R}_{1}=\mathrm{H} ; \mathrm{R}_{2}=\mathrm{CH}_{3}$

67. $\mathrm{R}=\mathrm{R}_{1}=\mathrm{R}_{4}=\mathrm{R}_{5}=\mathrm{R}_{2}=\mathrm{H}, \mathrm{H} ; \mathrm{R} 2=$ vazio; $\mathrm{R}_{3}=\mathrm{H} ; \mathrm{R}_{6}=\mathrm{R}_{1}=\mathrm{CH}_{3}$; $\mathrm{R}_{3}=\mathrm{CH}_{3} \mathrm{CCH}_{2}$

68. $\mathrm{R}=\mathrm{R}_{3}=\mathrm{R}_{4}=\mathrm{R}_{5}=\mathrm{R}_{6}=\mathrm{H} ; \mathrm{R}_{1}=\mathrm{CH}_{3} ; \mathrm{R} 2=\mathrm{R}_{1}=$ vazio; $\mathrm{R}_{2}=$ $\mathrm{CH} 3 \mathrm{CCH} 2 ; \mathrm{R}_{3}=\mathrm{H}, \mathrm{H}$

69. $\mathrm{R}=\mathrm{C}(\mathrm{OH})\left(\mathrm{CH}_{3}\right)_{2} ; \mathrm{R}_{1}=\mathrm{R}_{5}=\mathrm{R}_{6}=\mathrm{R}_{2}=\mathrm{R}_{3}=\mathrm{H}, \mathrm{H} ; \mathrm{R}_{2}=\mathrm{H} ; \mathrm{R}_{1}=$ $\mathrm{CH}_{3}$

70. $\mathrm{R}=\mathrm{R}_{3}=\mathrm{R}_{6}=\mathrm{R}_{3}=\mathrm{H}, \mathrm{H} ; \mathrm{R}_{1}=\mathrm{R}_{1}=\mathrm{H} ; \mathrm{R}_{4}=\mathrm{C}\left(\mathrm{CH}_{3}\right)_{2} ; \mathrm{R}_{5}=\mathrm{O}$; $\mathrm{R}_{2}=\mathrm{CH}_{3}$<smiles>[R]C1C([R3])C([R])C([R])C([R])C1[R]</smiles>

71. $\mathrm{R}_{1}=\mathrm{CH}_{3} \mathrm{CHCH}_{3} ; \mathrm{R}_{2}=\mathrm{R}_{3}=\mathrm{R}_{5}=\mathrm{R}_{6}=\mathrm{H}, \mathrm{H} ; \mathrm{R}_{4}=\mathrm{OH}, \mathrm{CH}_{3}$

72. $\mathrm{R}_{1}=\mathrm{CH}_{2}\left(\mathrm{CH}_{3}\right)\left(\mathrm{CH}_{2}\right)_{2} \mathrm{CH}\left(\mathrm{CH}_{3}\right)_{2} ; \mathrm{R}_{2}=\mathrm{R}_{3}=\mathrm{R}_{5}=\mathrm{R}_{6}=\mathrm{H}, \mathrm{H}$; $\mathrm{R}_{4}=\mathrm{CH}_{3}$

73. $\mathrm{R}_{1}=\mathrm{C}\left(\mathrm{CH}_{3}\right) \mathrm{CHCH}_{2} \mathrm{CC}\left(\mathrm{CH}_{3}\right)_{2} ; \mathrm{R}_{2}=\mathrm{R}_{3}=\mathrm{R}_{5}=\mathrm{R}_{6}=\mathrm{H}, \mathrm{H}$; $\mathrm{R}_{4}=\mathrm{CH}_{3}$

74. $\mathrm{R}_{1}=\mathrm{C}\left(\mathrm{CH}_{3}\right)(\mathrm{OH})\left(\mathrm{CH}_{2}\right)_{2} \mathrm{CHCH}\left(\mathrm{CH}_{3}\right)_{2} ; \mathrm{R}_{2}=\mathrm{R}_{5}=\mathrm{R}_{6}=\mathrm{H}, \mathrm{H}$; $\mathrm{R}_{3}=\mathrm{H}, \mathrm{R}_{4}=\mathrm{CH}_{3}$

75. $\mathrm{R}_{1}=\mathrm{C}\left(\mathrm{CH}_{3}\right) \mathrm{OH}\left(\mathrm{CH}_{2}\right)_{2} \mathrm{CHC}\left(\mathrm{CH}_{3}\right)_{2}, \mathrm{H} ; \mathrm{R}_{2}=\mathrm{R}_{5}=\mathrm{R}_{6}=\mathrm{H}, \mathrm{H}$; $\mathrm{R}_{3}=\mathrm{R}_{4}=\mathrm{H}$

76. $\mathrm{R}_{1}=\mathrm{CH}(\mathrm{OH})\left(\mathrm{CH}_{2}\right)_{5} \mathrm{CH}_{3} ; \mathrm{R}_{2}=\mathrm{R}_{3}=\mathrm{R}_{4}=\mathrm{R}_{5}=\mathrm{R}_{6}=\mathrm{H}, \mathrm{H}$

77. $\mathrm{R}_{1}=\mathrm{R}_{2}=\mathrm{H} ; \mathrm{R}_{3}=\mathrm{R}_{4}=\mathrm{R}_{5}=\mathrm{R}_{6}=\mathrm{H}, \mathrm{H}$

78. $\mathrm{R}_{1}=\mathrm{CH}\left(\mathrm{CH}_{3}\right)\left(\mathrm{CH}_{2}\right)_{2} \mathrm{CH}\left(\mathrm{CH}_{3}\right)_{2} ; \mathrm{R}_{2}=\mathrm{R}_{5}=\mathrm{R}_{6}=\mathrm{H}, \mathrm{H} ; \mathrm{R}_{3}=\mathrm{H}$, $\mathrm{R}_{4}=\mathrm{CH}_{3}$

79. $\mathrm{R}_{1}=\mathrm{CH}_{3} \mathrm{C}(\mathrm{OH}) \mathrm{CH}_{3}, \mathrm{H} ; \mathrm{R}_{2}=\mathrm{R}_{5}=\mathrm{R}_{6}=\mathrm{H}, \mathrm{H} ; \mathrm{R}_{3}=\mathrm{H}, \mathrm{R}_{4}=\mathrm{CH}_{3}$

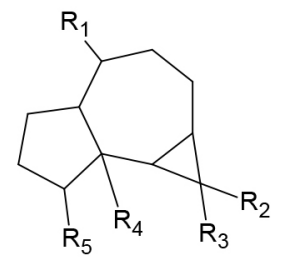

80. $\mathrm{R}_{1}=\mathrm{R}_{2}=\mathrm{R}_{3}=\mathrm{R}_{5}=\mathrm{CH}_{3} ; \mathrm{R}_{4}=\mathrm{H}$

81. $\mathrm{R}_{1}=\mathrm{R}_{2}=\mathrm{R}_{3}=\mathrm{R}_{5}=\mathrm{CH}_{3} ; \mathrm{R}_{4}=$ vazio

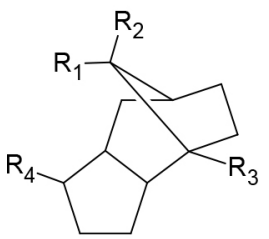

82. $\mathrm{R}_{1}=\mathrm{R}_{2}=\mathrm{R}_{3}=\mathrm{R}_{4}=\mathrm{CH}_{3}$<smiles>[R]C1CC2([R5])C([R])CCC2C([R])C([R2])C1[R]</smiles>

83. $\mathrm{R}_{1}=\mathrm{CH}_{3}, \mathrm{CH}_{3} ; \mathrm{R}_{2}=\mathrm{H} ; \mathrm{R}_{3}=\mathrm{O} ; \mathrm{R}_{4}=\mathrm{H}, \mathrm{H} ; \mathrm{R}_{5}=$ Ciclo $\left(\mathrm{CH}_{2}\right)$ $\mathrm{R}_{2} ; \mathrm{R}_{6}=\mathrm{CH}_{3}$

84. $\mathrm{R}_{1}=\mathrm{CH}_{3}, \mathrm{CH}_{3} ; \mathrm{R}_{2}=\mathrm{H} ; \mathrm{R}_{3}=\mathrm{CH}_{3}, \mathrm{OH} ; \mathrm{R}_{4}=\mathrm{H}, \mathrm{H} ; \mathrm{R}_{5}=$ ciclo $\left(\mathrm{CH}_{2}\right)-\mathrm{R}_{2} ; \mathrm{R}_{6}=\mathrm{CH}_{3}$

85. $\mathrm{R}_{1}=\mathrm{CH}_{3} ; \mathrm{R}_{2}=\mathrm{R}_{3}=\mathrm{R}_{5}=\mathrm{H}, \mathrm{H} ; \mathrm{R}_{4}=\mathrm{H}, \mathrm{C}\left(\mathrm{CH}_{3}\right)_{2}(\mathrm{OH}) ; \mathrm{R}_{6}=\mathrm{H}$, $\mathrm{CH}_{3}$ 
Figura 1 (continuação)

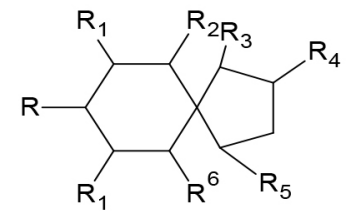

86. $\mathrm{R}_{1}=\mathrm{H}, \mathrm{H} ; \mathrm{R}_{2}=\mathrm{R}_{4}=\mathrm{CH}_{3} ; \mathrm{R}_{3}=\mathrm{H} ; \mathrm{R}_{5}=\mathrm{H}, \mathrm{H} ; \mathrm{R}_{6}=\mathrm{OH} ; \mathrm{R}_{1}=$ $\mathrm{CH}_{3} \mathrm{CHCH}_{3} ; \mathrm{R}=\mathrm{H}, \mathrm{H}$

87. $\mathrm{R}_{1}=\mathrm{H} ; \mathrm{R}_{2}=\mathrm{R}_{4}=\mathrm{R}_{6}=\mathrm{R}_{1}=\mathrm{H}, \mathrm{H} ; \mathrm{R}_{3}=\mathrm{H}, \mathrm{C}(\mathrm{OH})\left(\mathrm{CH}_{3}\right)_{2} ; \mathrm{R}_{5}=$ $\mathrm{CH}_{3} ; \mathrm{R}=\mathrm{H}$

88. $\mathrm{R}_{1}=\mathrm{R}_{2}=\mathrm{R}_{4}=\mathrm{R}_{6}=\mathrm{R}_{1}=\mathrm{H}, \mathrm{H} ; \mathrm{R}_{3}=\mathrm{H}, \mathrm{C}(\mathrm{OH})\left(\mathrm{CH}_{3}\right)_{2} ; \mathrm{R}_{5}=\mathrm{CH}_{3}$; $\mathrm{R}=\mathrm{H}, \mathrm{H}$

89. $\mathrm{R}_{1}=\mathrm{R}_{2}=\mathrm{R}_{4}=\mathrm{R}_{6}=\mathrm{H}, \mathrm{H} ; \mathrm{R}_{3}=\mathrm{H}, \mathrm{CH}_{3} ; \mathrm{R}_{5}=\mathrm{CH}_{3} \mathrm{CCH}_{2}$; $\mathrm{R}_{1}=\mathrm{H} ; \mathrm{R}=\mathrm{H}, \mathrm{CH}_{3}$

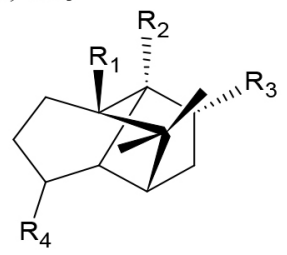

90. $\mathrm{R}_{1}=\mathrm{R}_{3}=\mathrm{OH} ; \mathrm{R}_{2}=\mathrm{R}_{4}=\mathrm{CH}_{3}$

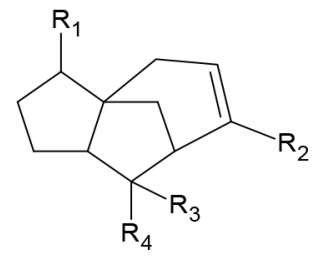

91. $\mathrm{R}_{1}=\mathrm{R}_{2}=\mathrm{R}_{4}=\mathrm{CH}_{3} ; \mathrm{R}_{3}=\mathrm{CH}_{2} \mathrm{OH}$

92. $\mathrm{R}_{1}=\mathrm{H}$

93. $\mathrm{R}_{2}=\mathrm{OH}$<smiles>[R]c1cccc2c3c(c(=O)n(C)c12)C=CC(C)(C)O3</smiles><smiles>[R3]c1ccc2c(O)c3ccoc3nc2c1O</smiles>

94. $\mathrm{R}_{1}=\mathrm{H}$

95. $\mathrm{R}_{1}=\mathrm{OH}$<smiles>[R]C1C=Cc2nccc3c4ccccc4n1c23</smiles>

96. $\mathrm{R}_{1}=\mathrm{O}$
97. $\mathrm{R}_{1}=\mathrm{OH}$<smiles>[R]c1c2ccccc2nc2occc12</smiles><smiles>[R]N1c2ccccc2C(=O)N2CCc3c([nH]c4ccccc34)C21</smiles>

98. $\mathrm{R}_{1}=$ vazio

99. $\mathrm{R}_{2}=\mathrm{CH}_{3}$

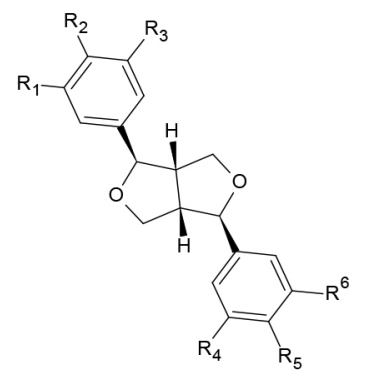

100. $R_{1}=R_{2}=R_{3}=R_{4}=R_{5}=R_{6}=O H$<smiles>[R3]C1c2c(ccc(O)c2O)C2([R])C=Cc3cc4c(cc3C2([R])N1[R2])OCO4</smiles>

101. $\mathrm{R}_{1}=\mathrm{R}_{4}=$ vazio; $\mathrm{R}_{2}=\mathrm{CH}_{3} ; \mathrm{R}_{3}=\mathrm{H}, \mathrm{H}$

102. $R_{1}=R_{2}=R_{4}=$ vazio; $R_{3}=H$<smiles>[R]c1c(C[C@H](O)C([R2])C)c(=O)n([R3])c2ccccc12</smiles>

103. $\mathrm{R}_{1}=\mathrm{OH} ; \mathrm{R}_{2}=\mathrm{R}_{3}=\mathrm{CH}_{3}$<smiles>[R4]CC([R3])=CC[C@@]12CCN([R2])C1N([R1])C1CCCCC12</smiles>

104. $\mathrm{R}_{1}=\mathrm{R}_{1}=\mathrm{R}_{3}=\mathrm{CH}_{3} ; \mathrm{R}_{4}=\mathrm{O}$ 
Figura 1 (continuação)

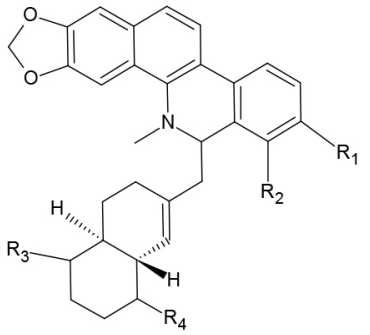

105. $\mathrm{R}_{1}=\mathrm{R}_{2}=\mathrm{R}_{3}=\mathrm{OH} ; \mathrm{R}_{4}=\mathrm{CH}_{3} \mathrm{CHCH}_{3}$

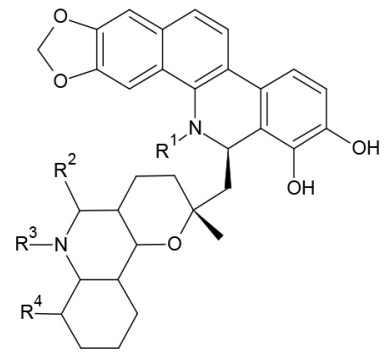

106. $\mathrm{R}_{1}=\mathrm{R}_{2}=\mathrm{R}_{4}=\mathrm{CH}_{3} ; \mathrm{R}_{3}=\mathrm{O}$

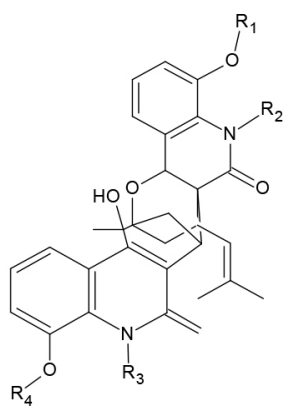

107. $\mathrm{R}_{1}=\mathrm{R}_{2}=\mathrm{R}_{3}=\mathrm{R}_{4}$

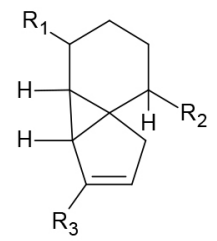

108. $\mathrm{R}_{1}=\mathrm{CH}_{3} \mathrm{CHCH}_{3} ; \mathrm{R}_{2}=\mathrm{R}_{3}=\mathrm{CH}_{3}$<smiles>[R]C([R])C(CO)CCCCC</smiles>

109. $\mathrm{R}_{1}=\mathrm{CH}_{2} ; \mathrm{R}_{2}=\mathrm{H}$

110. $\mathrm{R}_{1}=\mathrm{CH}_{3} ; \mathrm{R}_{2}=\mathrm{H}, \mathrm{H}$

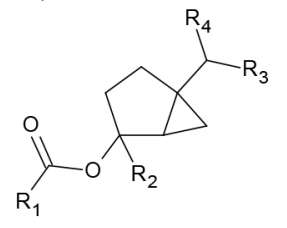

111. $\mathrm{R}_{1}=\mathrm{R}_{2}=\mathrm{R}_{3}=\mathrm{R}_{4}=\mathrm{CH}_{3}$<smiles>[R]C1=CC[C@@H]2[C@H](C1)C2([R6])[2H]</smiles>

112. $\mathrm{R}_{1}=\mathrm{R}_{2}=\mathrm{R}_{3}=\mathrm{CH}_{3}$

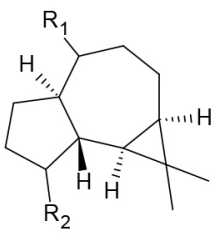

113. $\mathrm{R}_{1}=\mathrm{CH}_{2} ; \mathrm{R}_{2}=\mathrm{CH}_{3}(\mathrm{R})$

114. $\mathrm{R}_{1}=\mathrm{CH}_{2} ; \mathrm{R}_{2}=\mathrm{CH}_{3}(\mathrm{~S})$<smiles>[R8]C1C([R9])C([R])C([R])C([R])C1[R]</smiles>

115. $\mathrm{R}_{1}=\mathrm{CH}_{3} \mathrm{CHCH}_{3} ; \mathrm{R}_{2}=\mathrm{R}_{3}=\mathrm{H} ; \mathrm{R}_{4}=\mathrm{CH}_{3} ; \mathrm{R}_{5}=\mathrm{R}_{6}=\mathrm{H}, \mathrm{H}$ 116. $\mathrm{R}_{1}=\mathrm{CH}_{3} \mathrm{CCH}_{3} ; \mathrm{R}_{2}=\mathrm{R}_{3}=\mathrm{R}_{6}=\mathrm{H}, \mathrm{H} ; \mathrm{R}_{4}=\mathrm{CH}_{3} ; \mathrm{R}_{5}=\mathrm{H}$ 117. $\mathrm{R}_{1}=\mathrm{CH}_{3}, \mathrm{CHCH}_{2} ; \mathrm{R}_{2}=\mathrm{R}_{3}=\mathrm{H}, \mathrm{H} ; \mathrm{R}_{4}=\mathrm{CH}_{3} ; \mathrm{R}_{5}=\mathrm{H}$; $\mathrm{R}_{6}=\mathrm{CH}_{3} \mathrm{CCH}_{2}$

118. $\mathrm{R}_{1}=\mathrm{CH}_{3} \mathrm{CHCH}_{3} ; \mathrm{R}_{2}=\mathrm{R}_{5}=\mathrm{H} ; \mathrm{R}_{3}=\mathrm{R}_{6}=\mathrm{H}, \mathrm{H} ; \mathrm{R}_{4}=\mathrm{CH}_{3}$

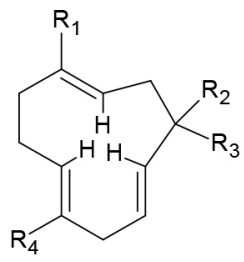

119. $\mathrm{R}_{1}=\mathrm{R}_{2}=\mathrm{R}_{3}=\mathrm{R}_{4}=\mathrm{CH}_{3}$

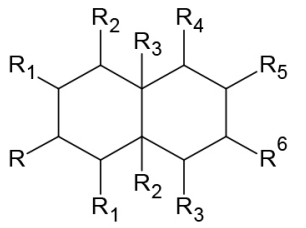

120. $\mathrm{R}_{1}=\mathrm{R}_{4}=\mathrm{R}_{5}=\mathrm{R}_{4}=\mathrm{H}, \mathrm{H} ; \mathrm{R}_{2}=\mathrm{CH}_{2} ; \mathrm{R}_{3}=\mathrm{R}_{1}=\mathrm{R}_{2}=\mathrm{H} ; \mathrm{R}_{6}=\mathrm{CH}_{3}$; $\mathrm{R}_{3}=\mathrm{CH}\left(\mathrm{CH}_{3}\right)_{2}$

121. $\mathrm{R}_{1}=\mathrm{CH}_{3} \mathrm{CHCH}_{3} ; \mathrm{R}_{2}=\mathrm{R}_{5}=\mathrm{R}_{6}=\mathrm{R}=\mathrm{R}_{1}=\mathrm{R}_{3}=\mathrm{H}, \mathrm{H} ; \mathrm{R}_{3}=\mathrm{H}$; $\mathrm{R}_{4}=\mathrm{CH}_{2} ; \mathrm{R}_{2}=\mathrm{CH}_{3}$

122. $\mathrm{R}_{1}=\mathrm{R}=\mathrm{H}, \mathrm{H} ; \mathrm{R}_{2}=\mathrm{R}_{6}=\mathrm{CH}_{3} ; \mathrm{R}_{3}=\mathrm{R}_{2}=$ vazio; $\mathrm{R}_{4}=\mathrm{R}_{5}=\mathrm{R}_{3}=$ $\mathrm{H} ; \mathrm{R}_{1}=\mathrm{CH}_{3} \mathrm{CHCH}_{3}$

123. $\mathrm{R}_{1}=\mathrm{R}_{3}=\mathrm{R}_{3}=\mathrm{R}_{2}=\mathrm{H} ; \mathrm{R}=\mathrm{R}_{4}=\mathrm{R}_{5}=\mathrm{H}, \mathrm{H} ; \mathrm{R}_{2}=\mathrm{R}_{6}=\mathrm{CH}_{3} ; \mathrm{R}_{1}=$ $\mathrm{CH}_{3} \mathrm{CHCH}_{3}$<smiles>[R2]C(C=C)=C(Br)CC=C(C)C</smiles>

124. $\mathrm{R}_{1}=\mathrm{H} ; \mathrm{R}_{2}=\mathrm{CH}_{3}(\mathrm{E})$ 


\section{Figura 1 (continuação)}

125. $\mathrm{R}_{1}=\mathrm{R}_{2}=\mathrm{R}_{4}=\mathrm{CH}_{3} ; \mathrm{R}_{3}=\mathrm{CH}_{2}$

126. $\mathrm{R}_{1}=\mathrm{R}_{2}=\mathrm{R}_{4}=\mathrm{CH}_{3} ; \mathrm{R}_{3}=\mathrm{H}, \mathrm{OH}$

127. $\mathrm{R}_{1}=\mathrm{R}_{2}=\mathrm{R}_{4}=\mathrm{CH}_{3} ; \mathrm{R}_{3}=\mathrm{OCOCH}_{3}$

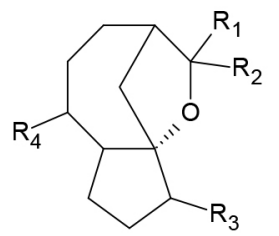

128. $\mathrm{R}_{1}=\mathrm{R}_{2}=\mathrm{R}_{3}=\mathrm{R}_{4}=\mathrm{CH}_{3}$

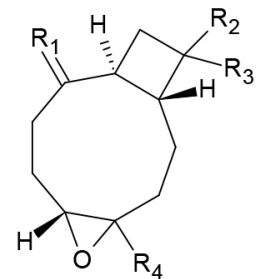

129. $\mathrm{R}_{1}=\mathrm{CH}_{2} ; \mathrm{R}_{2}=\mathrm{R}_{3}=\mathrm{R}_{4}=\mathrm{CH}_{3}$

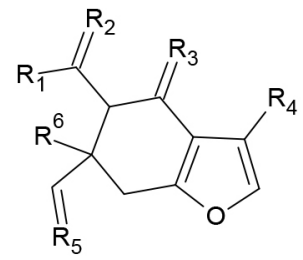

130. $\mathrm{R}_{1}=\mathrm{R}_{4}=\mathrm{R}_{6}=\mathrm{CH}_{3} ; \mathrm{R}_{2}=\mathrm{R}_{5}=\mathrm{CH}_{2} ; \mathrm{R}_{3}=\mathrm{O}$

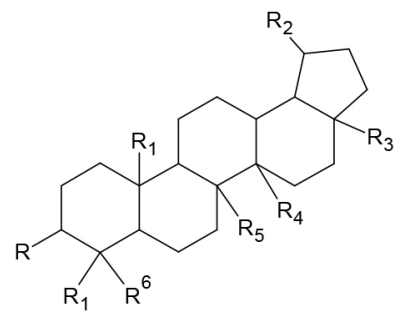

131. $\mathrm{R}_{1}=\mathrm{R}_{3}=\mathrm{R}_{4}=\mathrm{R}_{5}=\mathrm{R}_{6}=\mathrm{R}_{1}=\mathrm{CH}_{3} ; \mathrm{R}_{2}=\mathrm{CH}\left(\mathrm{CH}_{3}\right)_{2} ; \mathrm{R}=\mathrm{OH}$<smiles>c1ccc2c(c1)ccc1ccccc12</smiles>

132. $\mathrm{R}_{1}=\mathrm{N}$<smiles>[R]c1ccc2c(c1[R2])-c1c([R])c([R])cc3c1[C@@](C)(C2)[N+](C)(C)CC3</smiles>

133. $\mathrm{R}_{1}=\mathrm{R}_{4}=\mathrm{OCH}_{3} ; \mathrm{R}_{2}=\mathrm{R}_{3}=\mathrm{OH}$

134. $\mathrm{R}_{1}=\mathrm{R}_{3}=\mathrm{R}_{4}=\mathrm{OCH}_{3} ; \mathrm{R}_{2}=\mathrm{H}$<smiles>[R3]C1CCC(C[C@H]2C3CC([R])C([R3])CC3CCN2[R2])CC1[R4]</smiles>

135. $\mathrm{R}_{1}=\mathrm{R}_{3}=\mathrm{OCH}_{3} ; \mathrm{R}_{2}=\mathrm{CH}_{3} ; \mathrm{R}_{4}=\mathrm{R}_{5}=\mathrm{OH}$<smiles>[R3]c1c([R3])c([R])c2c(c1[R3])C([R])C([R])C([R])C2[R]</smiles>

136. $\mathrm{R}_{1}=\mathrm{R}_{5}=\mathrm{OCH}_{3} ; \mathrm{R}_{2}=\mathrm{R}_{3}=\mathrm{R}_{4}=\mathrm{R}_{1} \mathrm{H} ; \mathrm{R}_{6}=\mathrm{NH} ; \mathrm{R}=\mathrm{O}$

137. $\mathrm{R}_{1}=\mathrm{R}_{1}=\mathrm{H}, \mathrm{H} ; \mathrm{R}_{2}=\mathrm{R}_{5}=\mathrm{H} ; \mathrm{R}_{3}=\mathrm{OCH}_{3} ; \mathrm{R}_{4}=\mathrm{OH} ; \mathrm{R}_{6}=\mathrm{O}$; $\mathrm{R}=\mathrm{NH}$<smiles>[R6]C1=C([R5])C2([R])C([R3])N([R2])C3([R])c4cc5c(cc4C=CC3([R])C2([R])C=C1)OCO5</smiles>

138. $\mathrm{R}_{1}=\mathrm{R}_{4}=\mathrm{R}_{1}=\mathrm{R}_{2}=$ vazio; $\mathrm{R}_{2}=\mathrm{CH}_{3} ; \mathrm{R}_{3}=\mathrm{H} ; \mathrm{R}_{5}=\mathrm{R}_{6}=\mathrm{OCH}_{3}$<smiles>[R]c1ccc2cc3[n+](cc2c1[R2])CCc1cc2c(cc1-3)OCO2</smiles>

139. $\mathrm{R}_{1}=\mathrm{R}_{2}=\mathrm{OCH}_{3}$<smiles>[R3]C[n+]1cc2cc(O[R2])c(O[R2])cc2c2ccc3cc4c(cc3c21)OCO4</smiles>

140. $\mathrm{R}_{1}=\mathrm{R}_{3}=\mathrm{CH}_{3} ; \mathrm{R}_{2}=\mathrm{CH}_{3}(\mathrm{~S})$ 
Figura 1 (continuação)<smiles>[R9]c1cc([R9])c(CC2c3c(cc([R8])c([R6])c3[R3])CC[N+]2(C)C)cc1[R]</smiles>

141. $\mathrm{R}_{1}=\mathrm{OCH}_{3} ; \mathrm{R}_{2}=\mathrm{R}_{5}=\mathrm{OH} ; \mathrm{R}_{3}=\mathrm{R}_{4}=\mathrm{R}_{6}=\mathrm{H}$ 142. $\mathrm{R}_{1}=\mathrm{H} ; \mathrm{R}_{2}=\mathrm{R}_{5}=\mathrm{OCH}_{3} ; \mathrm{R}_{3}=\mathrm{R}_{4}=\mathrm{R}_{6}=\mathrm{OH}$

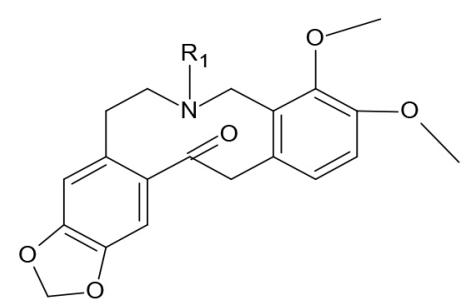

143. $\mathrm{R}_{1}=\mathrm{CH}_{3}(\mathrm{R})$

144. $\mathrm{R}_{1}=\mathrm{R}_{2}=\mathrm{CH}_{3}$<smiles>[R]C1([R])C=Cc2c(c3ccccc3[nH]c2=O)O1</smiles><smiles>[R]c1c([R3])c([R3])c2c(c1[R])-c1ccc3cc(OC=O)c(OC=O)cc3c1N(C)C2[R5]</smiles>

145. $\mathrm{R}_{1}=\mathrm{R}_{2}=\mathrm{H} ; \mathrm{R}_{3}=\mathrm{OH} ; \mathrm{R}_{4}=\mathrm{OCH}_{3} ; \mathrm{R}_{5}=\mathrm{H}, \mathrm{OH}$ 146. $\mathrm{R}_{1}=\mathrm{R}_{4}=\mathrm{H} ; \mathrm{R}_{2}=\mathrm{OH} ; \mathrm{R}_{3}=\mathrm{OCH}_{3} ; \mathrm{R}_{5}=$ vazio( $\left.\mathrm{N}^{+}\right)$ 147. $\mathrm{R}_{1}=\mathrm{R}_{2}=\mathrm{H} ; \mathrm{R}_{3}=\mathrm{R}_{4}=\mathrm{OH} ; \mathrm{R}_{5}=\operatorname{vazio}\left(\mathrm{N}^{+}\right)$

148. $\mathrm{R}_{1}=\mathrm{OCH}_{3} ; \mathrm{R}_{2}=\mathrm{H} ; \mathrm{R}_{3}=\mathrm{R}_{4}=\mathrm{OCHO} ; \mathrm{R}_{5}=\mathrm{H}, \mathrm{OH}$<smiles>[R]c1ccc(CC2c3c(ccc([R])c3[R5])CC[N+]2([R7])[2H])cc1Br</smiles>

149. $\mathrm{R}_{1}=\mathrm{R}_{2}=\mathrm{H} ; \mathrm{R}_{3}=\mathrm{R}_{5}=\mathrm{OH} ; \mathrm{R}_{4}=\mathrm{OCH}_{3}$<smiles></smiles>

150. (R) $\mathrm{R}_{1}=\mathrm{R}_{2}=\mathrm{CH}_{3} ; \mathrm{R}_{3}=\mathrm{R}_{5}=\mathrm{OH} ; \mathrm{R}_{4}=\mathrm{R}_{6}=\mathrm{OCH}_{3}$ 151. $\mathrm{R}_{1}=\mathrm{R}_{2}=\mathrm{R}_{3}=\mathrm{R}_{4}=\mathrm{OCH}_{3} ; \mathrm{R}_{5}=\mathrm{OH}$

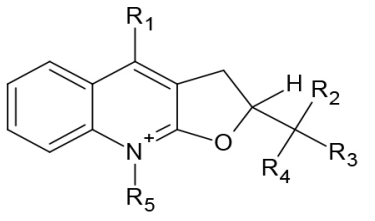

152. $\mathrm{R}_{1}=\mathrm{OCH}_{3} ; \mathrm{R}_{2}=\mathrm{R}_{4}=\mathrm{CH}_{3} ; \mathrm{R}_{3}=\mathrm{OH} ; \mathrm{R}_{5}=\mathrm{H}$<smiles>[R9]c1c(Br)ccc(-c2ccc3cc4c(cc3c2N(C)C=O)OCO4)c1O</smiles>

153. $\mathrm{R}_{1}=\mathrm{R}_{2}=\mathrm{OCH}_{3}$<smiles>[R3]C(=O)OCCC([R6])CCC=C([R3])C</smiles>

154. $\mathrm{R}_{1}=\mathrm{R}_{2}=\mathrm{CH}_{3}$

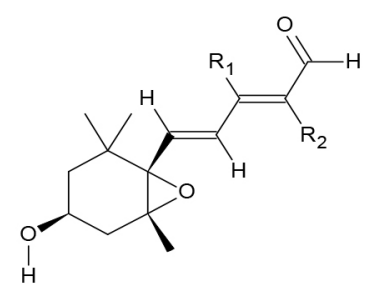

155. $\mathrm{R}_{1}=\mathrm{CH}_{3} ; \mathrm{R}_{2}=\mathrm{H}$<smiles>[R2]c1c2ccoc2c([R])c2oc(=O)ccc12</smiles>

156. $\mathrm{R}_{1}=\mathrm{R}_{2}=\mathrm{OCH}_{3}$

157. $\mathrm{R}_{1}=\mathrm{OCH}_{2} \mathrm{CHC}\left(\mathrm{CH}_{3}\right)_{2} ; \mathrm{R}_{2}=\mathrm{H}$

158. $\mathrm{R}_{1}=\mathrm{OCH}_{3} ; \mathrm{R}_{2}=\mathrm{H}$<smiles>[R]C([R])=CCc1cc2ccc([R])cc2oc1=O</smiles>

159. $\mathrm{R}_{1}=\mathrm{OH} ; \mathrm{R}_{2}=\mathrm{R}_{3}=\mathrm{CH}_{3}$<smiles>[R]C(=[R])c1ccccc1N([R9])C</smiles>

160. $\mathrm{R} 1=\mathrm{O}-; \mathrm{R} 2=\mathrm{O} ; \mathrm{R} 3=\mathrm{H} ; \mathrm{R} 4=\mathrm{CH} 3$ 


\section{Figura 1 (continuação)}

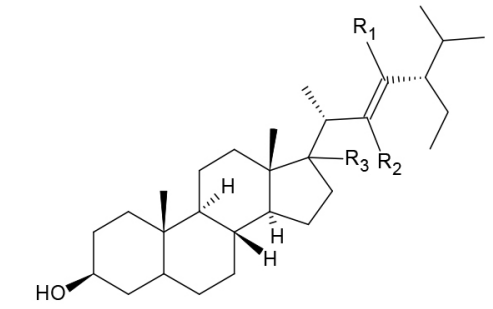

161. $\mathrm{R}_{1}=\mathrm{R}_{2}=\mathrm{R}_{3}=\mathrm{H}$

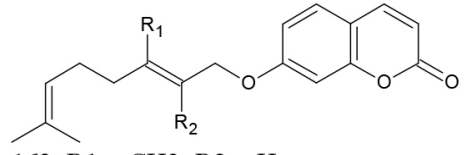

162. $\mathrm{R} 1=\mathrm{CH} 3 ; \mathrm{R} 2=\mathrm{H}$<smiles>[2H]C([18OH])=CCOc1ccc2ccc(=O)oc2c1</smiles>

163. $\mathrm{R}_{1}=\mathrm{R}_{2}=\mathrm{CH}_{3}$<smiles>[R9]c1cccc2c1C[N+]1([Y9])CCc3cc4c(cc3[C@@]1([2H])C2)OCO4</smiles>

164. $\mathrm{R}_{1}=\mathrm{R}_{2}=\mathrm{OCH}_{3} ; \mathrm{R}_{3}=\mathrm{CH}_{3}$<smiles>[R6]c1cccc2c(Br)c3ccoc3nc12</smiles>

165. $\mathrm{R}_{1}=\mathrm{OCH}_{3}(\mathrm{E}) ; \mathrm{R}_{2}=\mathrm{OH}$

166. $\mathrm{R}_{1}=\mathrm{OCH}_{3}(\mathrm{Z}) ; \mathrm{R}_{2}=\mathrm{H}$<smiles>[R9]c1ccc2c(c1[2H])C([B])N(C)c1c-2ccc2cc3c(cc12)OCO3</smiles>

167. $\mathrm{R}_{1}=\mathrm{R}_{2}=\mathrm{R}_{3}=\mathrm{OCH}_{3}$<smiles>[R8]c1ccc2c(c1[R9])CN1CCc3cc4c(cc3C1C2)OCO4</smiles>

168. $\mathrm{R}_{1}=\mathrm{R}_{2}=\mathrm{OCH}_{3}$<smiles>[R6]C1c2ccccc2-c2cc3ccccc3c[n+]2C1[R6]</smiles>

169. $R_{1}=R_{2}=H$

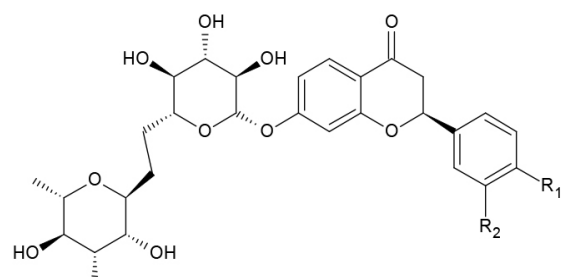

$\mathrm{OH}$

170. $\mathrm{R}_{1}=\mathrm{OCH}_{3} ; \mathrm{R}_{2}=\mathrm{OH}$<smiles>[R3]C(C)=CCCC([R2])C=[R]</smiles>

171. $\mathrm{R}_{1}=\mathrm{R}_{2}=\mathrm{CH}_{2} ; \mathrm{R}_{3}=\mathrm{CH}_{3}$

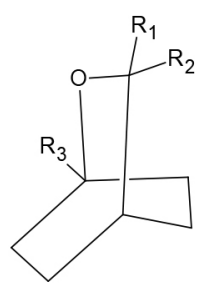

172. $\mathrm{R}_{1}=\mathrm{R}_{2}=\mathrm{R}_{3}=\mathrm{CH}_{3}$

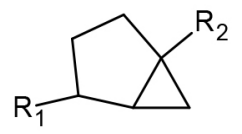

173. $\mathrm{R}_{1}=\mathrm{OH}, \mathrm{CH}_{3}(\mathrm{R}) ; \mathrm{R}_{2}=\mathrm{CH}\left(\mathrm{CH}_{3}\right)_{2}$ 174. $\mathrm{R}_{1}=\mathrm{OH}, \mathrm{CH}_{3}(\mathrm{~S}) ; \mathrm{R}_{2}=\mathrm{CH}\left(\mathrm{CH}_{3}\right)_{2}$<smiles>[R]C1C([R3])C([R])C([R])C([R])C1[R]</smiles>

175. $\mathrm{R}_{1}=\mathrm{CH}_{3} \mathrm{CCH}_{3} ; \mathrm{R}_{2}=\mathrm{R}_{3}=\mathrm{R}_{6}=\mathrm{H}, \mathrm{H} ; \mathrm{R}_{4}=\mathrm{CH}_{3} ; \mathrm{R}_{5}=\mathrm{H}$ 176. $\mathrm{R}_{1}=\mathrm{OH} ; \mathrm{R}_{2}=\mathrm{R}_{3}=\mathrm{H} ; \mathrm{R}_{4}=\mathrm{R}_{5}=\mathrm{R}_{6}=\mathrm{H}, \mathrm{H}$

177. $\mathrm{R}_{1}=\mathrm{OH}, \mathrm{CH}_{3} \mathrm{CHCH}_{3} ; \mathrm{R}_{2}=\mathrm{R}_{5}=\mathrm{R}_{6}=\mathrm{H}, \mathrm{H} ; \mathrm{R}_{3}=\mathrm{H} ; \mathrm{R}_{4}=\mathrm{CH}_{3}$ 178. $\mathrm{R}_{1}=\mathrm{CH}_{3} \mathrm{CCH}_{2} ; \mathrm{R}_{2}=\mathrm{R}_{3}=\mathrm{R}_{6}=\mathrm{H}, \mathrm{H} ; \mathrm{R}_{4}=\mathrm{H}, \mathrm{CH}_{3} ; \mathrm{R}_{5}=\mathrm{H}$, $\mathrm{OH}$

179. $\mathrm{R}_{1}=\mathrm{CH}_{3}, \mathrm{CH}_{2} \mathrm{CH}_{3} ; \mathrm{R}_{2}=\mathrm{R}_{3}=\mathrm{R}_{5}=\mathrm{H}, \mathrm{H} ; \mathrm{R}_{4}=\mathrm{H}, \mathrm{C}\left(\mathrm{CH}_{3}\right)_{2} \mathrm{OH}$ 180. $\mathrm{R}_{1}=\mathrm{R}_{3}=\mathrm{R}_{4}=\mathrm{H}, \mathrm{H} ; \mathrm{R}_{2}=\mathrm{R}_{6}=\mathrm{C}\left(\mathrm{CH}_{3}\right)_{2} ; \mathrm{R}_{5}=\mathrm{CHCH}_{3}$ 
Figura 1 (continuação)<smiles>[R]C(=O)OC1([R2])CCC2(C([R9])[R9])CC12</smiles>

181. $\mathrm{R}_{1}=\mathrm{R}_{2}=\mathrm{R}_{3}=\mathrm{R}_{4}=\mathrm{CH}_{3}$

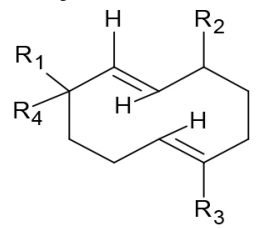

182. $\mathrm{R}_{1}=\mathrm{R}_{3}=\mathrm{CH}_{3} ; \mathrm{R}_{2}=\mathrm{CH}\left(\mathrm{CH}_{3}\right)_{2} ; \mathrm{R}_{4}=\mathrm{OH}$

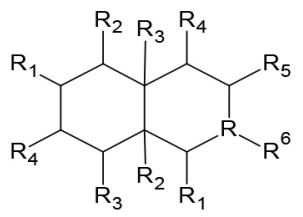

183. $\mathrm{R}_{1}=\mathrm{R}_{6}=\mathrm{R}_{1}=\mathrm{R}_{4}=\mathrm{H}, \quad \mathrm{H} ; \mathrm{R}_{2}=\mathrm{CH}\left(\mathrm{CH}_{3}\right)_{2} ; \mathrm{R}_{3}=\mathrm{R}_{2}=\mathrm{R}_{5}=\mathrm{CH}_{3}$; $\mathrm{R}_{4}=\mathrm{H} ; \mathrm{R}_{3}=\mathrm{OH}(\mathrm{R}), \mathrm{CH}_{3} ; \mathrm{R}=\mathrm{C}$

184. $\mathrm{R}_{1}=\mathrm{R}_{6}=\mathrm{R}_{1}=\mathrm{R}_{4}=\mathrm{H}, \mathrm{H} ; \mathrm{R}_{2}=\mathrm{CH}\left(\mathrm{CH}_{3}\right)_{2} ; \mathrm{R}_{3}=\mathrm{R}_{2}=\mathrm{R}_{5}=\mathrm{CH}_{3} ;$ $\mathrm{R}_{4}=\mathrm{H} ; \mathrm{R}_{3}=\mathrm{OH}(\mathrm{S}), \mathrm{CH}_{3} ; \mathrm{R}=\mathrm{C}$

185. $\mathrm{R}_{1}=\mathrm{H}, \mathrm{C}\left(\mathrm{CH}_{3}\right)_{2} \mathrm{OH} ; \mathrm{R}_{2}=\mathrm{R}_{5}=\mathrm{R}_{6}=\mathrm{R}_{3}=\mathrm{R}_{4}=\mathrm{H}, \mathrm{H} ; \mathrm{R}_{3}=\mathrm{H}$; $\mathrm{R}_{4}=\mathrm{CH}_{2} ; \mathrm{R}_{2}=\mathrm{CH}_{3} ; \mathrm{R}=\mathrm{C}$<smiles></smiles>

186. $\mathrm{R}_{1}=\mathrm{OCH}_{3} ; \mathrm{R}_{2}=\mathrm{R}_{4}=\mathrm{R}_{5}=\mathrm{R}_{3}=\mathrm{H}, \mathrm{H} ; \mathrm{R}_{3}=\mathrm{R}_{2}=\mathrm{H} ; \mathrm{R}=\mathrm{N} ; \mathrm{R}_{6}=$ $\mathrm{CH}_{3} ; \mathrm{R}_{1}=\mathrm{O} ; \mathrm{R}_{4}=\mathrm{OH}$

187. $\mathrm{R}_{1}=\mathrm{R}_{2}=\mathrm{R}_{4}=\mathrm{OCH}_{3} ; \mathrm{R}_{3}=\mathrm{OH}$<smiles>[R]/C(=C/CC/C(Br)=C/CO)CC/C=C(/[B])C</smiles>

188. $\mathrm{R}_{1}=\mathrm{R}_{2}=\mathrm{R}_{3}=\mathrm{CH}_{3}$<smiles>OC1(Cc2ccc3c(c2)OCO3)C(Cc2ccc3c(c2)OCO3)COC1(CBr)Cc1ccc2c(c1)OCO2</smiles>

189. $\mathrm{R}_{1}=\mathrm{CH}_{2}$<smiles>[R]c1cc2c(cc1[R])CC(=[18O])C=C2</smiles><smiles>[R]c1ccc([R])cc1</smiles>

191. $\mathrm{R}_{1}=\mathrm{CH}(\mathrm{OH}) \mathrm{CH}_{2} \mathrm{NHCH}_{3} ; \mathrm{R}_{2}=\mathrm{CH}_{3}$<smiles>[R8]C(CCO)CCC=C(C)C</smiles>

192. $\mathrm{R}_{1}=\mathrm{CH}_{3}(\mathrm{~S})$

193. $\mathrm{R}_{1}=\mathrm{CH}_{3}(\mathrm{R})$<smiles>[R3]c1cc2cnc3c4cc5c(cc4ccc3c2c([R])c1[R3])OCO5</smiles>

194. $\mathrm{R}_{1}=\mathrm{OCH}_{3} ; \mathrm{R}_{2}=\mathrm{OH} ; \mathrm{R}_{3}=\mathrm{H}$

195. $\mathrm{R}_{1}=\mathrm{H} ; \mathrm{R}_{2}=\mathrm{R}_{3}=\mathrm{OCH}_{3}$<smiles>[R9]c1ccc(C([R7])CNC(=O)c2ccccc2)cc1[R9]</smiles>

196. $\mathrm{R}_{1}=\mathrm{H}, \mathrm{OH} ; \mathrm{R}_{2}=\mathrm{OCH}_{3} ; \mathrm{R}_{3}=\mathrm{H}$

197. $\mathrm{R}_{1}=\mathrm{R}_{2}=\mathrm{R}_{3}=\mathrm{OCH}_{3}$

198. $\mathrm{R}_{1}=\mathrm{R}_{3}=\mathrm{H} ; \mathrm{R}_{2}=\mathrm{OCH}_{3}$

199. $\mathrm{R}_{1}=\mathrm{R}_{2}=\mathrm{OCH}_{3} ; \mathrm{R}_{3}=\mathrm{H}$<smiles>[R]C1CCC2(C)CCC3(C)C(CCC4C5(C)CCC([R3])C(C)(C)C5CCC43C)C12</smiles>

200. $\mathrm{R}_{1}=\mathrm{CH}_{3} \mathrm{CCH}_{2} ; \mathrm{R}_{2}=\mathrm{OCH}_{3}$

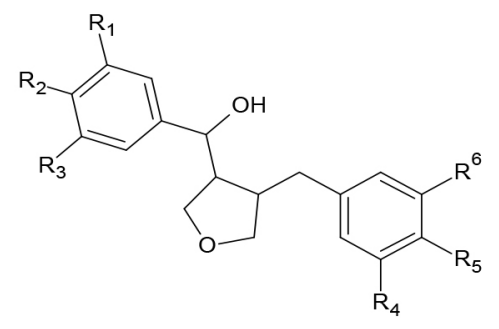

201. $\mathrm{R}_{1}=\mathrm{R}_{3}=\mathrm{R}_{4}=\mathrm{R}_{6}=\mathrm{OCH}_{3} ; \mathrm{R}_{2}=\mathrm{R}_{5}=\mathrm{OH}$

190. $\mathrm{R}_{1}=\mathrm{OCH}_{3} ; \mathrm{R}_{2}=\mathrm{OH} ; \mathrm{R}_{3}=\mathrm{O}$ 


\section{Figura 1 (continuação)}<smiles>[R9]c1ccc(CC2c3cc([R9])c(Br)cc3CC[N+]2(C)C)cc1[R9]</smiles>

202. $\mathrm{R}_{1}=\mathrm{R}_{4}=\mathrm{OCH}_{3} ; \mathrm{R}_{2}=\mathrm{R}_{3}=\mathrm{OH}$<smiles>[R3]c1c(C[C@H](O)C([2H])([2H])O)c(=O)n([R3])c2ccccc12</smiles>

203. $\mathrm{R}_{1}=\mathrm{OCH}_{3} ; \mathrm{R}_{2}=\mathrm{R}_{3}=\mathrm{R}_{4}=\mathrm{CH}_{3}$<smiles>[R8]c1ccc2c(c1[R6])[C@H](Cc1ccc(Br)cc1)[N+](C)(C)CC2</smiles>

204. $\mathrm{R}_{1}=\mathrm{OCH}_{3} ; \mathrm{R}_{2}=\mathrm{R}_{3}=\mathrm{CH}_{3}$

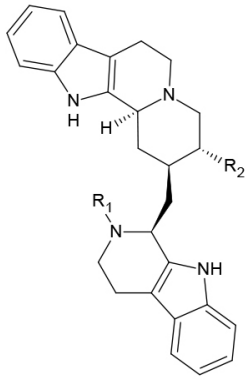

205. $\mathrm{R}_{1}=\mathrm{CH}_{3} ; \mathrm{R}_{2}=\mathrm{CHCH}_{2}$<smiles>[R]c1cc2ccc(=O)oc2c(C)c1[R]</smiles>

206. $\mathrm{R}_{1}=\mathrm{R}_{2}=\mathrm{OCH}_{3} ; \mathrm{R}_{3}=\mathrm{CH}_{2} \mathrm{CHC}\left(\mathrm{CH}_{3}\right)_{2}$

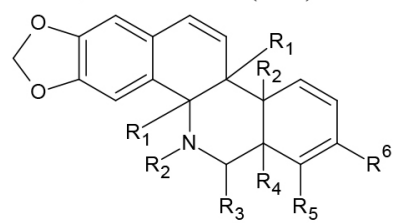

207. $\mathrm{R}_{1}=\mathrm{R}_{4}=\mathrm{R}_{1}=\mathrm{R}_{2}=\mathrm{H} ; \mathrm{R}_{2}=\mathrm{CH}_{3} ; \mathrm{R}_{3}=\mathrm{O} ; \mathrm{R}_{5}=\mathrm{R}_{6}=\mathrm{OCH}_{3}$ 208. $\mathrm{R}_{1}=\mathrm{R}_{2}=\mathrm{R}_{4}=\mathrm{R}_{1}=\mathrm{R}_{2}=$ vazio; $\mathrm{R}_{3}=\mathrm{H} ; \mathrm{R}_{5}=\mathrm{R}_{6}=\mathrm{OCH}_{3}$

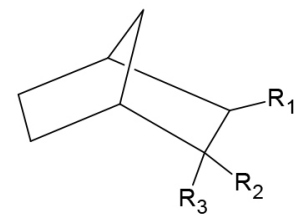

209. $\mathrm{R}_{1}=\mathrm{CH}_{2} ; \mathrm{R}_{2}=\mathrm{R}_{3}=\mathrm{CH}_{3}$<smiles>[R]C1=CCC2C(C1)C2([R])[R]</smiles>

210. $\mathrm{R}_{1}=\mathrm{R}_{2}=\mathrm{R}_{3}=\mathrm{CH}_{3}$<smiles>[R9]C1C([R9])C([R8])C([2H])C([2H])C1[R9]</smiles>

211. $\mathrm{R}_{1}=\mathrm{CH}\left(\mathrm{CH}_{3}\right)_{2} ; \mathrm{R}_{2}=\mathrm{R}_{3}=\mathrm{R}_{4}=\mathrm{R}_{5}=\mathrm{H} ; \mathrm{R}_{6}=\mathrm{CH}_{3}$

212. $\mathrm{R}_{1}=\mathrm{CH}_{2} \mathrm{CCH}_{3} ; \mathrm{R}_{2}=\mathrm{R}_{3}=\mathrm{R}_{6}=\mathrm{H}, \mathrm{H} ; \mathrm{R}_{4}=\mathrm{H} ; \mathrm{R}_{5}=\mathrm{CH}_{3}$

213. $\mathrm{R}_{1}=\mathrm{CH}_{3}, \mathrm{OH} ; \mathrm{R}_{2}=\mathrm{R}_{3}=\mathrm{H}, \mathrm{H} ; \mathrm{R}_{4}=\mathrm{CH}\left(\mathrm{CH}_{3}\right)_{2} ; \mathrm{R}_{5}=\mathrm{R}_{6}=\mathrm{H}$

214. $\mathrm{R}_{1}=\mathrm{CH}_{2} \mathrm{CCH}_{3} ; \mathrm{R}_{2}=\mathrm{R}_{6}=\mathrm{H}, \mathrm{H} ; \mathrm{R}_{3}=\mathrm{H} ; \mathrm{R}_{4}=\mathrm{CH}_{3} ; \mathrm{R}_{5}=\mathrm{H}$, $\mathrm{OH}$

215. $\mathrm{R}_{1}=\mathrm{CH}\left(\mathrm{CH}_{2}\right) ; \mathrm{R}_{2}=\mathrm{CH}_{3} ; \mathrm{R}_{3}=\mathrm{R}_{4}=\mathrm{R}_{5}=\mathrm{H}, \mathrm{H} ; \mathrm{R}_{6}=\mathrm{CH}_{3}$, $\mathrm{CH}_{3}$

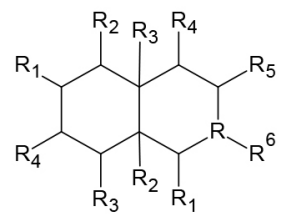

216. $\mathrm{R}_{1}=\mathrm{R}_{5}=\mathrm{R}_{4}=\mathrm{H}, \mathrm{H} ; \mathrm{R}_{2}=\mathrm{R}_{6}=\mathrm{R}_{3}=\mathrm{CH}_{3} ; \mathrm{R}_{3}=$ vazio; $\mathrm{R}_{4}=\mathrm{R}_{1}=\mathrm{H}$; $\mathrm{R}_{2}=\mathrm{H}$

217. $\mathrm{R}_{1}=\mathrm{R}_{4}=\mathrm{R}_{4}=\mathrm{H}, \mathrm{H} ; \mathrm{R}_{2}=\mathrm{R}_{6}=\mathrm{CH}_{3} ; \mathrm{R}_{3}=\mathrm{R}_{5}=\mathrm{R}_{1}=\mathrm{H} ; \mathrm{R}_{2}=$ vazio; $\mathrm{R}_{3}=\mathrm{CH}\left(\mathrm{CH}_{3}\right)_{2}$

218. $\mathrm{R}_{1}=\mathrm{R}_{4}=\mathrm{R}_{5}=\mathrm{R}_{6}=\mathrm{R}_{3}=H, H ; \mathrm{R}_{2}=H ; \mathrm{R}_{3}=$ vazio; $\mathrm{R}_{1}=\mathrm{R}_{2}=$ $\mathrm{CH}_{3} ; \mathrm{R}_{4}=\mathrm{H}, \mathrm{CH}_{3} \mathrm{CCH}_{2}$

219. $\mathrm{R}_{1}=\mathrm{R}_{4}=\mathrm{R}_{5}=\mathrm{R}_{4}=\mathrm{H}, \mathrm{H} ; \mathrm{R}_{2}=\mathrm{CH}_{2} ; \mathrm{R}_{3}=\mathrm{R}_{1}=\mathrm{R}_{2}=\mathrm{H} ; \mathrm{R}_{6}=\mathrm{CH}_{3}$; $\mathrm{R}_{3}=\mathrm{CH}\left(\mathrm{CH}_{3}\right)_{2}$

220. $\mathrm{R}_{1}=\mathrm{R}_{6}=\mathrm{R}_{1}=\mathrm{R}_{4}=\mathrm{H}, \mathrm{H} ; \mathrm{R}_{2}=\mathrm{CH}\left(\mathrm{CH}_{3}\right)_{2} ; \mathrm{R}_{3}=$ vazio; $\mathrm{R}_{4}=$ $\mathrm{R}_{2}=\mathrm{H} ; \mathrm{R}_{5}=\mathrm{CH}_{2} ; \mathrm{R}_{3}=\mathrm{CH}_{3}$

221. $\mathrm{R}_{1}=\mathrm{CH}\left(\mathrm{CH}_{3}\right)_{2} ; \mathrm{R}_{2}=\mathrm{R}_{6}=\mathrm{R}_{1}=\mathrm{R}_{3}=\mathrm{R}_{4}=\mathrm{H}, \mathrm{H} ; \mathrm{R}_{3}=\mathrm{R}_{5}=\mathrm{H}$; $\mathrm{R}_{4}=\mathrm{R}_{2}=\mathrm{CH}_{3}$

222. $\mathrm{R}_{1}=\mathrm{R}_{4}=\mathrm{R}_{5}=\mathrm{R}_{4}=\mathrm{H}, \mathrm{H} ; \mathrm{R}_{2}=\mathrm{R}_{6}=\mathrm{CH}_{3}$;

$\mathrm{R}_{3}=\mathrm{R}_{1}=\mathrm{H} ; \mathrm{R}_{2}=$ vazio; $\mathrm{R}_{3}=\mathrm{CH}\left(\mathrm{CH}_{3}\right)_{2}$

223. $\mathrm{R}_{1}=\mathrm{R}_{4}=\mathrm{R}_{5}=\mathrm{R}_{1}=\mathrm{R}_{2}=\mathrm{R}_{4}=\mathrm{H}, \mathrm{H} ; \mathrm{R}_{2}=\mathrm{OH} ; \mathrm{R}_{3}=\mathrm{R}_{3}=\mathrm{CH}_{2}$; $\mathrm{R}_{6}=\mathrm{CH}\left(\mathrm{CH}_{3}\right)_{2}$

224. $\mathrm{R}_{1}=\mathrm{R}_{2}=\mathrm{R}_{5}=\mathrm{R}_{6}=\mathrm{R}_{3}=\mathrm{H}, \mathrm{H} ; \mathrm{R}_{3}=$ vazio; $\mathrm{R}_{4}=\mathrm{H} ; \mathrm{R}_{1}=\mathrm{R}_{2}=$ $\mathrm{CH}_{3} ; \mathrm{R}_{4}=\mathrm{CH}_{3} \mathrm{CCH}_{2}$

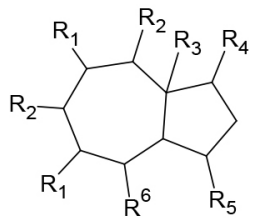

225. $\mathrm{R}_{1}=\mathrm{CH}_{3} \mathrm{CCH}_{2}(\mathrm{~S}) ; \mathrm{R}_{2}=\mathrm{R}_{5}=\mathrm{R}_{1}=\mathrm{R}_{2}=\mathrm{H}, \mathrm{H} ; \mathrm{R}_{3}=$ vazio; $\mathrm{R}_{6}=$ $\mathrm{CH}_{3}(\mathrm{~S})$

226. $\mathrm{R}_{1}=\mathrm{CH}_{3} \mathrm{CCH}_{2}(\mathrm{R}) ; \mathrm{R}_{2}=\mathrm{R}_{5}=\mathrm{R}_{1}=\mathrm{R}_{2}=\mathrm{H}, \mathrm{H} ; \mathrm{R}_{3}=$ vazio; $\mathrm{R}_{6}=$ $\mathrm{CH}_{3}(\mathrm{R})$

227. $\mathrm{R}_{1}=\mathrm{H} ; \mathrm{R}_{2}=\mathrm{R}_{4}=\mathrm{R}_{6}=\mathrm{R}_{1}=\mathrm{H}, \mathrm{H} ; \mathrm{R}_{3}=\mathrm{R}_{2}=\mathrm{CH}_{3} ; \mathrm{R}_{5}=$ $\mathrm{CH}_{3} \mathrm{CCH}_{2}$

228. $\mathrm{R}_{1}=\mathrm{R}_{4}=\mathrm{R}_{2}=\mathrm{H}, \mathrm{H} ; \mathrm{R}_{2}=\mathrm{R}_{5}=\mathrm{CH}_{3} ; \mathrm{R}_{3}=$ vazio; $\mathrm{R}_{6}=\mathrm{R}_{1}=$ $\operatorname{ciclo}\left[\mathrm{C}\left(\mathrm{CH}_{3}\right)_{2}\right]$

229. $\mathrm{R}_{1}=\mathrm{R}_{4}=\mathrm{R}_{2}=\mathrm{H}, \mathrm{H} ; \mathrm{R}_{2}=\mathrm{R}_{5}=\mathrm{H}, \mathrm{CH}_{3} ; \mathrm{R}_{3}=\mathrm{H} ; \mathrm{R}_{6}=\mathrm{R}_{1}=$ ciclo $\left[\mathrm{C}\left(\mathrm{CH}_{3}\right)_{2}\right]$ 
Figura 1 (continuacão)

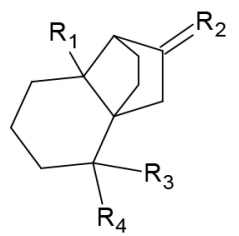

230. $\mathrm{R}_{1}=\mathrm{R}_{3}=\mathrm{R}_{4}=\mathrm{CH}_{3} ; \mathrm{R}_{2}=\mathrm{CH}_{2}$

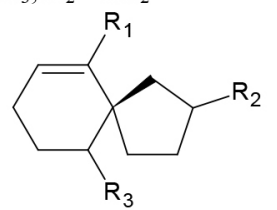

231. $\mathrm{R}_{1}=\mathrm{R}_{3}=\mathrm{CH}_{3} ; \mathrm{R}_{2}=\mathrm{CH}_{3} \mathrm{CCH}_{2}$<smiles>[R]CCCCCC</smiles>

232. $\mathrm{R}_{1}=\mathrm{O}$

233. $\mathrm{R}_{1}=\mathrm{OH}$<smiles>[R2]CC1([R3])CCC=C([R4])C12CC([R])([R])C2[R]</smiles>

234. $\mathrm{R}_{1}=\mathrm{R}_{2}=\mathrm{R}_{3}=\mathrm{R}_{4}=\mathrm{R}_{5}=\mathrm{R}_{6}=\mathrm{CH}_{3}$<smiles>[R4]c1ccc2c(c1[R3])C([R])N([R])c1c-2ccc2cc3c(cc12)OCO3</smiles>

235. $\mathrm{R}_{1}=\mathrm{CH}_{3} ; \mathrm{R}_{2}=\mathrm{CH}_{2} \mathrm{COCH}_{3} ; \mathrm{R}_{3}=\mathrm{R}_{4}=\mathrm{OCH}_{3}$

236. $\mathrm{R}_{1}=$ vazio; $\mathrm{R}_{2}=\mathrm{H} ; \mathrm{R}_{3}=\mathrm{OCH}_{3} ; \mathrm{R}_{4}=\mathrm{OH}$

237. $\mathrm{R}_{1}=\mathrm{CH}_{3} ; \mathrm{R}_{2}=\mathrm{R}_{3}=\mathrm{OCH}_{3} ; \mathrm{R}_{4}=\mathrm{CH}_{2} \mathrm{COOH}$

238. $\mathrm{R}_{1}=\mathrm{CH}_{3} ; \mathrm{R}_{2}=\mathrm{CH}_{2} \mathrm{COCH}_{3} ; \mathrm{R}_{3}=\mathrm{R}_{4}=\mathrm{OCH}_{3}$

239. $\mathrm{R}_{1}=\mathrm{H} ; \mathrm{R}_{2}=\mathrm{H}, \mathrm{H} ; \mathrm{R}_{3}=\mathrm{OCH}_{3} ; \mathrm{R}_{4}=\mathrm{OH}$<smiles>[R]C1C([R])C([R])C([R])C([R])C1[R]</smiles>

240. $\mathrm{R}_{1}=\mathrm{R}_{3}=\mathrm{R}_{4}=\mathrm{R}_{6}=\mathrm{H} ; \mathrm{R}_{2}=\mathrm{CHO} ; \mathrm{R}_{5}=\mathrm{OH}$

241. $\mathrm{R}_{1}=\mathrm{COOH} ; \mathrm{R}_{2}=\mathrm{R}_{5}=\mathrm{R}_{6}=\mathrm{H} ; \mathrm{R}_{3}=\mathrm{OCH}_{3} ; \mathrm{R}_{4}=\mathrm{OH}$

242. $\mathrm{R}_{1}=\mathrm{CHCHCH}_{2} \mathrm{CH}_{3} ; \mathrm{R}_{2}=\mathrm{R}_{3}=\mathrm{R}_{5}=\mathrm{R}_{6}=\mathrm{H} ; \mathrm{R}_{4}=$ $\mathrm{OCH}_{2} \mathrm{CHC}\left(\mathrm{CH}_{3}\right)_{2}$

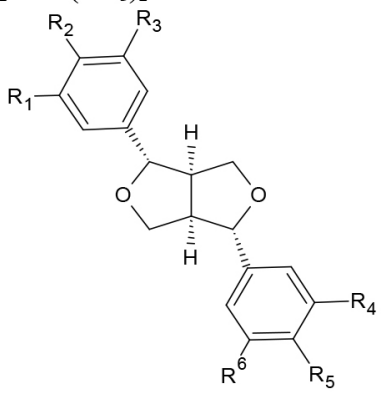

243. $\mathrm{R}_{1}=\mathrm{R}_{4}=\mathrm{R}_{6}=\mathrm{OCH}_{3} ; \mathrm{R}_{2}=\mathrm{R}_{5}=\mathrm{CH}_{3} ; \mathrm{R}_{3}=\mathrm{CH}_{2} \mathrm{OH}$

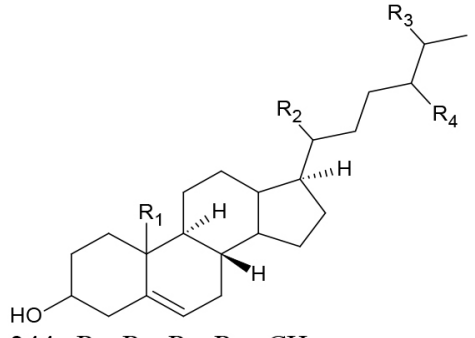

244. $\mathrm{R}_{1}=\mathrm{R}_{2}=\mathrm{R}_{3}=\mathrm{R}_{4}=\mathrm{CH}_{3}$<smiles>[R]c1cc2c(cc1[R2])C1Cc3ccc([R5])c([R4])c3C[N+]1([R3])CC2</smiles>

245. $\mathrm{R}_{1}=\mathrm{R}_{2}=\mathrm{R}_{4}=\mathrm{R}_{5}=\mathrm{OCH}_{3} ; \mathrm{R}_{3}=\mathrm{CH}_{3}$

246. $\mathrm{R}_{1}=\mathrm{OH} ; \mathrm{R}_{2}=\mathrm{R}_{4}=\mathrm{R}_{5}=\mathrm{OCH}_{3} ; \mathrm{R}_{3}=\mathrm{CH}_{3}$<smiles>[R]c1ccc(C[C@H]2c3c(ccc([R])c3[R5])CC[N+]2([R7])[R])cc1[R3]</smiles>

247. (S) $\mathrm{R}_{1}=\mathrm{R}_{2}=\mathrm{CH}_{3} ; \mathrm{R}_{3}=\mathrm{R}_{5}=\mathrm{OH} ; \mathrm{R}_{4}=\mathrm{R}_{6}=\mathrm{OCH}_{3}$<smiles>[R7]c1ccc2c(c[n+]([R3])c3c4cc5c(cc4ccc23)OCO5)c1[R2]</smiles>

248. $\mathrm{R}_{1}=\mathrm{R}_{2}=\mathrm{OCH}_{3} ; \mathrm{R}_{3}=\mathrm{CH}_{3}$<smiles>[R]C1C([R])C([R])C([R])C([R])C1[R]</smiles>

249. $\mathrm{R}_{1}=\mathrm{C}\left(\mathrm{CH}_{2}\right)_{2} \mathrm{OH} ; \mathrm{R}_{2}=\mathrm{R}_{3}=\mathrm{R}_{5}=\mathrm{R}_{6}=\mathrm{H} ; \mathrm{R}_{4}=\mathrm{CH}_{3}$<smiles>[R3]C(C)=CCCC([R])=CCCC([R1])([R])C=C</smiles>

250. $\mathrm{R}_{1}=\mathrm{OH} ; \mathrm{R}_{2}=\mathrm{R}_{3}=\mathrm{R}_{4}=\mathrm{CH}_{3}$<smiles></smiles>

251. $\mathrm{R}_{1}=\mathrm{CH}_{2} ; \mathrm{R}_{2}=\mathrm{OCH}_{3}$ 


\section{Figura 1 (continuação)}

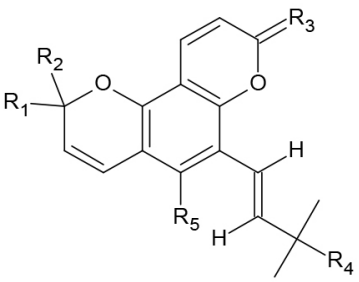

252. $\mathrm{R}_{1}=\mathrm{R}_{2}=\mathrm{CH}_{3} ; \mathrm{R}_{3}=\mathrm{O} ; \mathrm{R}_{4}=\mathrm{R}_{5}=\mathrm{OH}$<smiles>[R]c1cc2c(cc1[2H])C(=[R])N([R1])c1c-2ccc2cc3c(cc12)OCO3</smiles>

253. $\mathrm{R}_{1}=\mathrm{CH}_{3} ; \mathrm{R}_{2}=\mathrm{O} ; \mathrm{R}_{3}=\mathrm{R}_{4}=\mathrm{OCH}_{3}$<smiles>[R]C1=C2C([R8])C([R3])O[C@@H]2N([R2])c2c1ccc([R])c2[R]</smiles>

254. $\mathrm{R}_{1}=\mathrm{OCH}_{3} ; \mathrm{R}_{2}=\mathrm{R}_{3}=\mathrm{R}_{6}=\mathrm{H} ; \mathrm{R}_{4}=$ vazio; $\mathrm{R}_{5}=\mathrm{H}$

255. $\mathrm{R}_{1}=\mathrm{R}_{5}=\mathrm{OCH}_{3} ; \mathrm{R}_{2}=\mathrm{R}_{3}=\mathrm{R}_{4}=\mathrm{H} ; \mathrm{R}_{6}=\mathrm{CH}_{2}$

256. $\mathrm{R}_{1}=\mathrm{OCH}_{3} ; \mathrm{R}_{2}=\mathrm{H}, \mathrm{H} ; \mathrm{R}_{3}=\mathrm{R}_{5}=\mathrm{R}_{6}=\mathrm{H}, \mathrm{C}\left(\mathrm{CH}_{3}\right)_{2} \mathrm{OH} ; \mathrm{R}_{4}=$ vazio<smiles>[R9]C1C([R9])C([R9])C([R9])C([R9])C1[R9]</smiles>

257. $\mathrm{R}_{1}=\mathrm{OCH}_{3} ; \mathrm{R}_{2}=\mathrm{R}_{4}=\mathrm{R}_{5}=\mathrm{H} ; \mathrm{R}_{3}=\mathrm{CHO} ; \mathrm{R}_{6}=\mathrm{OH}$

258. $\mathrm{R}_{1}=\mathrm{COOCH}_{3} ; \mathrm{R}_{2}=\mathrm{R}_{3}=\mathrm{R}_{6}=\mathrm{H} ; \mathrm{R}_{4}=\mathrm{OH} ; \mathrm{R}_{5}=\mathrm{OCH}_{3}$<smiles>[R]C(=O)OCCc1ccc([R8])c([R9])c1</smiles>

259. $\mathrm{R}_{1}=\mathrm{OH} ; \mathrm{R}_{2}=\mathrm{OCH}_{3} ; \mathrm{R}_{3}=\left(\mathrm{CH}_{2}\right)_{23} \mathrm{CH}_{3}$

260. $\mathrm{R}_{1}=\mathrm{OH} ; \mathrm{R}_{2}=\mathrm{H} ; \mathrm{R}_{3}=\left(\mathrm{CH}_{2}\right)_{25} \mathrm{CH}_{3}$<smiles>[R]C1C([R])C([R])C2([R])C([R])C([R3])C([R3])C2([R3])C1[R]</smiles>

261. $\mathrm{R}_{1}=\mathrm{R}_{3}=\mathrm{R}_{1}=\mathrm{R}_{2}=\mathrm{H} ; \mathrm{R}_{2}=\mathrm{R}_{6}=\mathrm{CH}_{3} ; \mathrm{R}_{4}=\mathrm{R}_{5}=\mathrm{R}_{4}=\mathrm{H}, \mathrm{H} ; \mathrm{R}_{3}=$ $\mathrm{C}\left(\mathrm{CH}_{3}\right)_{2}$

262. $\mathrm{R}_{1}=\mathrm{R}_{4}=\mathrm{R}_{1}=\mathrm{R}_{4}=\mathrm{H}, \mathrm{H} ; \mathrm{R}_{2}=\mathrm{C}\left(\mathrm{CH}_{3}\right)_{2} ; \mathrm{R}_{3}=\mathrm{R}_{6}=\mathrm{R}_{2}=\mathrm{R}_{4}=\mathrm{H}$; $\mathrm{R}_{\mathrm{S}}=\mathrm{CH}_{3} ; \mathrm{R}_{3}=\mathrm{CH}_{3}, \mathrm{OH}(\mathrm{R})$

263. $\mathrm{R}_{1}=\mathrm{R}_{4}=\mathrm{R}_{1}=\mathrm{R}_{4}=\mathrm{H}, \mathrm{H}(\mathrm{R}) ; \mathrm{R}_{2}=\mathrm{C}\left(\mathrm{CH}_{3}\right)_{2} ; \mathrm{R}_{3}=\mathrm{R}_{6}=\mathrm{R}_{2}=\mathrm{R}_{4}=$ $\mathrm{H} ; \mathrm{R}_{5}=\mathrm{CH}_{3} ; \mathrm{R}_{3}=\mathrm{CH}_{3}, \mathrm{OH}(\mathrm{S})$

264. $\mathrm{R}_{1}=\mathrm{R}_{4}=\mathrm{R}_{1}=\mathrm{R}_{4}=\mathrm{H}, \mathrm{H}(\mathrm{S}) ; \mathrm{R}_{2}=\mathrm{C}\left(\mathrm{CH}_{3}\right)_{2} ; \mathrm{R}_{3}=\mathrm{R}_{6}=\mathrm{R}_{2}=\mathrm{R}_{4}=$ $\mathrm{H} ; \mathrm{R}_{5}=\mathrm{CH}_{3} ; \mathrm{R}_{3}=\mathrm{CH}_{3}, \mathrm{OH}$

265. $\mathrm{R}_{1}=\mathrm{R}_{4}=\mathrm{H}, \mathrm{H} ; \mathrm{R}_{2}=\mathrm{CH}_{2} ; \mathrm{R}_{3}=\mathrm{R}_{2}=$ vazio; $\mathrm{R}_{4}=\mathrm{R}_{5}=\mathrm{R}_{1}=\mathrm{H}$; $\mathrm{R}_{6}=\mathrm{CH}_{3} ; \mathrm{R}_{3}=\mathrm{H}, \mathrm{C}\left(\mathrm{CH}_{3}\right)_{2}$<smiles>[R]CC([R9])([R])CCC=C([R3])CCC=C([R])C</smiles>

266. $\mathrm{R}_{1}=\mathrm{CH}_{2} ; \mathrm{R}_{2}=\mathrm{OH} ; \mathrm{R}_{3}=\mathrm{R}_{4}=\mathrm{R}_{5}=\mathrm{CH}_{3}$<smiles>[R3]C1C[C@H]2CC[C@H]1C2([R8])[2H]</smiles>

267. $\mathrm{R}_{1}=\mathrm{R}_{2}=\mathrm{CH}_{3} ; \mathrm{R}_{3}=\mathrm{CH}_{2}$<smiles>[R7]c1c2c(nc3ccccc13)OC([R1])([R3])C([R])C2</smiles>

268. $\mathrm{R}_{1}=\mathrm{OCH}_{3} ; \mathrm{R}_{2}=\mathrm{OH} ; \mathrm{R}_{3}=\mathrm{R}_{4}=\mathrm{CH}_{3}$<smiles></smiles>

269. $\mathrm{R}_{1}=\mathrm{OCH}_{2} \mathrm{CHCH}\left(\mathrm{CH}_{3}\right)_{2}$

270. $\mathrm{R}_{1}=\mathrm{CH}_{3}, \mathrm{OH} ; \mathrm{R}_{2}=\mathrm{R}_{3}=\mathrm{R}_{5}=\mathrm{R}_{6}=\mathrm{H} ; \mathrm{R}_{4}=\mathrm{CH}_{3} \mathrm{CCH}_{2}$<smiles>[R]C1C([R3])C([R])C([R])C([R])C1[R]</smiles>

271. $\mathrm{R}_{1}=\mathrm{C}\left(\mathrm{CH}_{3}\right)_{2} ; \mathrm{R}_{2}=\mathrm{R}_{3}=\mathrm{R}_{5}=\mathrm{H}, \mathrm{H} ; \mathrm{R}_{4}=\mathrm{CH}_{3} ; \mathrm{R}_{6}=\mathrm{OH}$ 272. $\mathrm{R}_{1}=\mathrm{OCH}_{3} ; \mathrm{R}_{2}=\mathrm{R}_{4}=\mathrm{R}_{5}=\mathrm{H} ; \mathrm{R}_{3}=\mathrm{C}\left(\mathrm{CH}_{3}\right)_{2} ; \mathrm{R}_{6}=\mathrm{CH}_{3}$<smiles>[R6]C(C)C([R6])CCCCCCC</smiles>

273. $\mathrm{R}_{1}=\mathrm{H}, \mathrm{H} ; \mathrm{R}_{2}=\mathrm{O}$

274. $\mathrm{R}_{1}=\mathrm{CH}_{2} ; \mathrm{R}_{2}=\mathrm{H}, \mathrm{H}$<smiles>[R3]C1=CCC2(CC1)C([R])CCC2[R]</smiles>

275. $\mathrm{R}_{1}=\mathrm{CH}_{3} \mathrm{CCH}_{2} ; \mathrm{R}_{2}=\mathrm{R}_{3}=\mathrm{CH}_{3}$<smiles>[R3]C1=CC2C(=C([R3])CCCC2([R6])[R6])CC1</smiles>

276. $\mathrm{R}_{1}=\mathrm{R}_{2}=\mathrm{R}_{3}=\mathrm{R}_{4}=\mathrm{CH}_{3}$ 
Figura 1 (continuação)

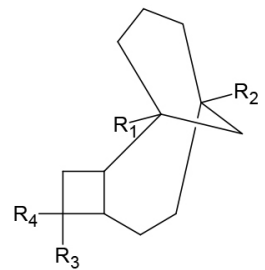

277. $\mathrm{R}_{1}=\mathrm{OH} ; \mathrm{R}_{2}=\mathrm{R}_{3}=\mathrm{R}_{4}=\mathrm{CH}_{3}$

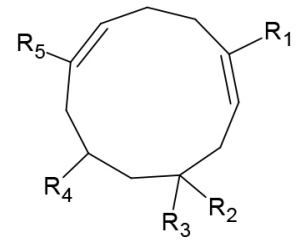

278. $\mathrm{R}_{1}=\mathrm{R}_{2}=\mathrm{R}_{3}=\mathrm{R}_{5}=\mathrm{CH}_{3} ; \mathrm{R}_{4}=\mathrm{OH}$<smiles>[R]C1=CC2C([R3])CCC([R1])C2CC1</smiles>

279. $\mathrm{R}_{1}=\mathrm{CH}_{2} ; \mathrm{R}_{2}=\mathrm{CH}_{3} ; \mathrm{R}_{3}=\mathrm{C}\left(\mathrm{CH}_{3}\right)_{2}$

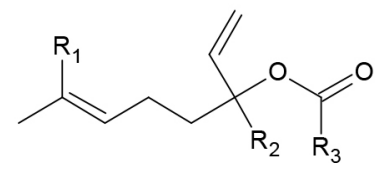

280. $\mathrm{R}_{1}=\mathrm{R}_{2}=\mathrm{R}_{3}=\mathrm{CH}_{3}$

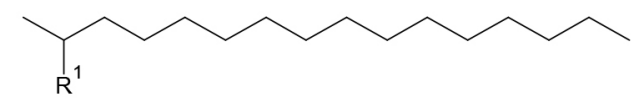

281. $\mathrm{R}_{1}=\mathrm{H}, \mathrm{H}$

282. $\mathrm{R}_{1}=\mathrm{H}, \mathrm{CH}_{3}$

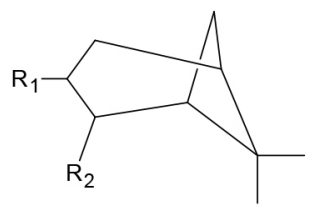

283. $\mathrm{R}_{1}=\mathrm{O} ; \mathrm{R}_{2}=\mathrm{CH}_{2}$

284. $\mathrm{R}_{1}=\mathrm{H} ; \mathrm{R}_{2}=\mathrm{CHO}$

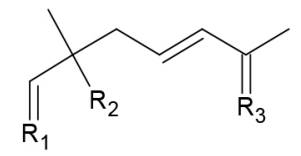

285. $\mathrm{R}_{1}=\mathrm{R}_{3}=\mathrm{CH}_{2} ; \mathrm{R}_{2}=\mathrm{OH}$<smiles>[R9]C1C([R3])C([R])C([R])C([R9])C1[R9]</smiles>

286. $\mathrm{R}_{1}=\mathrm{C}\left(\mathrm{CH}_{3}\right)_{3} ; \mathrm{R}_{2}=\mathrm{R}_{3}=\mathrm{H} ; \mathrm{R}_{4}=\mathrm{OH} ; \mathrm{R}_{5}=\mathrm{R}_{6}=\mathrm{H}, \mathrm{H}$
287. $\mathrm{R}_{1}=\mathrm{C}\left(\mathrm{CH}_{3}\right)_{2} \mathrm{OCOCH}_{3} ; \mathrm{R}_{2}=\mathrm{R}_{5}=\mathrm{R}_{6}=\mathrm{H}, \mathrm{H} ; \mathrm{R}_{3}=\mathrm{H} ; \mathrm{R}_{4}=$ $\mathrm{CH}_{3}$

288. $\mathrm{R}_{1}=\mathrm{C}\left(\mathrm{CH}_{2}\right) \mathrm{CH}_{3} ; \mathrm{R}_{2}=\mathrm{R}_{6}=\mathrm{H}, \mathrm{H} ; \mathrm{R}_{3}=\mathrm{H} ; \mathrm{R}_{4}=\mathrm{CH}_{3} ; \mathrm{R}_{5}=\mathrm{O}$

289. $\mathrm{R}_{1}=\mathrm{CH}_{2} \mathrm{COOCH}_{3} ; \mathrm{R}_{2}=\mathrm{R}_{3}=\mathrm{R}_{4}=\mathrm{R}_{5}=\mathrm{R}_{6}=\mathrm{H}$

290. $\mathrm{R}_{1}=\mathrm{COCH}_{3} ; \mathrm{R}_{2}=\mathrm{R}_{3}=\mathrm{R}_{5}=\mathrm{H} ; \mathrm{R}_{4}=\mathrm{R}_{6}=\mathrm{CH}_{3}$

291. $\mathrm{R}_{1}=\mathrm{CH}_{2} \mathrm{CH}_{2} \mathrm{OCOCH}_{3} ; \mathrm{R}_{2}=\mathrm{R}_{3}=\mathrm{R}_{4}=\mathrm{R}_{5}=\mathrm{R}_{6}=\mathrm{H}$

292. $\mathrm{R}_{1}=\mathrm{CH}_{2} \mathrm{CCH}_{3} ; \mathrm{R}_{2}=\mathrm{R}_{3}=\mathrm{R}_{5}=\mathrm{H}, \mathrm{H} ; \mathrm{R}_{4}=\mathrm{CH}_{3} ; \mathrm{R}_{6}=\mathrm{OH}$

293. $\mathrm{R}_{1}=\mathrm{C}\left(\mathrm{CH}_{3}\right)_{2} ; \mathrm{R}_{2}=\mathrm{R}_{3}=\mathrm{H}, \mathrm{H} ; \mathrm{R}_{4}=\mathrm{CH}_{3} ; \mathrm{R}_{5}=\mathrm{H} ; \mathrm{R}_{6}=\mathrm{O}$

294. $\mathrm{R}_{1}=\mathrm{CH}_{3}(\mathrm{~S}), \mathrm{CH}_{3}(\mathrm{R}) ; \mathrm{R}_{2}=(\mathrm{S}) \mathrm{CH}_{2} \mathrm{CH}_{2} \mathrm{CH}(\mathrm{OH}) \mathrm{CH}_{3}$; $\mathrm{R}_{3}=\mathrm{COOCH}_{3} ; \mathrm{R}_{4}=\mathrm{H} ; \mathrm{R}_{5}=\mathrm{O} ; \mathrm{R}_{6}=\mathrm{H}, \mathrm{H}$<smiles>[R1]C(C)CCCCC=O</smiles>

295. $\mathrm{R}_{1}=\mathrm{CH}_{3}$<smiles>[R]C(C)=CCCC([R3])=CCOC([R])[R2]</smiles>

296. $\mathrm{R}_{1}=\mathrm{O} ; \mathrm{R}_{2}=\mathrm{R}_{3}=\mathrm{R}_{4}=\mathrm{CH}_{3}$<smiles>[R]C1=CC2C([R3])CCC([R])C2CC1</smiles>

297. $\mathrm{R}_{1}=\mathrm{CH}_{2} ; \mathrm{R}_{2}=\mathrm{CH}_{3} ; \mathrm{R}_{3}=\mathrm{C}\left(\mathrm{CH}_{3}\right)_{2}$<smiles>O=CCCCCCCC(Br)Br</smiles>

298. $\mathrm{R}_{1}=\mathrm{H}, \mathrm{H}$ 299. $\mathrm{R}_{1}=\mathrm{H}, \mathrm{CH}_{3}$

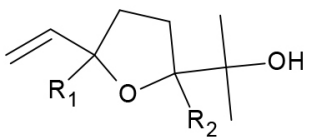

300. $\mathrm{R}_{1}=\mathrm{CH}_{3}(\mathrm{R}) ; \mathrm{R}_{2}=\mathrm{H}(\mathrm{S})$

301. $\mathrm{R}_{1}=\mathrm{CH}_{3}(\mathrm{R}) ; \mathrm{R}_{2}=\mathrm{H}(\mathrm{R})$

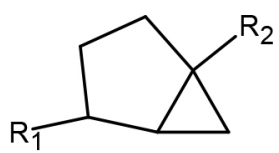

302. $\mathrm{R}_{1}=\mathrm{O} ; \mathrm{R}_{2}=\mathrm{C}\left(\mathrm{CH}_{3}\right)_{2} ; \mathrm{R}_{3}=\mathrm{CH}_{3}$

303. $\mathrm{R}_{1}=\mathrm{H}, \mathrm{H} ; \mathrm{R}_{2}=\mathrm{C}\left(\mathrm{CH}_{3}\right)_{2} ; \mathrm{R}_{3}=\mathrm{CH}_{3}$

304. $\mathrm{R}_{1}=\mathrm{CH}\left(\mathrm{CH}_{3}\right)_{2} ; \mathrm{R}_{2}=\mathrm{CH}_{3} ; \mathrm{R}_{3}=\mathrm{OH}$<smiles>[R]C(C)CCCCCO</smiles>

305. $\mathrm{R}_{1}=\mathrm{CH}_{3}$ 
Figura 1 (continuação)<smiles>[R7]c1cnn([R2])c1</smiles>

306. $\mathrm{R}_{1}=\mathrm{R}_{2}=\mathrm{CH}_{3}$<smiles>[R2]/C(CCC)=C(\Br)C=O</smiles>

307. $\mathrm{R}_{1}=\mathrm{R}_{2}=\mathrm{H}$<smiles>[R]C(C)C([R9])CCC([R5])C([R9])C([R8])C</smiles>

308. $\mathrm{R}_{1}=\mathrm{CH}_{3} ; \mathrm{R}_{2}=\mathrm{R}_{3}=\mathrm{R}_{4}=\mathrm{R}_{5}=\mathrm{H}, \mathrm{H} ; \mathrm{R}_{6}=\mathrm{O}$

309. $\mathrm{R}_{1}=\mathrm{CH}_{2} ; \mathrm{R}_{2}=\mathrm{R}_{3}=\mathrm{H} ; \mathrm{R}_{4}=\mathrm{R}_{5}=\mathrm{CH}_{3} ; \mathrm{R}_{6}=\mathrm{H}$<smiles>[R]C1C([R3])C([R])C([R])C([R])C1[R]</smiles>

310. $\mathrm{R}_{1}=\mathrm{C}_{(}\left(\mathrm{CH}_{2}\right) \mathrm{CH}_{3} ; \mathrm{R}_{2}=\mathrm{R}_{3}=\mathrm{H} ; \mathrm{R}_{4}=\mathrm{CH}_{3} ; \mathrm{R}_{5}=\mathrm{R}_{6}=\mathrm{H}, \mathrm{H}$ 311. $\mathrm{R}_{1}=\mathrm{CH}_{3}(\mathrm{R}) ; \mathrm{OH} ; \mathrm{R}_{2}=\mathrm{R}_{3}=\mathrm{H}, \mathrm{H} ; \mathrm{R}_{4}=\mathrm{C}\left(\mathrm{CH}_{3}\right)_{2}(\mathrm{~S}) ; \mathrm{R}_{5}=$ $\mathrm{R}_{6}=\mathrm{H}, \mathrm{H}$

312. $\mathrm{R}_{1}=\mathrm{CH}_{3}(\mathrm{~S}) ; \mathrm{OH} ; \mathrm{R}_{2}=\mathrm{R}_{3}=\mathrm{H}, \mathrm{H} ; \mathrm{R}_{4}=\mathrm{C}\left(\mathrm{CH}_{3}\right)_{2}(\mathrm{R}) ; \mathrm{R}_{5}=$ $\mathrm{R}_{6}=\mathrm{H}, \mathrm{H}$

313. $\mathrm{R}_{1}=\mathrm{C}\left(\mathrm{CH}_{3}\right)_{2} \mathrm{OH} ; \mathrm{R}_{2}=\mathrm{R}_{3}=\mathrm{R}_{5}=\mathrm{R}_{6}=\mathrm{H}, \mathrm{H} ; \mathrm{R}_{4}=\mathrm{CH}_{2}$ 314. $\mathrm{R}_{1}=\mathrm{C}\left(\mathrm{CH}_{3}\right)_{2} ; \mathrm{R}_{2}=\mathrm{R}_{3}=\mathrm{H}, \mathrm{H} ; \mathrm{R}_{4}=\mathrm{R}_{6}=\mathrm{CH}_{3} ; \mathrm{R}_{5}=\mathrm{H}$ 315. $\mathrm{R}_{1}=\mathrm{C}\left(\mathrm{CH}_{3}\right)_{2} ; \mathrm{R}_{2}=\mathrm{R}_{3}=\mathrm{H}, \mathrm{H} ; \mathrm{R}_{4}=\mathrm{CH}_{3} ; \mathrm{R}_{5}=\mathrm{H} ; \mathrm{R}_{6}=\mathrm{O}$<smiles>[R]C(C)CCCCCCCC</smiles>

316. $\mathrm{R}_{1}=\mathrm{O}$

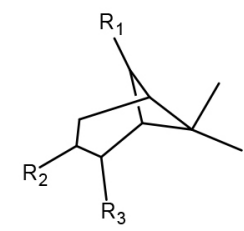

317. $\mathrm{R}_{1}=\mathrm{H}, \mathrm{H} ; \mathrm{R}_{2}=\mathrm{O} ; \mathrm{R}_{3}=\mathrm{CH}_{3}$ 318. $\mathrm{R}_{1}=\mathrm{H}, \mathrm{OCOCH}_{3} ; \mathrm{R}_{3}=\mathrm{CH}_{3}$

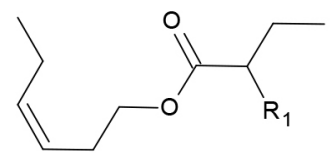

319. $\mathrm{R}_{1}=\mathrm{CH}_{3}$<smiles>[R4]CC([R5])C([R3])CC([R2])C([R2])CCC([R])C([R])C</smiles>

320. $\mathrm{R}_{1}=\mathrm{R}_{2}=\mathrm{R}_{3}=\mathrm{R}_{5}=\mathrm{R}_{6}=\mathrm{H}, \mathrm{H} ; \mathrm{R}_{4}=\mathrm{CH}_{3} ; \mathrm{R}_{1}=\mathrm{O}$

321. $\mathrm{R}_{1}=\mathrm{R}_{2}=\mathrm{R}_{3}=\mathrm{H} ; \mathrm{R}_{4}=\mathrm{CH}_{2} ; \mathrm{R}_{5}=\mathrm{R}_{6}=\mathrm{R}_{1}=\mathrm{CH}_{3}$<smiles>[B]C(C)CCCCCCCCCCC</smiles>

322. $\mathrm{R}_{1}=\mathrm{O}$<smiles>[R]C1CCC([R])C2CCC([R])([R])C=C12</smiles>

323. $\mathrm{R}_{1}=\mathrm{OH}, \mathrm{CH}_{3} ; \mathrm{R}_{2}=\mathrm{R}_{4}=\mathrm{CH}_{3} ; \mathrm{R}_{3}=\mathrm{C}\left(\mathrm{CH}_{3}\right)_{2}$<smiles>[R]C(C)=CCC/C([R8])=C/CC/C([R8])=C\CCC([R8])(O)C=C</smiles>

324. $\mathrm{R}_{1}=\mathrm{R}_{2}=\mathrm{R}_{3}=\mathrm{R}_{4}=\mathrm{CH}_{3}$

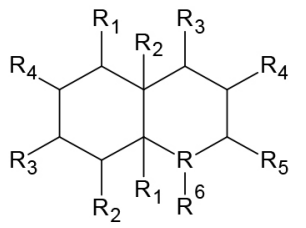

325. $\mathrm{R}_{1}=\mathrm{R}_{1}=\mathrm{CH}_{3} ; \mathrm{R}_{2}=\mathrm{R}_{5}=\mathrm{R}_{6}=\mathrm{R}_{3}=\mathrm{R}_{4}=\mathrm{H} ; \mathrm{R}_{3}=\mathrm{R}_{2}=\mathrm{H}, \mathrm{H} ; \mathrm{R}_{4}=$ $\mathrm{C}\left(\mathrm{CH}_{3}\right)_{2} \mathrm{OH} ; \mathrm{R}=\mathrm{C}$

326. $\mathrm{R}_{1}=\mathrm{R}_{5}=\mathrm{CH}_{3} ; \mathrm{R}_{2}=\mathrm{R}_{4}=\mathrm{R}_{1}=\mathrm{R}_{4}=\mathrm{H} ; \mathrm{R}_{3}=\mathrm{R}_{6}=\mathrm{R}_{3}=\mathrm{H}, \mathrm{H} ; \mathrm{R}_{2}=$ $\mathrm{C}\left(\mathrm{CH}_{3}\right)_{2} ; \mathrm{R}=\mathrm{C}$

327. $\mathrm{R}_{1}=\mathrm{R}_{3}=\mathrm{R}_{4}=\mathrm{R}_{2}=\mathrm{R}_{3}=\mathrm{R}_{4}=\mathrm{H} ; \mathrm{R}_{2}=\mathrm{R}_{1}=$ vazio; $\mathrm{R}_{5}=\mathrm{O} ; \mathrm{R}=\mathrm{O}$<smiles>[R]C1C([R3])C([R])C([R])C([R])C1[R]</smiles>

328. $\mathrm{R}_{1}=\mathrm{OH}, \mathrm{CH}_{3} ; \mathrm{R}_{2}=\mathrm{R}_{3}=\mathrm{R}_{5}=\mathrm{R}_{6}=\mathrm{H}, \mathrm{H} ; \mathrm{R}_{4}=\mathrm{C}\left(\mathrm{CH}_{2}\right)_{2} \mathrm{CH}_{3}$ 329. $\mathrm{R}_{1}=\mathrm{OH}, \mathrm{C}\left(\mathrm{CH}_{3}\right)_{2} ; \mathrm{R}_{2}=\mathrm{R}_{5}=\mathrm{R}_{6}=\mathrm{H}, \mathrm{H} ; \mathrm{R}_{3}=\mathrm{H} ; \mathrm{R}_{4}=\mathrm{CH}_{3}$ 330. $\mathrm{R}_{1}=\mathrm{C}\left(\mathrm{CH}_{3}\right)_{2} \mathrm{OH} ; \mathrm{R}_{2}=\mathrm{R}_{5}=\mathrm{R}_{6}=\mathrm{H}, \mathrm{H} ; \mathrm{R}_{3}=\mathrm{H} ; \mathrm{R}_{4}=\mathrm{CH}_{3}$ 331. $\mathrm{R}_{1}=\mathrm{C}\left(\mathrm{CH}_{3}\right)_{2} ; \mathrm{R}_{2}=\mathrm{R}_{3}=\mathrm{R}_{5}=\mathrm{R}_{6}=\mathrm{H} ; \mathrm{R}_{4}=\mathrm{CHCH}_{2}$

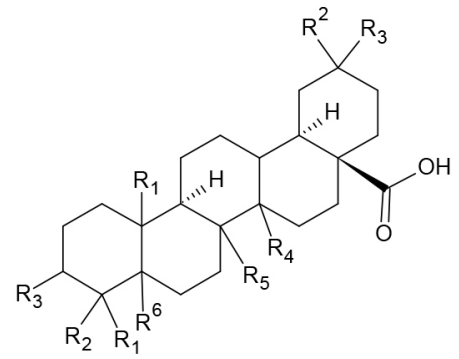

332. $\mathrm{R}_{1}=\mathrm{C}\left(\mathrm{CH}_{2}\right) \mathrm{CH}_{3} ; \mathrm{R}_{2}=\mathrm{R}_{3}=\mathrm{H}, \mathrm{H} ; \mathrm{R}_{4}=\mathrm{CH}_{3} ; \mathrm{R}_{5}=\mathrm{H} ; \mathrm{R}_{6}=\mathrm{OH}$ 333. $\mathrm{R}_{1}=\mathrm{C}\left(\mathrm{CH}_{2}\right) \mathrm{CH}_{3} ; \mathrm{R}_{2}=\mathrm{R}_{6}=\mathrm{H}, \mathrm{H} ; \mathrm{R}_{3}=\mathrm{H} ; \mathrm{R}_{4}=\mathrm{CH}_{3} ; \mathrm{R}_{5}=$ $\mathrm{OH}$

334. $\mathrm{R}_{1}=\mathrm{R}_{2}=\mathrm{R}_{3}=\mathrm{R}_{4}=\mathrm{R}_{5}=\mathrm{R}_{6}=\mathrm{R}_{1}=\mathrm{R}_{2}=\mathrm{CH}_{3}$ 
Figura 1 (continuação)<smiles>[R]C([R])=CCC([R3])([R])C1CO1</smiles>

335. $\mathrm{R}_{1}=\mathrm{R}_{2}=\mathrm{R}_{3}=\mathrm{CH}_{3}$<smiles>[R9]C1CCC2C(C3C([R9])CCC13)C2([2H])C</smiles>

336. $\mathrm{R}_{1}=\mathrm{R}_{2}=\mathrm{R}_{3}=\mathrm{CH}_{3} ; \mathrm{R}_{4}=\mathrm{CH}_{2}$<smiles>[R9]c1ccc(CC2(C)C(=O)OCC2([2H])Cc2ccc3c(c2)OCO3)cc1Br</smiles>

337. $\mathrm{R}_{1}=\mathrm{R}_{4}=\mathrm{OCH}_{3} ; \mathrm{R}_{2}=\mathrm{R}_{3}=\mathrm{CH}_{3}$<smiles>Brc1ccc2c(c1)OCO2</smiles>

338. $\mathrm{R}_{1}-\mathrm{OH}$<smiles>[R]c1cc(/C=C2/C(=O)OC[C@H]2CC2CCC3OCOC3C2)ccc1Br</smiles>

339. $\mathrm{R}_{1}=\mathrm{R}_{2}=\mathrm{OCH}_{3}$<smiles>[R]/C(C)=C/CCC([R3])([R3])C=C</smiles>

340. $\mathrm{R}_{1}=\mathrm{R}_{2}=\mathrm{CH}_{3} ; \mathrm{R}_{3}=\mathrm{OH}$<smiles>[R]C1CC(C)CCC1([R])[R]</smiles>

341. $\mathrm{R}^{1}=\mathrm{C}\left(\mathrm{CH}_{2}\right) \mathrm{CH}_{3} ; \mathrm{R}_{2}=\mathrm{CHCH}_{2} ; \mathrm{R}^{3}=\mathrm{CH}_{3}$<smiles>[R3]C1c2cc3c(cc2-c2ccc4cc5c(cc4c2N1[R2])OCO5)OCO3</smiles>

342. $\mathrm{R}_{1}=\mathrm{CH}_{2} \mathrm{COCH}_{3} ; \mathrm{R}_{2}=\mathrm{CH}_{3}$<smiles>[Z7]c1ccc(C[C@@H]2COC(=O)[C@@H]2Cc2ccc([R])c([R])c2)cc1[R]</smiles>

343. $\mathrm{R}_{1}=\mathrm{R}_{2}=\mathrm{R}_{3}=\mathrm{R}_{4}=\mathrm{OCH}_{3}$

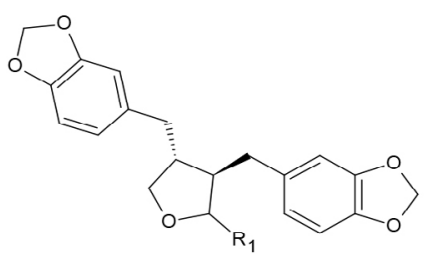

344. $R_{1}=O$

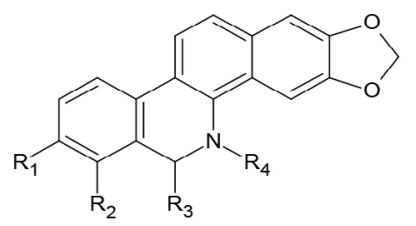

345. $\mathrm{R}_{1}=\mathrm{OH} ; \mathrm{R}_{2}=\mathrm{OCH}_{3} ; \mathrm{R}_{3}=\mathrm{CH}_{2} \mathrm{COCH}_{3} ; \mathrm{R}_{4}=\mathrm{CH}_{3}$ 346. $\mathrm{R}_{1}=\mathrm{OCH}_{3} ; \mathrm{R}_{2}=\mathrm{OCH}_{3} ; \mathrm{R}_{3}=\mathrm{CH}_{2} \mathrm{COCH}_{3} ; \mathrm{R}_{4}=\mathrm{CH}_{3}$<smiles>[2H]/C(C)=C/COc1ccc([C@@H]2OCC3C2CO[C@H]3c2ccc3c(c2)OCO3)cc1[2H]</smiles>

347. $\mathrm{R}_{1}=\mathrm{OCH}_{3} ; \mathrm{R}_{2}=\mathrm{CH}_{3}$ 


\section{Agradecimentos}

Os autores agradecem ao Programa de Mestrado em Recursos Naturais, da Universidade Estadual do Ceará; à FUNCAP, ao Laboratório de Microbiologia e ao Herbário HUVA da Universidade Estadual Vale do Acaraú, pelo apoio técnico.

\section{Literatura citada}

Ahmad, M.U., Rahman, M.A., Huq, E. \& Chowdhury, R. 2003. Alkaloids of Zanthoxylum budrunga. Fitoterapia 74: 191-193.

Ahsan, M., Haque, M.R., Hossain, M.B., Islam, S.N., Gray, A.I. \& Hasan, C.M. 2014. Cytotoxic dimeric quinolone-terpene alkaloids from the root bark of Zanthoxylum rhetsa. Phytochemistry 103: 8-12.

Al-Fatimi, M., Wurster, M., Schröder, G. \& Lindequist, U. 2007. Antioxidant, antimicrobial and cytotoxic activities of selected medicinal plants from Yemen. Journal of Ethnopharmacology 111: 657-666.

Amaro-Luis, J.M., Fronczek, F.R., Massanet, G., Pando, E., Rodriguez-Luis, F., Watkins, S. F. \& Zubía, E. 1988. Meridinol, a lignan from Zanthoxylum fagara. Phytochemistry 27: 3933-3935.

Anza, M., Haile, E., Tadesse, S., Mammo, F. \& Endale, M. 2014. A coniferyl alcohol derivative from the roots of Zanthoxylum chalybeum. Journal of Coastal Life Medicine 2: 970-974.

Arruda, M.S.P., Fernandes, J.B., Silva, F.G.F., Paula C. Vieira, P.C. \& Pirani, J.R. 1992. Quinolone alkaloids from Zanthoxylum acutifoliuim. Plrytockemistry 31:3617-3619.

Arruda, M.S.P., Fernandes, J.B., Vieira, P.C., Fatima, M. \& Pirani, J.R. 1994. Protolimonoid and lignans from Zanthoxylum petiolare. Phytochemistry 36: 1303-1306.

Balami, N. P. 2004. Ethnomedicinal uses of plants among the newar community of pharping village of kathmandu district, nepal. Tribhuvan University Journal 24: 1-10.

Banerjee, H., Pal, S. \& Adityachaudhury, N. 1989. Occurrence of Rutaecarpine in Zanthoxylum budrunga. Planta Medica 55: 403-403.

Barkatullah, M.I., Muhammad, N., Rehman, I., Rehman, M.U. \& Khan, A. 2013. Chemical Composition and Biological Screening of Essential Oils of Zanthoxylum armatum DC Leaves. Journal of Clinical Toxicology 04: 2-6.

Bastos, J. K., Albuquerque, S. \& Silva, M.L.A. 1999. Evaluation of the trypanocidal activity of lignans isolated from the leaves of Zanthoxylum naranjillo. Planta Medica 65: 541-544.

Beirigo, P.J., Torquato, H.F.V., Santos, C.H.C., Carvalho, M.G., Castro, R.N., Paredes-Gamero, E. J., Sousa, P.T., Jacinto, M.J. \& Silva, V.C. 2016. [1-8-NalC]-Zanriorb A1, a Proapoptotic Orbitide from Leaves of Zanthoxylum riedelianum. Journal of Natural Products 79: 1454-1458.
Biavatti, M.W., Westerlon, R., Vieira, P.C., Silva, M.F.G.F., Peñaflor, M.F.G.V., Bueno, O. C. \& Elen, J. 2005. Leaf-Cutting Ants Toxicity of Limonexic Acid and Degraded Limonoids from Raulinoa echinata. X-Ray Structure of Epoxy-fraxinellone Maique. Journal of the Brazilian Chemical Society 16: 1443-1447.

Braguine, C., Costa, E.S., Magalhães, L.G., Rodrigues, V., Silva-Filho, A.A., Bastos, J.K., Silva, M.L.A., Cunha, W.R., Januário, A.H. \& Pauletti, P.M. 2009. Schistosomicidal evaluation of Zanthoxylum naranjillo and its isolated compounds against Schistosoma mansoni adult worms. Zeitschrift fur Naturforschung 64: 793-797.

Carvalho, A.P. \& Conceição, G.M. 2015. Utilização de plantas medicinais em uma área da estratégia de saúde da família, Caxias, Maranhão. Enciclopédia Biosfera 11: 3477-3488.

Carvalho, L.E. 2009. Estudo químico de galhos de Zanthoxylum Djalma-batistae e ráquis foliar de Spathelia excelsa (RUTACEAE), AM - Brasil. Dissertação de Mestrado, Universidade Federal do Amazonas, Manaus.

Castro, S.B.R. Leal, C.A.G., Freire, F.R., Carvalho, D.A., Oliveira, D.F. \& Figueiredo, H.C.P. 2008. Antibacterial activity of plant extracts from Brazil against fish pathogenic bacteria. Brazilian Journal of Microbiology 39: 756-760.

Cebrián-Torrejón, G., Spelman, K., Leblanc, K., Muñoz-Durango, K., Gutiérrez, S.T., Ferreira, M.E., Arias, A.R., Figadère, B., Fournet, A., Maciuk, A., Grellier, P., Cech, N.B. \& Poupon, E. 2011.The antiplasmodium effects of a traditional South American remedy: Zanthoxylum chiloperone var. Angustifolium against chloroquine resistant and chloroquine sensitive strains of Plasmodium falciparum. Brazilian Journal of Pharmacognosy 21: 652-661.

Cebrián-Torrejón, G., Doménech-Carbó, A., Figadère, B., Poupon, E. \& Fournet, A. 2017. Phytoelectrochemical analysis of Zanthoxylum chiloperone. Phytochemical Analysis 28: 171-175.

Chan, W.K., Tan, L.T.H., Chan, K.G., Lee, L.H. \& Goh, B.H. 2016. Nerolidol: A sesquiterpene alcohol with multi-faceted pharmacological and biological activities. Molecules 21: 1-40.

Chang, C.E. \& Hartley, T.G. 1993. Rutaceae in Flora of Taiwan. In: Rutaceae in Flora of Taiwan. ed. Taipei, Taiwan: Committee of the Flora of Taiwan 2: 510-544.

Cheng, M.J., Lin, C.F, Chang, H.S. \& Chen, I.S. 2008. Chemical constituents from the stem bark of Zanthoxylum sacandens. Journal of the Chilean Chemical Society 53: 1631-1634.

Choi, H.J. 2016. Evaluation of Antiviral Activity of Zanthoxylum Species Against Picornaviruses. Osong Public Health and Research Perspectives, 7: 400-403.

Choi, J.Y., Kim, H.M., Lee, J.M., Choi, K., Ku, J., Park, K.W., Cho, E.J. \& Lee, S. 2012. Antibacterial activity of Zanthoxylum schinifolium. Natural Product Sciences 18: 137-140. 
Cornejo-Garrido, J., Salinas-Sandoval, M., Díaz-López, A., Jácquez-Ríos, P., Arriaga-Alba, M. \& OrdazPichardo, C. 2015. In vitro and in vivo antifungal activity, liver profile test, and mutagenic activity of five plants used in traditional Mexican medicine. Brazilian Journal of Pharmacognosy 25: 22-28.

Costa, E.C.C., Christofoli, M., Costa, G.C.S., Peixoto, M.F.P., Fernandes, J.B., Forim, M.R., Pereira, K.C., Silva, F.G. \& Cazal, C.M. 2017a. Essential oil repellent action of plants of the genus Zanthoxylum against Bemisia tabaci biotype B (Homoptera: Aleyrodidae). Scientia Horticulturae. 226: 327-332.

Costa, E.S., Mychelli, B., Sampaio, S., Ademar, A.S.F., R Cunha, Jairo K Bastos S.A. \& Márcio, L.A.S. 2007. Estudo fitoquímico e avaliação da atividade tripanocida das folhas de Zanthoxylum naranjillo Engler (Rutaceae). Sociedade Brasileira de Química - SBQ 6-7.

Costa, J.G.M., Campos, A.R., Brito, S.A., Pereira, C.K.B., Souza, E.O. \& Rodrigues, F.F.G. 2010. Biological screening of araripe basin medicinal plants using Artemia salina Leach and pathogenic bacteria. Pharmacognosy Magazine 6: 331-335.

Costa, R.S., Lins, M.O., Le, H.M., Barros, T.F. \& Velozo, E.S. 2017b. In vitro antibacterial effects of Zanthoxylum tingoassuiba root bark extracts and two of its alkaloids against multiresistant Staphylococcus aureus. Brazilian Journal of Pharmacognosy 27: 195-198.

Costa, R.S., Souza-Filho, O.P., Júnior- Otávio, C.S.D., Silva, J.J., Hyaric, M.L., Santos, M.A. V. \& Velozo, E.S. 2018. In vitro antileishmanial and antitrypanosomal activity of compounds isolated from the roots of Zanthoxylum tingoassuiba. Brazilian Journal of Pharmacognosy 28: 551-558.

Cruz, G.L. 1985. Dicionário de Plantas úteis do Brasil. 3a edição ed. Rio de Janeiro: Civilização Brasileira S. A.

Cuca, L.E., Martínez, J.C., Franco, V. \& Monache, F.D. 1998. Constituyentes químicos de Zanthoxylum monophyllum. Revista Colombiana de Química 27: 17-27.

Cui, H.Z., Choi, H.R., Choi, D.H., Cho, K.W., Kang, D.G. \& Lee, H.S. 2009. Aqueous extract of Zanthoxylum schinifolium elicits contractile and secretory responses via $\beta 1$-adrenoceptor activation in beating rabbit atria. Journal of Ethnopharmacology 126: 300-307.

Detoni, C.B., Cabral-Albuquerque, E.C.M., Hohlemweger, S.V.A., Sampaio, C., Barros, T.F. \& Velozo, E.S. 2009. Essential oil from Zanthoxylum tingoassuiba loaded into multilamellar liposomes useful as antimicrobial agents. Journal of Microencapsulation 26: 684-691.

Deus, R.J.A., Alves, C.N. \& Arruda, M.S.P. 2011. Avaliação do efeito antifúngico do óleo resina e do óleo essencial de copaíba (Copaifera multijuga Hayne). Revista Brasileira de Plantas Medicinais 13: 1-7.
Diao, W.R., Hu, Q.P., Feng, S.S., Li, W.Q. \& Xu, J.G. 2013. Chemical composition and antibacterial activity of the essential oil from green huajiao (Zanthoxylum schinifolium) against selected foodborne pathogens. Journal of Agricultural and Food Chemistry, 61: 60446049.

Díaz, W. \& Ortega, F. 2006. Inventario de recursos botánicos útiles y potenciales de la cuenca del Río Morón, estado Carabobo, Venezuela. Ernstia 16: 31-67.

Diéguez-Hurtado, R., Garrido-Garrido, G., PrietoGonzález, S., Iznaga, Y., Gonzalez, Molina-Torres, J., M. Curini, M.F., Epifano, F. \& Marcotullio, M.C. 2003. Antifungal activity of some Cuban Zanthoxylum species. Fitoterapia 74: 384-386.

Engeu, O.P., Ralph, T., Moses, A., Gerosome, M., Kyeyune, G.N., Badru, G. \& Paul, W. 2008. Repeatdose effects of Zanthoxylum chalybeum root bark extract: A traditional medicinal plant used for various diseases in Uganda. African Journal of Pharmacy and Pharmacology 2: 101-105.

Facundo, V.A., Morais, S.M., Machado, M.I.L., Francisco, F.J. \& Frota, L.C.M. 1999. Essential oil of Zanthoxylum syncarpum tull leaves. Journal of Essential Oil Research 11: 426-428.

Facundo, V.A., Rezende, C.M., Pinto, A.C. \& Morais, S.M. 2003. Essential oil of Zanthoxylum ekmanii (Urb.) Alain. Leaves. Journal of Essential Oil Research 15: 402-403.

Facundo, V.A., Pinto, S.A.S., Filho, R.B., Pinto, A.C. \& Rezende, C.M. 2005. Constituintes químicos de Zanthoxylum ekmanii (URB.) alain. Química Nova 28: 224-225.

Facundo, V.A. \& Silveira, A.S.P. 2005. Constituintes químicos de Zanthoxylum ekmanii (URB.) alain. Química Nova 28: 224-225.

Fang, Z., Min, B.S., Kim, A.K., Woo, M.H., Jun, D.Y. \& Kim, Y.H. 2010. Cytotoxic constituents from the leaves of Zanthoxylum schinifolium. Bulletin of the Korean Chemical Society 31: 1081-1084.

Feder, D., Gonzalez, M.S., Mello, C.B., Santos, M.G., Rocha, L., Kelecom, A. \& Folly, E. 2019. Exploring the insecticide and acaricide potential of development regulators obtained from restinga vegetation from Brazil. Anais da Academia Brasileira de Ciencias 91: 2-18.

Fernandes, C.C., Vieira, P.C., Da Silva, V.C., Dall'Oglio, E.L., Da Silva, L.E. \& Sousa-Junior, P.T. 2009. 6-Acetonyl-N-methyl-dihydrodecarine, a New Alkaloid from Zanthoxylum riedelianum. Journal of the Brazilian Chemical Society 20: 379-382.

Fernandes, T.S. 2016. Analise Fitoquímica de duas espécies de Rutaceae: Helietta Apiculata Benth e Zanthoxylum Fagara (L.) Sarg. RS -Brasil. Tese de Doutorado, Universidade Federal de Santa Maria, Santa Maria. 
Ferreira, M.E., Nakayama, H., Arias, A.R., Schinini, A., Bilbao, N.F., Serna, E., Lagoutte, D., Soriano-Agatón, F., Pouponb, E., Hocquemiller, R. \& Fournet, A. 2007. Effects of canthin-6-one alkaloids from Zanthoxylum chiloperone on Trypanosoma cruzi - infected mice. Journal of Ethnopharmacology 109: 258-263.

Ferreira, M.E., Cebrián-Torrejón, G., Corrales, A.S., Bilbao, N.V., Rolón, M., Gomez, C.V., Leblanc, K., Yaluf, G., Schinini, A., Torres, S., Serna, E., Arias, A.R., Poupon, E. \& Fournet, A. 2011. Zanthoxylum chiloperone leaves extract: First sustainable Chagas disease treatment. Journal of Ethnopharmacology133: 986-993.

Freitas, F.F.B.P., Fernandes, H.B., Piauilino, C.A., Pereiraa, S.S., Carvalho, K.I.M., Chaves, M.H., Soares, P.M.G., Miurad, L.M.C.V., Leited, J.R.S.A., Oliveira, R.C.M. \& Oliveira, F.A. 2011. Gastroprotective activity of Zanthoxylum rhoifolium Lam. in animal models. Journal of Ethnopharmacology 137: 700-708.

Gansane, A., Sanon, S., Ouattara, P.L., Hutter, S., Ollivier, E., Azas, N., Traore, A., Traore, A.S., Guissou, I.P., Nebie, I. \& Sirima, B.S. 2010. Antiplasmodial activity and cytotoxicity of semi purified fractions from Zanthoxylum zanthoxyloides Lam. Bark of Trunk. International Journal of Pharmacology6: 921-925.

Gessler, M.C., Nkunya, M.H.H., Mwasumbi, L.B., Heinrich, M. \& Tanner, M. 1994. Screening Tanzanian medicinal plants for antimalarial activity. Acta Tropica 56: $65-77$.

Gómez, Y., Gil, K., González, E. \& Farías, L.M. 2007. Actividad antifúngica de extractos orgánicos del árbol Fagara monophylla (Rutaceae) en Venezuela. Revista de Biologia Tropical 55: 767-775.

Gong, Y. Huang, Y. Zhou, L. Shi, X. Guo, Z. Wang, M. \& Jiang, W. 2009. Chemical composition and antifungal activity of the fruit oil of Zanthoxylum bungeanum maxim. (Rutaceae) from China. Journal of Essential Oil Research 21: 174-178.

Gonzaga, W.D.A., Weber, A.D., Giacomelli, S.R., Simionatto, E., Dalcol, I.I., Dessoy, E.C.M. \& Morel, A.D. 2003. Composition and antibacterial activity of the essential oils from Zanthoxylum rhoifolium. Planta Medica 69: 773-775.

Guy, I., Charles, B., Guinaudeaul, H., Ferreira, M.E., Arias, A.R. \& Fournet, A. 2001a. Essential Oils from Zanthoxylum chiloperone and Z. riedelianum Growing in Paraguay. Pharmaceutical Biology 39: 152-154.

Guy, I., Charles, B., Hélène, G., Fournet, A., Ferreira, M.E. \& Arias, A.R. 2001b. Essential Oils from Leaves of Two Paraguayan Rutaceae: Zanthoxylum hyemale A. St. Hil. and Z. naranjilo Griseb. Jessent. Oil Res 13: 200-201.
Hamuy, R., Vera, B.N., Ferreira, M.E., Acosta, N. \& Lopez, E. 2013. Determinacion de la sensibilidad in vitro de diferentes cepas de Trypanosoma cruzi al benznidazol y al extracto de hoja de la planta Zanthoxylum chiloperone. Mem. Inst. Invest. Cienc. Salud 9: 16-25.

He, W., Van, P.L., De Kimpe, N., Verbruggen, L., Anthonissen, K., Flaas, M.V., Bosselaers, J., Mathenge, S.G. \& Mudida, F.P. 2002. Chemical constituents and biological activities of Zanthoxylum usambarense. Phytotherapy Research 16: 66-70.

Hohlemwerger, S.V.A., Sales, E.M., Santos, C.R., Silva, V.E. \& Silva, G. M.L. 2012. Alcaloides das cascas das raízes de Zanthoxylum spp. Química Nova 35: 21732176.

Hu, L., Wang, K., Wang, Z., Liu, J., Wang, K., Zhang, J., Luo, Z., Xue, Y., Zhang, Y. \& Zhang, Y. 2016. A new megastigmane sesquiterpenoid from Zanthoxylum schinifolium Sieb. et Zucc. Molecules 21: 1-7.

Islam, A., Sayeed, A., Bhuiyan, M.S.A., Mosaddik, M.A., M.AU Islam, M. A.U. \& Klan, A.M. 2001. Antimicrobial activity and cytotoxicity of Zanthoxylum budrunga. Fitoterapia 72: 428-430.

Islam, M.K., Biswas, N.N., Saha, S., Hossain, H., Jahan, I. A., Khan, T.A., Awang, K. \& Shilpi, J.A. 2014 a. Anti-nociceptive and antioxidant activity of Zanthoxylum budrunga Wall (Rutaceae) seeds. The Scientific World Journal 2014: 1-7.

Islam, M.K., Saha S., Mahmud, I., Mohamad, K., Awang, K., Uddin, S.J., Rahman, M.D.M. \& Shilpi, J.U. 2014b. An ethnobotanical study of medicinal plants used by tribal and native people of Madhupur forest area, Bangladesh. Journal Ethnopharmacol 151: 921-930.

Islam, M.K., Acharzo, A.K., Saha, S., Hossain, H., Shilpi, J.A., Das A.K. \& Biswas, N.N. 2018. Bioactivity studies on Zanthoxylum budrunga wall (Rutaceae) root bark. Clinical Phytoscience 4: 2-12.

Jain, N., Srivastava, S.K., Aggarwal, K.K., Ramesh, S. \& Kumar, S. 2001. Essential oil composition of Zanthoxylum alatum seeds from northern India. Flavour and Fragrance Journal 16: 408-410.

Jie,Y., Li, S. \& Ho, C.T. 2019. Chemical composition, sensory properties and application of Sichuan pepper (Zanthoxylum genus). Food Science and Human Wellness 8: 115-125.

Joshi, B.S., Moore, K.M., Pelletier, S.W., Puar, M.S. 1991. Alkaloids of Zanthoxylum budrunga wall.: NMR assignments of dihydrochelerythrine, $( \pm)$-evodiamine and zanthobungeanine. Phytochemical Analysis 2: 20-25.

Jullian, V., Bourdy. G., Georges, S., Maurel, S. \& Sauvain, M. 2006. Validation of use of a traditional antimalarial remedy from French Guiana, Zanthoxylum rhoifolium Lam. Journal of Ethnopharmacology 106: 348-352. 
Kato, A., Moriyasu, M., Ichimaru, M. \& Nishiyama, Y. 1996. Isolation of alkaloidal constituents of Zanthoxylum usambarense and Zanthoxylum chalybeum using ionpair HPLC. Journal of Natural Products 59: 316-318.

Kim, S., Seo, H., Mahmud, H.A.I., Islam, M.I., Leeb, B.E., Choc, M.L. \& Song, H.Y. 2018. In vitro activity of collinin isolated from the leaves of Zanthoxylum schinifolium against multidrug- and extensively drugresistant Mycobacterium tuberculosis. Phytomedicine 46: 104-110.

Kiraithe, M.N., Nguta, J.M., Mbaria, J.M. \& Kiama, S.G. 2016. Evaluation of the use of Ocimum suave Willd. (Lamiaceae), Plectranthus barbatus Andrews (Lamiaceae) and Zanthoxylum chalybeum Engl. (Rutaceae) as antimalarial remedies in Kenyan folk medicine. Journal of Ethnopharmacology 178: 266-271.

Kirira, P.G., Rukunga, G.M., Wanyonyi, A.W., Muregi, F.M., Gathirwa, J.W., Muthaurab, C. N., Omarc, S.A., Tolob, F., Mungaid, G.M. \& Ndiege, I. 2006. Antiplasmodial activity and toxicity of extracts of plants used in traditional malária therapy in Meru and Kilifi Districts of Kenya. Journal of Ethnopharmacology 106: 403-407.

Kirtikar, K.R. \& Basu, B.D.1993. Indian medicinal plants. 1 ed D Publisher DD. India.

Ladino, O.J.L., Rodríguez, J.A.P., Moreno, J.M.L., Sarmiento, L.L. \& Suárez, L.E.C. 2011. Propiedades antibacterianas in vitro de metabolitos secundarios aislados de Zanthoxylum (Rutaceae). Revista Cubana de Farmacia 45: 431-438.

Ladino, O.J.P. \& Suárez, L.E.C. 2004. Alcaloides benzofenantridinicos de Zanthoxylum quinduensis. Revista Colombiana de Química 33: 13-20.

Ladino, O.J.P. \& Suárez, L.E.C. 2007. Estudio Fitoquimico de da espécie Zanthoxylum quinduense (Rutaceae). Scientia et Technica 1: 171-172.

Ladino, O.J.P. \& Suárez, L.E.C. 2010.Chemical constituents of the wood from Zanthoxylum quinduense tul. (Rutaceae). Química Nova 33: 1019-1021.

Lamorde, M., Tabuti, J.R.S., Obua, C., KUKUNDA, B.C., Lanyero, H., Byakika-Kibwika, P., Bbosa, G.S., Lubega, A., Ogwal-Okeng, J., Ryan, M., Waako, P.J. \& Merry, C. 2010. Medicinal plants used by traditional medicine practitioners for the treatment of HIV/AIDS and related conditions in Uganda. Journal of Ethnopharmacology 30: 130-136.

Lan, Y., Wang, J., He, S., Shuying Li, S., Tan, P., Lin, H. \& Wu, Q. 2016. Transdermal permeation of Zanthoxylum bungeanum essential oil on TCM components with different lipophilicity. Journal of Traditional Chinese Medical Sciences 3: 157-167.

Li, W., Zhou, W., Shim, S.H. \& Kim, Y.H. 2014.Chemical constituents of Zanthoxylum schinifolium (Rutaceae). Biochemical Systematics and Ecology 55: 60-65.
Lima, D.F., Grasiela, L., Marques, A., Costa, L.M., De Morais, M.R. \& Santos, C. 2015a. Prospecção tecnológica do jaborandi (Pilocarpus microphyllus): espécie economicamente importante no Norte e Nordeste do Brasil. Revista Geintec 5: 1626-1638.

Lima, L.M., Perazzo, F.F., Carvalho, J.C.T. \& Bastos, J.K. 2007. Anti-inflammatory and analgesic activities of the ethanolic extracts from Zanthoxylum riedelianum (Rutaceae) leaves and stem bark . Journal of Pharmacy and Pharmacology 59: 1151-1158.

Lima, R.B.S., Rocha, S.L.F., Melo, M.R.S., Costa, J,S., Picanço, N.S., Lima, E.S., Vasconcellos, M.C., Boleti, A.P.A., Santos, J.M.P., Amorim, R.C.N., Chaves, F.C.M., Coutinho, J.P., Tadei, W.P., Krettli, A.U. \& Pohlit, A.M. 2015b. In vitro and in vivo anti-malarial activity of plants from the Brazilian Amazon. Malaria Journal 14: 1-14.

Liu, S.M., Wang, S.J., Song, S.Y., Zou, Y., Wang, J.R. \& Sun, B.Y. 2017. Characteristic differences in essential oil composition of six Zanthoxylum bungeanum Maxim. (Rutaceae) cultivars and their biological significance. Journal of Zhejiang University- Science B 18: 917-920.

Lorenzi, H. 1992. Arvores brasileiras: manual de identificacão e cultivo de plantas arbóreas nativas do Brasil. ed. Platurum 312.

Loureiro, A.A., Vasconcelos, F.J. \& Albuquerque, B.W.P. 1981. Anatomia do lenho de 4 espécies de Zanthoxylum Linnaeus ( Rutaceae) da Amazônia. Acta Amazonica 11: 809-820.

Macías, V.V.E., Ericsson, D.C.B. \& Cuca, L.E. 2010. Novel furocarbazole a lkaloids and antibacterial activity of ethanol extract from Zanthoxylum fagara (L.) Sargent. Revista Colombiana de Química 39: 333-341.

Malla, B., Gauchan, D., P. \& Chhetri, R., B. 2014. Medico-ethnobotanical investigations in Parbat district of Western Nepal. Journal of Medicinal Plants Research 8: 95-108.

Matu, E. N. \& Van Staden, J. 2003. Antibacterial and antiinflammatory activities of some plants used for medicinal purposes in Kenya. Journal of Ethnopharmacology 87: $35-41$.

Melo, M. \& Zickel, C. 2004. Os gêneros Zanthoxylum L. e Esenbeckia Kunth ( Rutaceae ) no Estado de Pernambuco, Brasil. Acta Botânica Brasilica 18: 73-90.

Mesquita, M.C.A. 2018. Atividade antifúngica e composição química do óleo essencial de Zanthoxylum petiolare A. St. -Hil. \& Tul (RUTACEAE). CE - Brasil. Monografia, Universidade do Vale do Acaraú, Sobral.

Min, B.K., Hyun, D.G., Jeong, S.Y., Kim, Y. H., Ma, E.S. \& Woo, M.H.A. 2011. A new cytotoxic coumarin, 7-[(E)3', 7'-dimethyl-6'-oxo- 2',7'-octadienyl] oxy Coumarin, from the leaves of Zanthoxylum schinifolium. Archives of Pharmacal Research 34: 723-726. 
Moura, N.F., Morel, A.F., Dessoy, E.C., Zanatta, N., Bürger, M.M., Ahlert, N. \& Porto, G.P. 2002. Alkaloids, amides and antispasmodic activity of Zanthoxylum hyemale. Planta Medica 68: 534-538.

Moura, N.F., Strapazzon, J.O., Loro, F., Morel, A.F. \& Flach, A. 2006. Composition of the leaf oils of Rutaceae : Zanthoxylum hyemale A. St. Hill, Z. rhoifolium Lam. and Z. rugosum A. St. Hill et. Tul. Journal of Essential Oil Research 18: 627-628.

Nantongo, J.S., Odoi, J.B., Abigaba, G. \& Gwali, S. 2018. Variability of phenolic and alkaloid content in different plant parts of Carissa edulis Vahl and Zanthoxylum chalybeum Engl. BMC Research Notes 11: 1-5.

Nanyingi, M.O., Mbaria, J.M., Lanyasunya, A.L., Wagate, C.G., Koros, K.B., Kaburia, H.F., Munenge, R. W. \& Ogara, W.O. 2008. Ethnopharmacological survey of Samburu district, Kenya. Journal of Ethnobiology and Ethnomedicine 4: 1-12.

Neto, B.M., Leitão, J.M.S.R., Oliveira, L.G.C., Santos, S.E.M., Carneiro, S.M.P., Rodrigues, K.A.F., Chaves, M.H., Arcanjo, D.D.R. \& Carvalho, F.A.A. 2016. Inhibitory effects of Zanthoxylum rhoifolium lam. (Rutaceae) against the infection and i.fectivity of macrophages by Leishmania amazonensis. Anais da Academia Brasileira de Ciências 88: 1851-1861.

Nguta, J.M., Mbaria, J.M., Gakuya, D.W., Gathumbi, P.K. \& Kiama, S.G. 2010. Traditional antimalarial phytotherapy remedies used by the South Coast community, Kenya. Journal of Ethnopharmacology 131: 256-267.

Nguyen, Q.A., Van-Dufat, H.T., Michel, S., Tillequin, F., Dumontet, V.M. \& Sévenet, T. 2002. A new phenylpropanoid ester from the bark of Zanthoxylum scandens (Rutaceae). Zeitschrift fur Naturforschung 57: 986-989.

Nooreen, Z., Singh, S., Singh, D.K., Tandon, S., Ahmad, A. \& Luqman, S. 2017. Characterization and evaluation of bioactive polyphenolic constituents from Zanthoxylum armatum DC., a traditionally used plant. Biomedicine and Pharmacotherapy 89: 366-375.

Nogueira, J., Mourão, S.C., Dolabela, I.B., Santos, M.G., Mello, C.B., Kelecom, A., Mexas, R., Feder, D., Fernandes, C.P., Gonzalez, M.S. \& Rocha, L. 2014a. Zanthoxylum caribaeum (Rutaceae) essential oil: chemical investigation and biological effects on Rhodnius prolixus nymph. Parasitology Research113: 4271-4279.

Nogueira, J., Vinturelle, R., Mattos, C., Tietbohl, L.A.C., Santos, M.G., Junior, I.S.V., Mourão, S.C., Rocha, L. \& Folly, E. 2014b. Acaricidal properties of the essential oil from Zanthoxylum caribaeum against Rhipicephalus microplus. Journal of Medical Entomology 5: 971-975.

Nordstrom, B.L., Friedman, D.S., Mozaffari, E., Quigley, H. \& Walker, A.M. 2005. Persistence and adherence with topical glaucoma therapy. American journal of ophthalmology 140: 598-606.
Ocheng, F., Bwanga, F., Joloba, M., Borg-Karlson, A.K ., Gustafsson, A. \& Obua, C. 2014. Antibacterial activities of extracts from Ugandan medicinal plants used for oral care. Journal of Ethnopharmacology 155: 852-855.

Ocheng, F., Bwanga, F., Almer B.E., Boström, E.B., Joloba, M., Borg-Karlson, A.K., Yucel-Lindberg, T. \& Obua, C. 2016. Essential oils from Ugandan medicinal plants: in vitro cytotoxicity and effects on IL-1 $\beta$-induced proinflammatory mediators by human gingival fibroblasts. Hindawi Publishing Corporation 2016: 1-8.

Oliveira, E.L., Freitas, P.C., Maria, L.S.G. \& Velozo, E.S. 2002. Estudo fitoquímico de Zanthoxylum stelligerum (Turcz). Revista Brasileira de Farmacognosia 12: 29-30.

Paik, S.Y., Koh, K.H., Beak, S. M., Paek, S.H. \& Kim, J.A. 2005.The Essential oils from Zanthoxylum schinifolium pericarp induce apoptosis of hepg2 human hepatoma cells through increased production of reactive oxygen species. Biological \& Pharmaceutical Bulletin 28: 802-807.

Pavarini, M.F., Regis, M.I.C.A., Gonçãoves, G.L., Estumano, A.R. \& Duarte, J.R.M. 2000. Estudo do potencial de mercado de fármacos (medicamentos e cosméticos) fitomedicamentos, bancos de extratos e compostos e serviços de patenteamento e certificação, Superintendência do Desenvolvimento da Amazônia, Belém.

Pavela, R. \& Govindarajan, M. 2016. The essential oil from Zanthoxylum monophyllum a potential mosquito larvicide with low toxicity to the non-target fish Gambusia affinis. Journal of Pest Science 90: 369-378.

Pereira, K.D.C., Quintela, E.D., Silva, D.J., Nascimento, Nascimento. A., Rocha, D.V.M., Arruda e Silva, J.F., Forim, M.R., Silva, F.G. \& Cazal, C.M. 2018. Characterization of nanospheres containing Zanthoxylum riedelianum fruit essential oil and their insecticidal and deterrent activities against Bemisia tabaci (Hemiptera: Aleyrodidae). Molecules, v. 23, n. 8, p. 2-19.

Pessini, G.L., Holetz, F.B., Sanches, N.R., Cortez, D.A.G., Dias Filho, B.P. \& Nakamura, C.V. 2003. Avaliação da atividade antibacteriana e antifúngica de extratos de plantas utilizados na medicina popular. Revista Brasileira de Farmacognosia 13: 21-24.

Phuyal, N., Jha, P.K., Raturi, P.P. \& Rajbhandary, S. 2019. Zanthoxylum armatum DC.: Current knowledge, gaps and opportunities in Nepal. Journal of Ethnopharmacology 229: 326-341.

Pichardo, C.O., Garcés, R.C., Villafranco, M.E.L., Garza, M. \& Arriaga-alba, M. 2014. Estudio de mutagenicidad y actividad antibacteriana de Erythrina herbacea, Zanthoxylum caribaeum y Dendropanax arboreus. Revista Mexicana de Ciências Farmacêuticas 45: 78-85.

Pirani, J.R. 1999. Estudos taxonômicos em Rutaceae: Revisão de Helietta e Balfourodendron (Pteleinae); análise cladística de Pteleinae; Sinopse de Rutaceae do Brasil Revisão taxonômica das Rutaceae do Estado do Amazonas2: 4-66. 
Pirani, J.R. 2005. Flora da Reserva Ducke, Amazonas, Brasil: Rutaceae. Rodriguésia 56: 189-204.

Prieto, J.A., Patiño, O.J., Delgado, W.A., Moreno, J.P. \& Cuca, L.E. 2011. Chemical composition, insecticidal, and antifungal activities of fruit essential oils of three colombian Zanthoxylum species. Chilean journal of agricultural research 71: 73-82.

Quesada, R.M. \& Fernández, J.V. 2005. Actualización de listado de espécies arbóreas de uso forestal y otros usos en Costa Rica. Kurú: Revista Forestal 2: 44-87.

Rahman, M.T., Alimuzzaman, M., Ahmad, S. \& Chowdhury, A.A. 2002. Antinociceptive and antidiarrhoeal activity of Zanthoxylum rhetsa. Fitoterapia 73: 340-342.

Rahman, M.M., Islam, M.A., Khondkar, P. \& Gray, A.I. 2005. Alkaloids and lignans from Zanthoxylum budrunga (Rutaceae). Biochemical Systematics and Ecology 33: 91-96.

Reis, M.S., Mariot, A. \& Steenbock W. 2003. Diversidade e domesticação de plantas medicinais. In. Farmacognosia: da planta ao medicamento (Simões, C.M.O. et al.). 5 ed., Porto Alegre/ Florianópolis.

Rodríguez-Guzmán, R., Johansmann, F.L.C., Radwan, M.M., Burandt, C.L. \& Ross, S.A. 2011. Chemical constituents, antimicrobial and antimalarial activities of Zanthoxylum monophyllum. Planta Medica 77: 15421544.

Ross, S.A., Sultana, G.N.N., Burandt, C.L., EISohly, M.A., Marais, J.P.J. \& Ferreira, D. 2004. Syncarpamide, a New Antiplasmodial (+)-Norepinephrine Derivative from Zanthoxylum syncarpum. Journal of Natural Products 67: 88-90.

Saraiva, J., Veja, C., Rolon, M., Da Silva, R., Silva, M.I.A., Donate, P.M., Bastos, J.K., Gomez-Barrio, A. \& Albuquerque, S. 2007. In vitro and in vivo activity of lignan lactones derivatives against Trypanossoma cruzi. Parasitology Research 100: 791-795.

Seo, J.W., Park, D.H., Li, Y.C., Kang, H.J., Xu, H.D., Kim, Y.J., Lee, J.H. \& Lee, M.S., In Lee C., Lee, Y.L., Ahn, J.B., Cho, S.C., Lee, M.J. 2012. The Zanthoxylum schinifolium seed oil modulates immune function under the biological safety level. Molecular and Cellular Toxicology 8: 179-185.

Sharma, S., Rasal, V.P., JR, K. \& Patil, P.A. 2018. In vivo evaluation of antiasthmatic activity of the essential oil of Zanthoxylum armatum. Indian Journal of Pharmaceutical Sciences80: 383-390

Silva, A.A.S., Júnior, J.M.F., Silva, M.G.V. \& Morais, S. M. 2014. Estudo fitoquímico e atividades biológicas do limãozinho (Zanthoxylum syncarpum Tull.). Revista Brasileira de Higiene e Sanidade Animal 8: 37-53.

Silva, L.A. \& Soares, J.J. 2003. Composição florística de um fragmento de floresta estacional semidecídua no município de São Carlos-SP. Revista Arvore 27: 647-656.
Silva, P.H., Oliveira, Y.R. \& Abreu, M.C. 2018. Entre símbolos, mistérios e a cura: plantas místicas dos quintais de uma comunidade rural piauiense. Gaia Scientia 12: $1-16$.

Silva, C.V., Velozo, E.S. \& Guedes, M.L. 2002. Micromoléculas de Zanthoxylum stelligerum (Turcz). Revista Brasileira de Plantas Medicinais 5: 75-78.

Silva, C.V., Detoni, C.B., Velozo, E.S. \& Guedes, M.L.S. 2008. Alcalóides e outros metabólitos do caule e frutos de Zanthoxylum tingoassuiba A. St. Hil. Química Nova 31: 2052-2055.

Silva, S.L., Figueiredo, P.M.S. \& Yano, T. 2007a. Chemotherapeutic potential of the volatile oils from Zanthoxylum rhoifolium Lam leaves. European Journal of Pharmacology 576: 180-188.

Silva, S.L., Figueiredo, P.M. \& Yano, T. 2007b. Cytotoxic evaluation of essential oil from Zanthoxylum rhoifolium Lam. leaves. Acta Amazonica 37: 281-286.

Silva, S.L., Figueredo, P.M.S. \& Yano, T. 2006. Antibacterial and antifungal activities of volatile oils from Zanthoxylum rhoifolium leaves. Pharmaceutical Biology 44: 657-659.

Silva, C.V., Reis, A.L.V., Ferrer, S.R., Guerreiro, H.M.N., Barros, T.F. \& Velozo, E.S. 2009. Avaliação da atividade antimicrobiana de duas espécies de Rutaceae do Nordeste brasileiro. Brazilian Journal of Pharmacognosy 20: 355360 .

Simionatto, U. 2004. Estudo dos constituintes químicos de óleos voláteis de plantas medicinais do Rio Grande do Sul : Isolamento, determinação e modificação estrutural e atividade Biológica. RS - Brasil. Tese de Doutorado, Universidade Federal de Santa Maria, Santa Maria.

Simionatto, E., Porto, C., Dalcol, I.I., Da Silva, U.F. \& Morel, A.F. 2005. Essential oil from Zanthoxylum hyemale. Planta Medica 71: 759-763.

Singh, T.D., Meitei, H.T., Sharma, A.L., Robinson, A., Singh, L.S. \& Singh, T.R. 2015. Anticancer properties and enhancement of therapeutic potential of cisplatin by leaf extract of Zanthoxylum armatum DC. Biological Research 48: 1-9.

Souza, J.G.L., Toledo, A.G., Santana, C.B., Dos Santos, C.G., Mallmann, A.P., Da Silva, J.P.B. \& Pinto, F.G.S. 2017. Chemical composition and antibacterial activity of essential oil and leaf extracts of Zanthoxylum caribaeum Lam. against serotypes of Salmonella. Revista Brasileira de Saúde e Produção Animal 18: 446-453.

Stappen, I., Tabanca, N., Ali, A., Wanner, J., Lal, B., Jaitak, V., Wedge, D.E., Kaul, V.K., Schmidt, E. \& Jirovetz, L. 2018. Antifungal and repellent activities of the essential oils from three aromatic herbs from western Himalaya. Open Chemistry 16: 306-316.

Subedi, R. 2017. Ethnobotanical study of panchase protected forest, Kaski District, Central Nepal. Dissertação de Mestrado, Tribhuvan University, Nepal. 
Tabanez, M.F., Durigan, G., Keuroghlian. A., Barbosa, A.F., Freitas, C.A., Silva, C.E. F., Silva, D.A., Eaton, D.P., Brisolla, G., Faria, H.H., Mattos, I.F.A., Lobo, M.T., Barbosa, M.R., Rossi, M., Souza, M.G., Machado, R.B., Pfeifer, R.M., Ramos, V.S., Andrade, W.J.D. \& Contieri, W.A. 2005. Plano de manejo da Estação Ecológica dos Crateús. Instituto Florestal Série Registros 29: 1-104.

Tabuti, J.R.S. 2011. Zanthoxylum chalybeum Engl. Record from PROTA4U. Schmelzer, G.H. \& Gurib-Fakim, A. (Editors). Disponível em $<$ http://www.prota4u.org/ search.asp $>$ (acesso em 24-IV-2018.

Tavares, D.L.C., Zanon, G., Weber, A.D., Neto, A.T., Mostardeiro, C.P., Cruz, I.B.M., Oliveira, R.M., Ilha, V., Dalcol, I.I. \& Morel, A.F. 2014. Structure-activity relationship of benzophenanthridine alkaloids from Zanthoxylum rhoifolium having antimicrobial activity. PLoS ONE 9: 1-10.

Terezan, A.P., Rossi, R.A., Almeida, R.N.A., Freitas, T.G., Fernandes, J.B., Silva, M.F.G.F., Vieira, P.C., Bueno, O.C., Pagnocca, F.C. \& Pirani, J.R. 2010. Activities of extracts and compounds from Spiranthera odoratissima St. Hil. (Rutaceae) in leaf-cutting ants and their symbiotic fungus. Journal of the Brazilian Chemical Society 21: 882-886.

Thouvenel, C., Gantier, J.C., Duret, P., Fourneau, C., Hocquemiller, R., Ferreira, M.E., Arrais, A.R., F. \& Fournet, A. 2003. Antifungal compounds from Zanthoxylum chiloperone var. angustifolium. Phytotherapy Research 17: 678-680.

Tian, Y.,Zhang, C. \& Guo, M. 2017. Comparative study on alkaloids and their anti-proliferative activities from three Zanthoxylum species. BMC Complementary and Alternative Medicine 17: 1-16.

Tsai, J.C., McClure, C.A., Ramos, S. E. \& Schlundt, D. G. 2003. Compliance barriers in glaucoma: A Systematic Classification. Journal of glaucoma 12: 393-8.

Tu, X.F., Hu, F., Thakur, K., Li, X.L., Zhang, Y.S. \& Wei, Z.J. 2018. Comparison of antibacterial effects and fumigant toxicity of essential oils extracted from different plants. Industrial Crops and Products 124: 192-200.

Vieira, M.G.S., Freitas, J.V.B., Lima, N.M.N., Gramosa, N.V. \& Nunes, E.P. 2009. Constituintes químicos voláteis das folhas e galhos de Zanthoxylum syncarpum Tull. Química Nova 32: 391-393.

Villalba, M.A., Carmo, M.I., Leite, M.N. \& Sousa, O.V. 2007. Pharmacological activities of extracts of Zanthoxylum chiloperone (Rutaceae). Brazilian Journal of Pharmacognosy 17: 236-241.
Villamizar, M.V.E., Coy Barrera, C.E.D. \& Suárez, C.L.E. 2011. Análisis fitoquímico preliminar y actividad antioxidante, antiinflamatoria y antiproliferativa del extracto etanólico de corteza de Zanthoxylum fagara (L.) Sarg. (Rutaceae) TT - Preliminary phytochemical analysis and antioxidant, antiinflammatory and ant. Revista Cubana de Plantas Medicinales 16: 43-53.

Wazir, A., Mehjabeen, Jahan, N., Sherwani, S.K. \& Ahmad, M. 2014. Antibacterial, Antifungal and antioxidant activities of some medicinal plants. Pakistan journal of pharmaceutical sciences 27: 2145-2152.

Were, P.S., Kinyanjui, P., Gicheru, M.M., Mwangi, E. \& Ozwara, H.S. 2010. Prophylactic and curative activities of extracts from Warburgia ugandensis Sprague (Canellaceae) and Zanthoxylum usambarense (Engl.) Kokwaro (Rutaceae) against Plasmodium knowlesi and Plasmodium berghei. Journal of Ethnopharmacology 130: 158-162.

Xiang, L., Liu, Y., Xie, C., Li, X., Yu, Y., Ye, M. \& Chen, S. 2016. The chemical and genetic characteristics of szechuan pepper (Zanthoxylum bungeanum and $Z$. armatum) cultivars and their suitable habitat. Frontiers in Plant Science 7: 1-11.

Xing-Dong, L. \& Hua-li, X. 2014. Antifungal activity of the essential oil of Zanthoxylum bungeanum and its major constituent on Fusarium sulphureum and dry rot of potato tubers. Phytoparasitica 42: 509-517.

Yu, X. Q., Zheng, X.Y., Kan, J.Q. \& Guo, J. 2009. Evaluation of specific quality of Zanthoxylum bungeanum Maxim and Zanthoxylum schinifolium Sieb. et Zucc. Food Science 30: 45-48.

Zanon, G. 2010. Análise fitoquímica e estudo das atividades antimicrobiana, antioxidante e de inibição da enzima acetilcolinesterase das espécies Zanthoxylum rhoifolium e Zanthoxylum hyemale. RS - Brasil. Dissertação de Mestrado, Universidade Federal de Santa Maria, Santa Maria.

Zhang, M., Wang, J., Zhu, L., Li, T., Jiang, W., Zhou, J., Peng, W. \& Wu, C. 2017. Zanthoxylum bungeanum Maxim. (Rutaceae): A systematic review of its traditional uses, botany, phytochemistry, pharmacology, pharmacokinetics, and toxicology. International Journal of Molecular Sciences 18: 2-31.

Zhu, R.X., Zhong, K., Zeng, W.C., He, X.Y., Gu, X.Q., Zhao, Z.F. \& Gao, H. 2011. Essential oil composition and antibacterial activity of Zanthoxylum bungeanum. African Journal of Microbiology Research 5: 46314637. 